\title{
The Dynamics of Economic Status and Health among Working- Age Adults in the United States
}

\author{
Abdulkarim Mohammad Meraya
}

Follow this and additional works at: https://researchrepository.wvu.edu/etd

\section{Recommended Citation}

Meraya, Abdulkarim Mohammad, "The Dynamics of Economic Status and Health among Working-Age Adults in the United States" (2017). Graduate Theses, Dissertations, and Problem Reports. 6219.

https://researchrepository.wvu.edu/etd/6219

This Dissertation is protected by copyright and/or related rights. It has been brought to you by the The Research Repository @ WVU with permission from the rights-holder(s). You are free to use this Dissertation in any way that is permitted by the copyright and related rights legislation that applies to your use. For other uses you must obtain permission from the rights-holder(s) directly, unless additional rights are indicated by a Creative Commons license in the record and/ or on the work itself. This Dissertation has been accepted for inclusion in WVU Graduate Theses, Dissertations, and Problem Reports collection by an authorized administrator of The Research Repository @ WVU.

For more information, please contact researchrepository@mail.wvu.edu. 
The Dynamics of Economic status and Health among Working-Age Adults in the United States

\author{
Abdulkarim Mohammad Meraya \\ Dissertation submitted \\ to the School of Pharmacy \\ at West Virginia University \\ in partial fulfillment of the requirements for the degree of \\ Doctor of Philosophy in \\ Health Services and Outcomes Research
}

Nilanjana Dwibedi, Ph.D, Chair

Usha Sambamoorthi, Ph.D, Co-Chair

Xi Tan, Ph.D.

Kim Innes, Ph.D.

Sophie Mitra, Ph.D.

Department of Pharmaceutical Systems and Policy

Morgantown, West Virginia

2017

Keywords: Labor Income, Family Income, Net Wealth, Physical Health, Mental Health Copyright 2017 Abdulkarim Mohammad Meraya 


\title{
ABSTRACT \\ The Dynamics of Economic status and Health among Working-Age Adults in the United States
}

\begin{abstract}
Abdulkarim Mohammad Meraya
The relationship between economic status and health has been documented in the previous literature. Economic, sociological and epidemiological studies have indicated that higher economic status is associated with better physical and mental health. While these studies have made significant contributions in this area, a comprehensive evaluation of the relationships between economic indicators and health is still lacking. Most studies focused on a single measure of economic status or health. Further, most studies have focused on one-direction economic indicators affecting health; little is known about the effect of health improvement on gain in economic status. Furthermore, only a few studies have conducted comparative analysis of whites and racial minorities. To fill the knowledge gap, the three related aims of this dissertation were to: (1) examine the dynamic relationships between economic status (family income, labor income and net wealth) and physical health measures (self-rated health and functional limitations due to chronic conditions) among working-age adults in the United States US; (2) evaluate the dynamic relationships between economic indicators (family income, labor income and net wealth) and mental health (psychological distress and mental illnesses) among working-age adults in the US; (3) evaluate the heterogeneous relationships between labor income and physical and mental health by racial groups. The study utilized a retrospective observational longitudinal design with repeated measures of economic indicators and health for a period of 14 years using 8 waves of the Panel Study of Income Dynamics: 1999 through 2013. In first aim, SystemGeneralized Method of Moment (system-GMM) models were used to evaluate the dynamic relationships between economic indicators and physical health measures. Additionally, firstdifference estimators were used to examine the associations between changes in economic status and changes in physical health. System-GMM revealed a significant positive relationships between all economic indicators and self-rated health. Nevertheless, only labor income and net wealth were associated with functional limitations. Self-rated health declined due to losses in family income and labor income; decreases in self-rated health resulted in losses in family income, labor income and net wealth. In the second aim, Probit and instrumental variable (IV) probit models were used to evaluate the relationships between economic indicators and mental illnesses. Further, ordinary least squares regression (OLS) and IV OLS were used to examine the relationships between economic indicators and psychological distress scores. First-difference estimators were used to assess the associations between changes in economic status and changes in mental health. After controlling for the endogeneity between economic status and mental health, we observed a significant inverse relationship between net wealth and the presence of a mental illness. On the other hand, adjusted IV OLS revealed significant inverse relationships between family income, net wealth and psychological distress. First-difference estimators indicated that a decline in economic status resulted in a decline in mental health. Similarly, a decline in mental health resulted in losses to net wealth, family and labor income. In the third aim, System-GMM and heteroscedasticity-based instrument regressions were used to examine the relationships between labor income and physical and mental health measures by racial
\end{abstract}


groups. First-difference and lagged fixed effects models were used to examine the effect of loss in income on physical and mental health. We found that adults in higher labor income quartiles had better self-rated health than those in the lowest quartile regardless of racial group. However, the relationship between labor income and psychological distress varied by race group; whites and African Americans in higher labor income quartiles had lower psychological distress scores than their counterparts in the lowest quartile. This was not the case with Hispanics. Reductions in labor income were associated with increases in psychological distress among whites only. In summary, this dissertation revealed that not adjusting for the endogeneity between economic status and health overestimates the relationship between the two. The results of this dissertation suggest that the relationship between economic indicators and health is dependent on the health measures that used to examine the relationship. Health is a multidimensional concept and economic indicators seem to have different dynamic relationships with different components of health. Findings of this dissertation study suggest a strong, bidirectional relationship between economic status and physical health. Finally, the findings suggest heterogeneous relationships between labor income and physical and mental health across racial groups.

\section{DEDICATION}

I dedicate this dissertation to my mother (Awatif Bassihi), my father (Mohammad), my wife (Amnah Alsum), and my sons (Mohammad and Hesham) without their support this would not have been possible. 
I thank Dr. Usha Sambamoorthi who has provided me an extensive training, guidance, and support for an area of research that was completely new to me. I would like also to thank Dr. Dwibedi for serving as dissertation committee chair.

I would like to thank my committee members: Dr. Xi Tan, Dr. Kim Innes and Dr. Sophie Mitra for their critical inputs and continuous support. I want also to thank the Pharmaceutics Systems and Policy family: Dr. Suresh Madhavan, Dr. Virginia Scott, Dr. Kimberly Kelly and Angie Frame, and all the graduate students for their love and support. I also want to acknowledge the Saudi Arabian Cultural Mission and Jazan University for supporting the tuition of my education, providing monthly salary and other benefits that make it possible to study in the United States. Finally, I want to thank my family and friends in Sabya and Jazan for their support and love. 


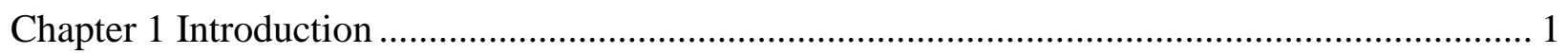

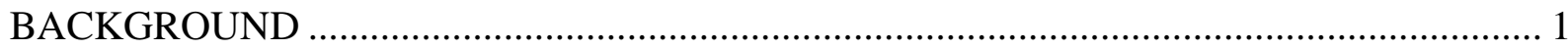

Physical and Mental Health Measures ............................................................................... 2

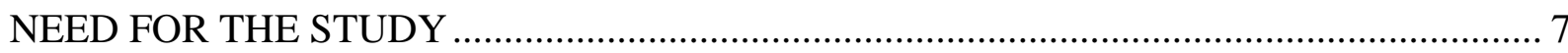

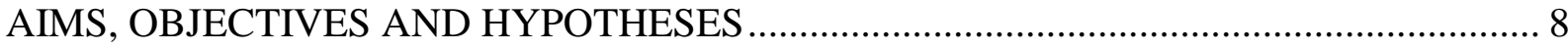

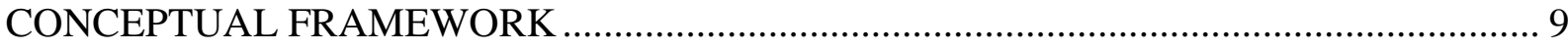

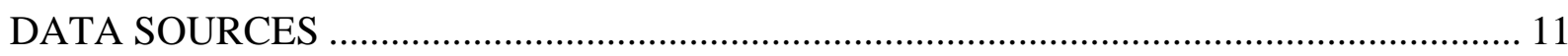

The Panel Study of Income Dynamics.................................................................................... 11

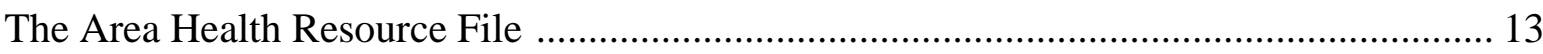

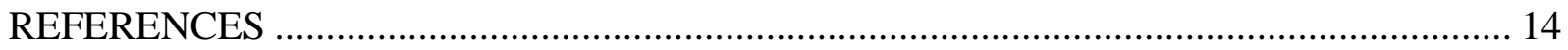

Chapter 2 The Dynamic Relationships between Economic Indicators and Physical Health Measures among Working-Age Adults in the United States ..................................................... 20

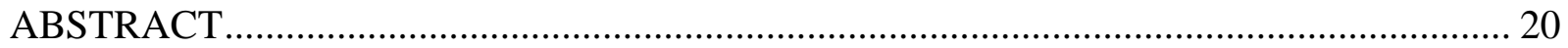

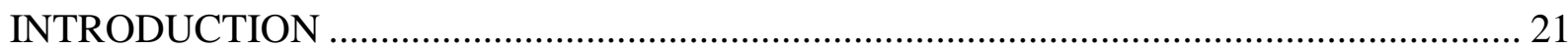

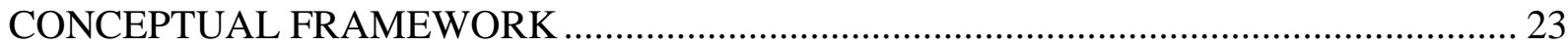

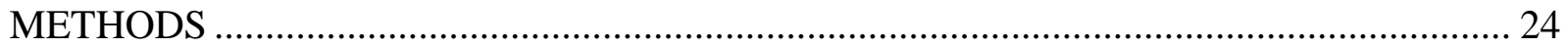

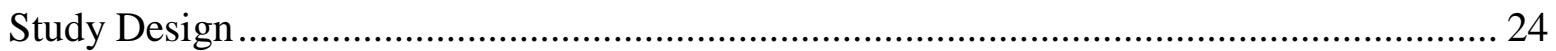

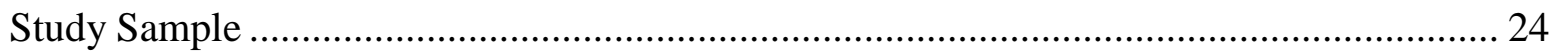

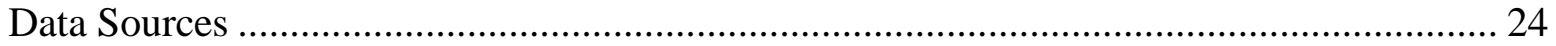

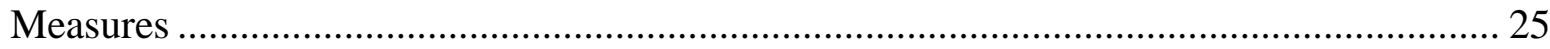

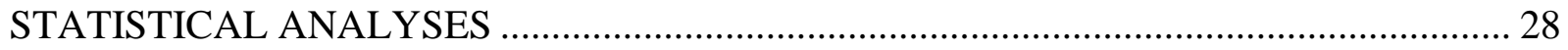

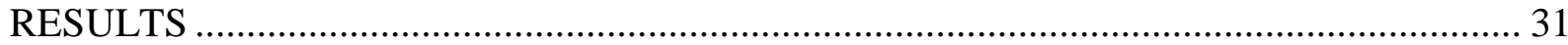

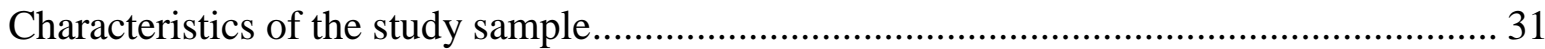

Economic indicators and physical health measures over time............................................... 31

The adjusted relationships between economic indicators and physical health measures ..... 32

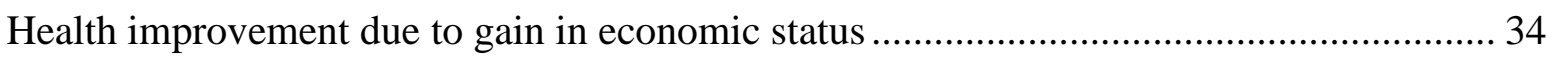

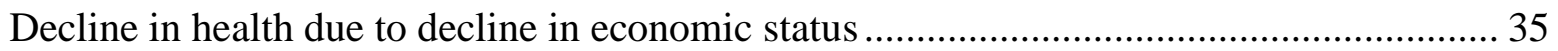

The effects of health improvement and health decline on economic status ......................... 35

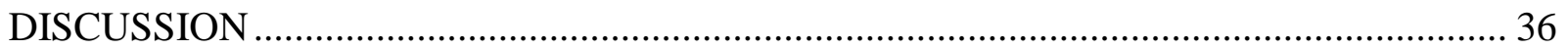

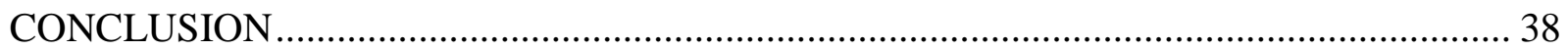

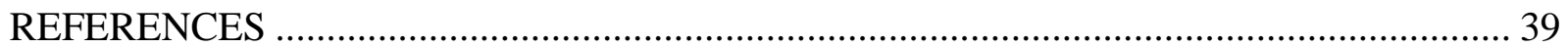

Chapter 3 The Dynamics of Economic status and Mental Health among Working-Age Adults in the United States ................................................................................................................ 54 
ABSTRACT

INTRODUCTION

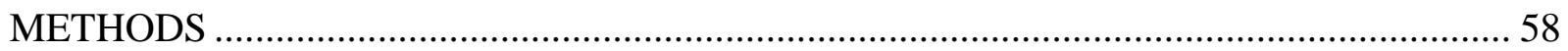

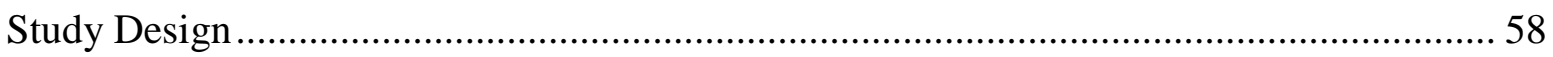

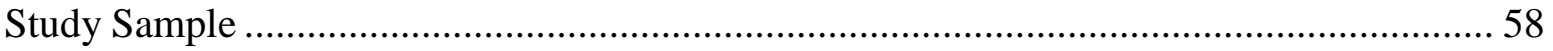

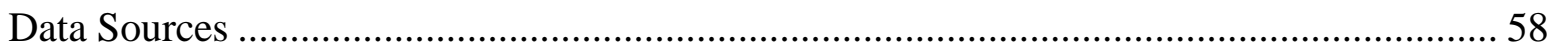

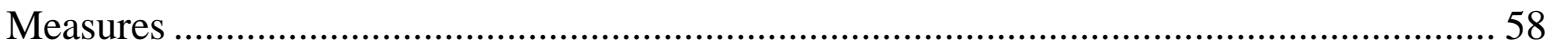

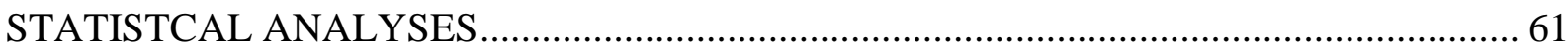

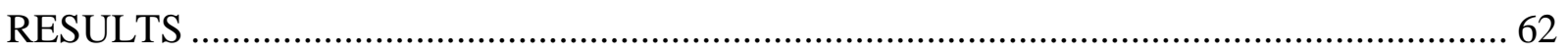

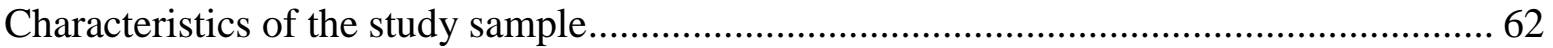

Economic Indicators and mental health measures over time ............................................... 62

The relationship between economic indicators and mental health measures ....................... 62

Increase in economic status and mental health improvement................................................. 64

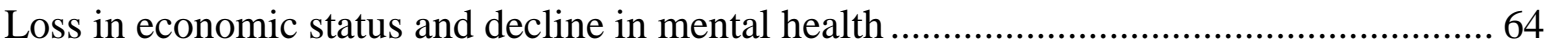

Mental health improvement and increase in economic status .............................................. 65

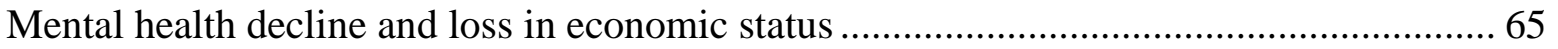

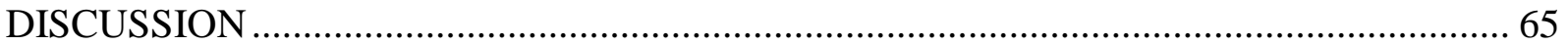

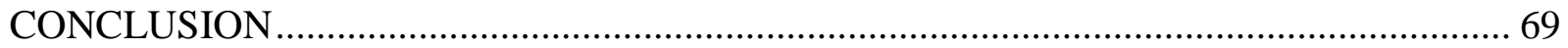

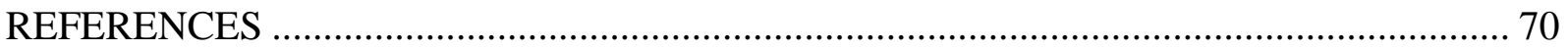

Chapter 4 Heterogeneous relationships between Labor Income and Health by Race/Ethnicity .. 82

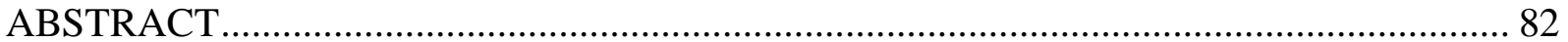

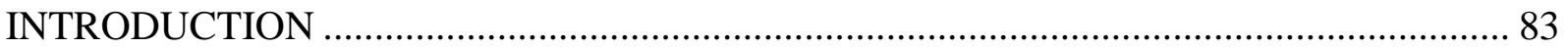

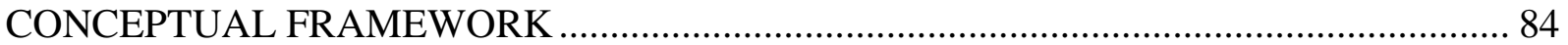

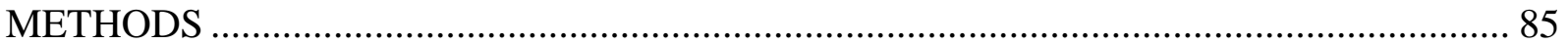

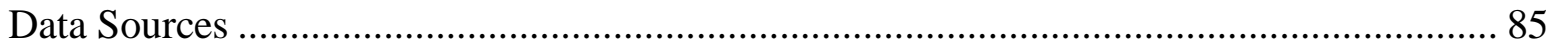

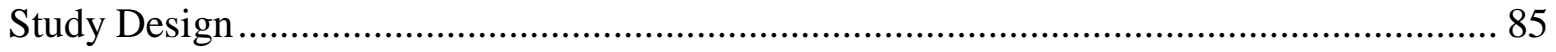

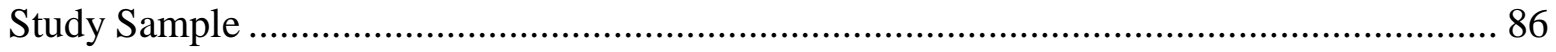

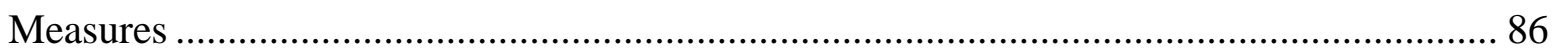

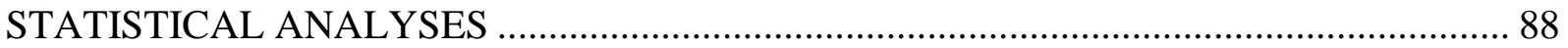

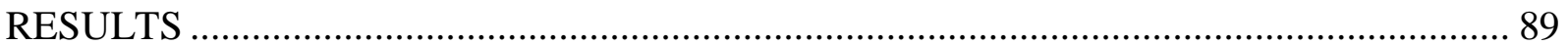

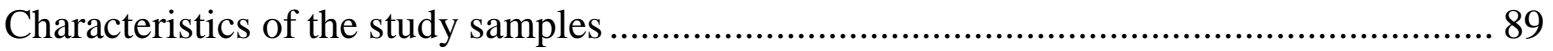

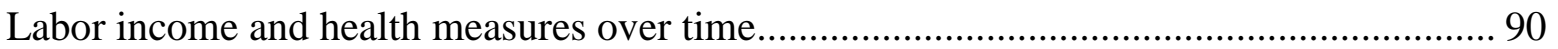

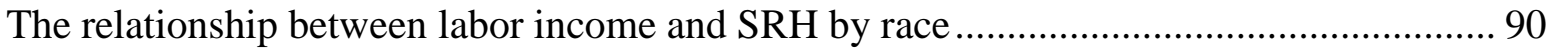

The relationship between labor income and psychological distress scores by race ............. 91 
Changes in labor income and changes in SRH by race ........................................... 91

Changes in labor income and changes in psychological distress scores by race ................ 92

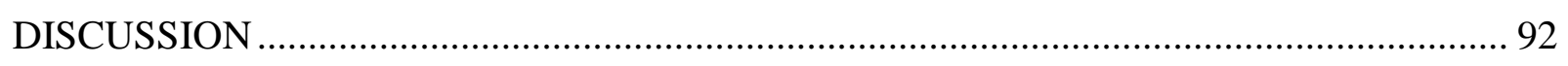

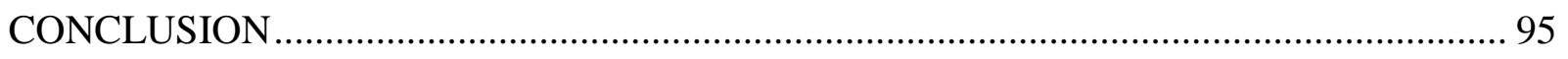

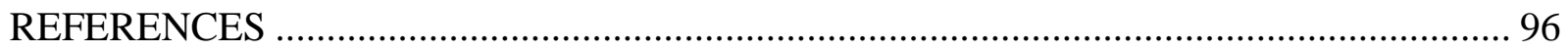

Chapter 5 Summary and Conclusions .......................................................................... 109

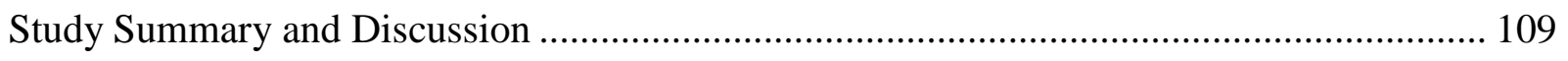

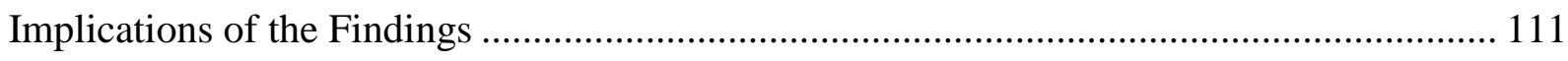

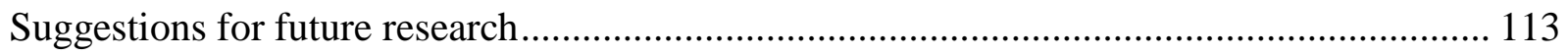

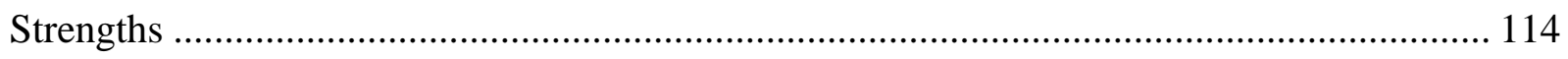

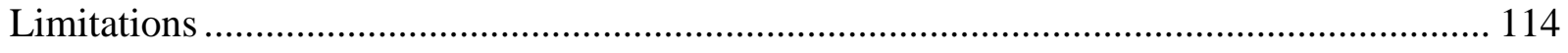

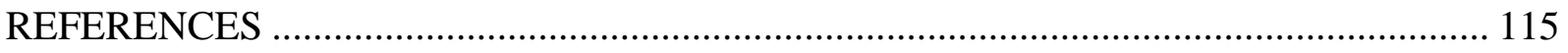




\section{LIST OF TABLES}

Table 2.1 Weighted Percentages of Selected Characteristics of Working-Age Adults, Panel

Study of Income Dynamics, 1999-2013, (N=2,693) . 42

Table 2.2 Mean and Standard Errors of Economic Indicators and Health Measures, Panel Study

of Income Dynamics, 1999-2013, (N=2,693) 44

Table 2.3 Adjusted Parameter Estimates and Standard Errors of Economic Indicators on Self-

Reported Health and Functional Limitations, Standard Regressions 45

Table 2.4 The Dynamic Relationships between Economic Indicators and Self-rated Health, System Generalized Method of Moment 47

Table 2.5 The Dynamic Relationship between Economic Indicators and Functional Limitations, System Generalized Method of Moment 48

Table 2.6 Changes in Economic Status and Changes in Physical Health Measures, First-

Difference 49

Table 2.7 Changes in Physical Health and Changes in Economic Status, First-Difference 51

Table 3.1 Weighted Percentages of Selected Characteristics of Working-Age Adults, Panel Study of Income Dynamics, 2007-2013, (N=4,867) 74

Table 3.2 Mean and Standard Errors of Economic Indicators, Panel Study of Income Dynamics, 2007-2013, $(\mathrm{N}=4,867)$ 76

Table 3.3 Mental Illness and Psychological Distress Descriptive Statistics, Panel Study of Income Dynamics, 2007-2013, $(\mathrm{N}=4,867)$ 77

Table 3.4 Parameter Estimates and Standard Errors of Economic Indicators on Psychological

Distress, OLS and IV OLS. 78

Table 3.5 Estimated Marginal effects of Economic Indicators on Mental Illness Probabilities,

Probit and IV Probit 79 
Table 3.6 Changes in Economic Status and Changes in Mental Health, First-Difference 80

Table 3.7 Changes in Mental Health and Changes in Economic Status, First-Difference 81

Table 4.1 Weighted Percentages of Selected Characteristics of Working-Age Adults by Rece,

Panel Study of Income Dynamics, 1999, (N=2,693). 100

Table 4.2 Weighted Percentages of Selected Characteristics of Working-Age Adults by Race,

Panel Study of Income Dynamics, 2007-2013, (N=4,867). 102

Table 4.3 Parameter Estimates and Standard Errors of Labor Income on Self-Rated Health and

Psychological Distress Scores. 106

Table 4.4 The Relation of Changes in Labor Income to Changes in Physical and Mental Health,

First-Difference. 107

\section{LIST OF FIGURES}

Figure 1.1: The Bidirectional Relationship between Economic Status and Health................... 10

Figure 1.2: Steady State Panel Schematic, PSID ................................................................ 12

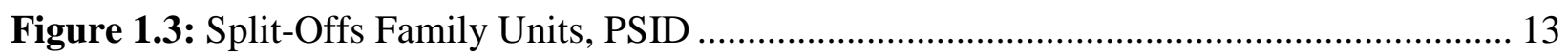

Figure 4.1 Mean Labor Income by Quartiles .................................................................. 104

Figure 4.2: Mean Self-Rated Health and Psychological Distress by Race............................ 105

\section{LIST OF APPENDIX}

Appendix 2.1 Specifications of Economic Gain and Loss Models. 53 


\section{LIST OF ABBREVIATIONS}

AHRF

FD

GMM

IV

OLS

PSID

SRH
The Area Health Resource File

First-Difference

Generalized Method of Moment

Instrumental Variable

Ordinary Least Squares Regression

The Panel Study of Income Dynamics

Self-Rated Health 


\section{STRUCTURE OF THIS DISSERTATION}

This dissertation is organized as the following: Chapter one briefly describes the different measures of health and economic indicators, need for this dissertation, conceptual framework used in this dissertation, and data sources utilized for this dissertation. Chapter two to four are individual manuscripts, which focused on the aims of this dissertation. Chapter two focused on the dynamic relationships between economic indicators and physical health measures among adults in the United States (US); chapter three focused on the dynamic relationships between economic indicators and mental health measures among adults in the US; Chapter four focused on the race-stratified relationships between labor income and physical and mental health measures. Chapter five included the discussion and the conclusion from the study findings. 


\section{Chapter 1}

Introduction

\section{BACKGROUND}

The relationships between economic indicators and health have been a subject of research for the last two decades in the United States (US) (1-12). Economic, epidemiological and sociological studies have been conducted to examine the direction of this relationship and determine the possible causal pathways (1-12). Mortality rates are the gold standard for measuring health status. However, mortality is an absorbing event, and cannot be used to examine the way that health changes over the life cycle (13). Therefore, prior studies used metrics other than mortality to analyze the link between economic indicators and health. Numerous studies have indicated that economic indicators (i.e. family income, labor income, net wealth) are positively associated with various physical health measures (e.g.: self-rated health) (1,4-6,14-18) and negatively with mental health measure (psychological distress and disorders) $(9,11,12)$ Nevertheless, the consensus on the magnitude of the relationships lacks among those studies. Further, some studies revealed no associations between economic indicators and some physical and mental health measures $(7,8,11)$.

The inconsistent findings may be attributed to four challenges to evaluating the relationships between economic indicators and health: 1) heterogeneity in measures of health;2) heterogeneity in measures of economic indicators; 3 ) endogeneity between economic indicators and health due to reverse causality and unobserved heterogeneity; and (4) lack of comprehensive adjustors such as race/ethnicity, sex, and other risk factors that may affect health (example: smoking, alcohol use, physical activity and obesity). 


\section{Physical and Mental Health Measures}

World Health Organization defines health as "a state of complete physical, social and mental well-being, and not merely the absence of disease or infirmity (19)." Therefore, health is a complex multidimensional concept, and is dependent on the interactions between physical, mental, and social dimensions. Although health is not only the absence of diseases, presence of diseases can affect various dimensions of health. For example, the presence of a high disabling disease like arthritis can affect physical, mental, and social dimensions of health. It should be noted that there is no single measure that captures all the dimensions of health (20). Also, it is difficult to measure all health aspects simultaneously. Therefore, the current dissertation focuses on physical and mental dimensions of health.

\section{Physical Health}

There is a wide variation in how physical health is measured. Some studies have used self-rated health $(2,4,6,7,14,21-24)$, presence of chronic conditions $(1,5,7,14,16,25-27)$ and functional limitations due to chronic conditions (16) to represent physical health. These measures are often chosen because they are highly correlated with mortality (28), productivity loss $(29,30)$, and are easy to obtain $(28,31)$. Descriptions of physical health measure are as follow:

\section{$\underline{\text { Self-rated Health }}$}

Self-rated health (SRH) is a widely used measure of physical health in epidemiological, medical and economic research (32-35). It is based on asking individuals to rate their health status on a five-point scale (Excellent, very good, good, fair, and poor) (32-35). SRH is a reliable and valid measure of health (32-35). SRH can be used independently as a predictor of mortality. In fact, previous studies suggested a consistent association between poor self-ratings of health 
and higher risk of mortality (28). Additionally, SRH is significantly associated with morbidity $(36,37)$. SRH also provides broad measure of individuals' health that goes beyond morbidity and

mortality (38). In 2014, $11.9 \%$ of US adults ( $\geq 18$ years) reported their health as fair or poor (39). In the US, SRH varies by poverty status, as $26.8 \%$ of poor adults reported their health as fair or poor while $7.4 \%$ of not poor adults reported their health as fair or poor (39). Therefore, this measure of health has been widely used in assessing the relationships between economic indicators and health. Some studies have reported positive associations between economic indicators (family income, labor income and net wealth) and SRH (4-6,15,40). However, one study revealed no relationship (7) between net wealth and SRH.

\section{Chronic Conditions-Attributable Functional Limitations}

Chronic conditions prevalence has increased dramatically in the US (41). In 2012, 117 million (1 in 2) adults lived with at least one chronic condition from a list of selected ten conditions (hypertension, coronary heart disease, stroke, diabetes, cancer, arthritis, hepatitis, weak or failing kidneys, current asthma, or chronic obstructive pulmonary disease) (41). Although WHO definition of health states that the absence of a disease does not equal perfect health, presence of a chronic condition imposes a threat to multiple dimensions of health. Chronic conditions are highly associated with psychological disorders such as depression and psychological distress $(42,43)$. Also, disabling chronic conditions can minimize the functioning of working-age and elderly adults (44). In 2014, 12.2\% of US adults who aged 18 or over had limitation(s) in their abilities to engage in work, social, and daily living activities due to one or more chronic conditions (44). Furthermore, chronic conditions are highly associated with productivity losses and lost in income $(45,46)$. The studies have found that adults with lower 
income and wealth have higher number of chronic conditions and higher limitations due to chronic conditions $(5,16,17)$.

\section{Mental Health}

Mental health is "a state of well-being in which every individual realizes his or her own potential, can cope with the normal stresses of life, can work productively and fruitfully, and is able to make a contribution to her or his community (47)." Mental health is an important dimension of an individual's health, and there is a paucity of research on the relationship between economic indicators and mental health. In the US, 43.6 million US adults (18.1\%) experienced poor mental health due to the presence of mental health conditions (48) such as anxiety, depression, and bipolar disorders (48). Poor mental health is profoundly disabling (49) and costly to the society and the patients and their families (50). For example, depression is the second leading cause of disability (49); both depression and anxiety were associated with high financial burden to the payors/patients and/or their families (51), productivity loss (52), and healthcare expenditures (50). Studies have reported that psychological disorders and stress are correlated with low-income $(9,11,43,53-56)$. Although numerous studies have evaluated the relationship between changes in mental health and the probability of employment (57-62), only a handful of studies has examined the link between economic indicators and mental health $(9,11,12,53)$. These studies have documented inverse associations between economic indicators and psychological distress and disorders $(9,11,12,53)$. Nonetheless, those studies did not relate the change in the economic indicators to the change in health. Therefore, the studies on the dynamic relationship between economic indicators and health are limited. 


\section{Economic Indicators}

It has been considerable debate over the best economic indicator that represents individuals' economic status. Household income, net wealth, home ownership, earnings and wages from employment, poverty, and household expenditures are all measures that have been used in the research to represent individuals' economic well-being. Income reflects a temporary flow of financial resources at one time-point and is considered more responsive to changes in health. As a result, many studies have used household, family or labor income $(4,15,16,18,22,25,26,63)$ to represent the economic well-being of an individual. On the other hand, wealth is the accumulated financial resources over the lifetime of an individual $(64,65)$ and considered more stable than income. As individuals and families can rely on accumulated wealth in times of unemployment or times of declining health, some studies used wealth to examine the relationships between economic indicators and health $(5,6)$. However, health is a multidimensional concept and economic indicators seem to have different dynamic relationships with different components of health $(4-7,22,23)$.

\section{Endogeneity between Economic Indicators and Health}

The relationship between economic indicators and health may be reciprocal. From economic point of view, individuals with good health may have higher financial resources compared to those with poor health because they can participate in activities that generate income $(22,66,67)$. From epidemiology and health policy perspectives, individuals with higher financial resources have better health because they have better access to healthcare through health insurance or able to spend out-of-pocket on healthcare $(22,67,68)$. It is important to address the endogeneity due to reverse causality between economic indicators and health in the analyses to compute consistent unbiased estimates. Previous studies have employed some 
statistical techniques including instrumental variables to address the endogeneity. However, it is difficult to find a valid instrument that is strongly correlated with economic indicators and has no direct effect on health. Therefore, future research needs to employ statistical techniques that address the endogeneity between economic indicators and health without using weak instruments.

\section{Factors affect economic indicators, health or both}

Many factors can alter the relationships between economic indicators and health including age, sex, race/ethnicity and others. For example, the relationships between economic indicators and health may vary by age groups as a result of the differences between working-age and elderly adults (69-71). To capture the actual magnitude of the relationships between economic indicators and health, researchers need to examine the relationships between the two within working-age and elderly adults separately. Elderly adults have different economic resources as compared to working-age adults (69-71). Elderly adults may have no labor income because they are less likely to be employed. Another factor is the type of health insurance. Working-age adults usually get their health insurance through their work or they buy private health insurance (72). Conversely, elderly adults are eligible for public health insurance through the government (73). Furthermore, elderly adults have higher health care needs due to the natural process of aging. All these factors may alter the relationships between economic indicators and health, and it is expected that the magnitude of the relationships would be different between these two age groups. The appropriate economic indicators and health measures also vary by these two age groups (1-12). Further, it is crucial to control for other factors that can affect economic indicators or health such as marital status, physical activity, alcohol use, region of residence, metro status, and others. 
Studies on the racial/ethnic disparities in the relationships between economic indicators are sparse. Racial and ethnic minorities have poorer health and less wealth as compared to the white individuals (74,75). From 1984 to 2007, the wealth gap increased more than four times between whites and African Americans (74). Also, African Americans and Hispanics have higher mortality rates as compared to their white counterparts (75). Few studies have highlighted the differences in the relationship between racial minorities and white individuals $(11,16,76,77)$. Nonetheless, most of these studies have utilized cross-sectional samples and all of them suffer from the limitations mentioned above.

\section{NEED FOR THE STUDY}

Prior studies have suggested positive or no relationships between economic indicators and health (1-12). While these studies have made significant contributions in this area, a comprehensive evaluation of the relationships between economic indicators and health is still lacking. Most studies have used a single measure of health (1-12); the concept of health is abstract, and no single measure can capture all health dimensions (20). Of special interest is the relationship between economic indicators and mental health, specifically psychological distress, depression and/or anxiety because of the heavy illness burden (49). Yet, there are only a few studies in this area $(9,11,12,53)$. Further, most studies have focused on one-direction - economic indicators affecting health; little is known about the effect of health improvement on gain in economic status. Moreover, given the long-history of racial discrimination, differential effect of poverty on health between whites and African Americans, racial inequities in education and healthcare resources $(74,78,79)$, it is important to examine racial disparities in the relationship between economic indicators and health. Only a few studies have conducted comparative analysis of whites and racial minorities $(11,16,76,77)$. Furthermore, previous studies have not 
adequately controlled for endogeneity between economic indicators and health due to reverse causality, omitted variables and unobserved heterogeneity $(2,4-6,9,11,12,40)$.

Understanding the relationship between economic indicators and health is crucial to suite policies and programs. If there is a strong positive relationship between economic indicators and health, policy makers need to focus on upstream factors (i.e. economic status) rather than healthcare behavior and services. In addition, any sex or racial disparities in the link between economic indicators and health will inform the policy makers on the need for special programs for the minorities in US. Such programs need to address the racial economic inequality to attenuate the racial health disparities in US.

The present dissertation addressed many of the limitations of existing studies by (1) using a variety of health measures and economic indicators; (2) modeling dynamic rather than static relationship between economic indicators and health; (3) adjusting for endogeneity that is caused by unobserved heterogeneity, measurement error and reverse causality by using novel statistical techniques; (4) and using a nationally representative database with the ability to track individuals over time.

\section{AIMS, OBJECTIVES AND HYPOTHESES}

AIM 1: Examine the dynamic relationships between economic status (family income, labor income and net wealth) and physical health measures (self-rated health and functional limitations due to chronic conditions) among working-age adults in the US.

Hypothesis 1.1: A decrease in economic indicators will lead to a decline in health; improvements in health will lead to increases in economic indicators. 
AIM 2: Evaluate the dynamic relationships between economic indicators (family income, labor income and net wealth) and mental health (psychological distress and mental illnesses) among working-age adults in the US.

Hypothesis 2.1: A decrease in economic indicators will lead to a decline in mental health; improvements in mental health will lead to increases in economic indicators.

AIM 3: Evaluate the heterogeneous relationships between labor income and physical and mental health by racial groups.

Hypothesis 3.1: Whites and African Americans with higher labor income will have better physical health.

Hypothesis 3.2: Whites who experience a decline in labor income will also experience a decline in physical and mental health.

Hypothesis 3.3: There will not be a statistically significant relationship between labor income and mental health among African Americans and Hispanics.

\section{CONCEPTUAL FRAMEWORK}

The present dissertation was guided by a simple health economics framework in which health capital, human capital and financial capital interact with each other. From a health economic perspective, an individual born with a fixed health capital stock (health capital), which declines with age because of biological processes (13). Michael Grossman (80) posits that education (human capital) increases the efficient use of medical care and educated individuals are more likely to improve their healthcare or effectively address/reverse a health decline. Therefore, education rather than income or wealth is the primary driver of health. Case and Deaton (13) improved on Michael Grossman's framework and suggested that the link between health and economic indicators are affected not only by health capital and human capital, but 
also the financial resources an individual has (financial capital). The model further assumes that there is equitable distribution of health at time of birth and this is not the case with human and financial capital. Individuals with less human and financial capital, rely heavily on their health capital and health capital deteriorates faster. Therefore, poor and less educated individuals are more likely to have poor health. This was further expanded by Galama (66) who used health capital as the foundation and suggested that health may also affect economic indicators. Under his framework, "unhealthy individuals drop out of the labor force sooner, and lose income as a result". Although Case and Deaton acknowledge that other factors may affect both health and financial capital, these factors were operationalized by Strauss and Thomas (81).

In this dissertation, we have integrated the frameworks and suggest that lower economic well-being leads to health decline and subsequent improvement in health can lead to higher economic well-being while adjusting for other factors that affect both economic indicators and health (Figure 1.1).

Figure 1.1: The Bidirectional Relationship between Economic Status and Health

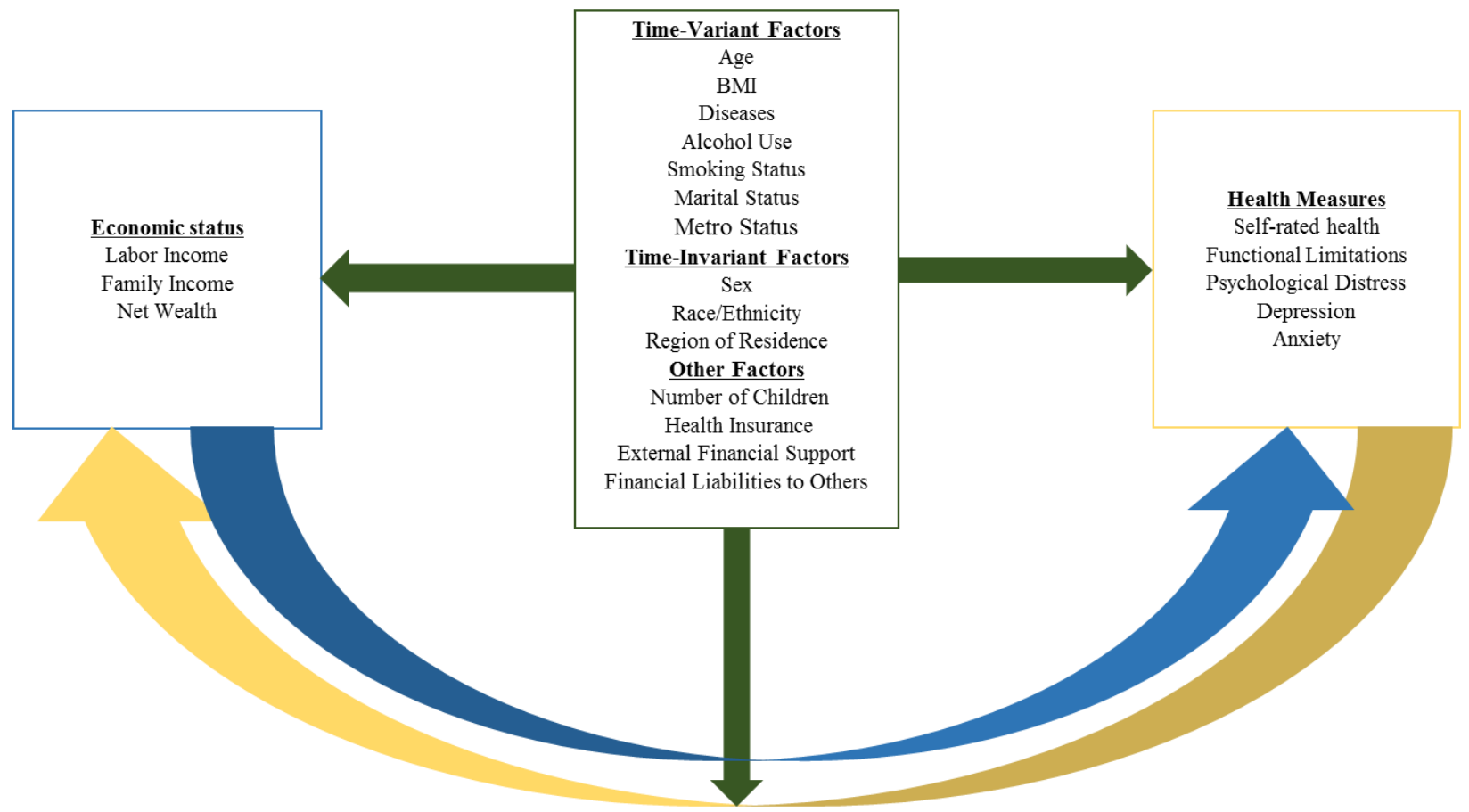




\section{DATA SOURCES}

Information from the Panel study of Income Dynamics was utilized in all specific aims. Information on metros' level of unemployment rate was retrieved from The Area Health Resource File, and was linked to the PSID at the state and metro level.

\section{The Panel Study of Income Dynamics (PSID)}

The PSID was created in 1966 to assess President Lyndon Johnson's War on Poverty $(82,83)$. The original PSID 1968 sample was drawn from two independent samples: an oversample of 1,872 low-income families from the Survey of Economic Opportunity; and a nationally representative sample of 2,930 families $(82,83)$. Those two samples constituted a national probability sample of U.S. families in 1968 (82,83). The PSID further follow these families and others to maintain a representative sample at any point in time and across time. The PSID included all Individuals in the 1968 families and new-born or adopted Individuals $(82,83)$. The PSID also follow Individuals in 1968 families who started new families $(82,83)$. In the PSID, individuals in 1968 families are called "sample individuals". Those sample individuals and their descendants are followed for their lifetime. In addition, non-sample individuals are followed if they marry sample individuals as long as they stay in the sample individual family unit. The PSID has achieved high response rates (e.g.: 94.7\% in 2009) (82,83). Households were interviewed annually between 1968 and 1997, and biannually since then. As of 2015, 39 waves of PSID have been collected, and 25,000 individuals in 10,000 families have been interviewed (82-84).

Currently, the individuals in any panel come from three sources: the original 1968 sample; the 1997 refresher sample of post 1968 immigrants; and births and marriages in existing 
families (82-84). PSID is the only data set that provides information on life course and multigenerational economic conditions, well-being, and health (82-84).

Figure 1.2: Steady State Panel Schematic

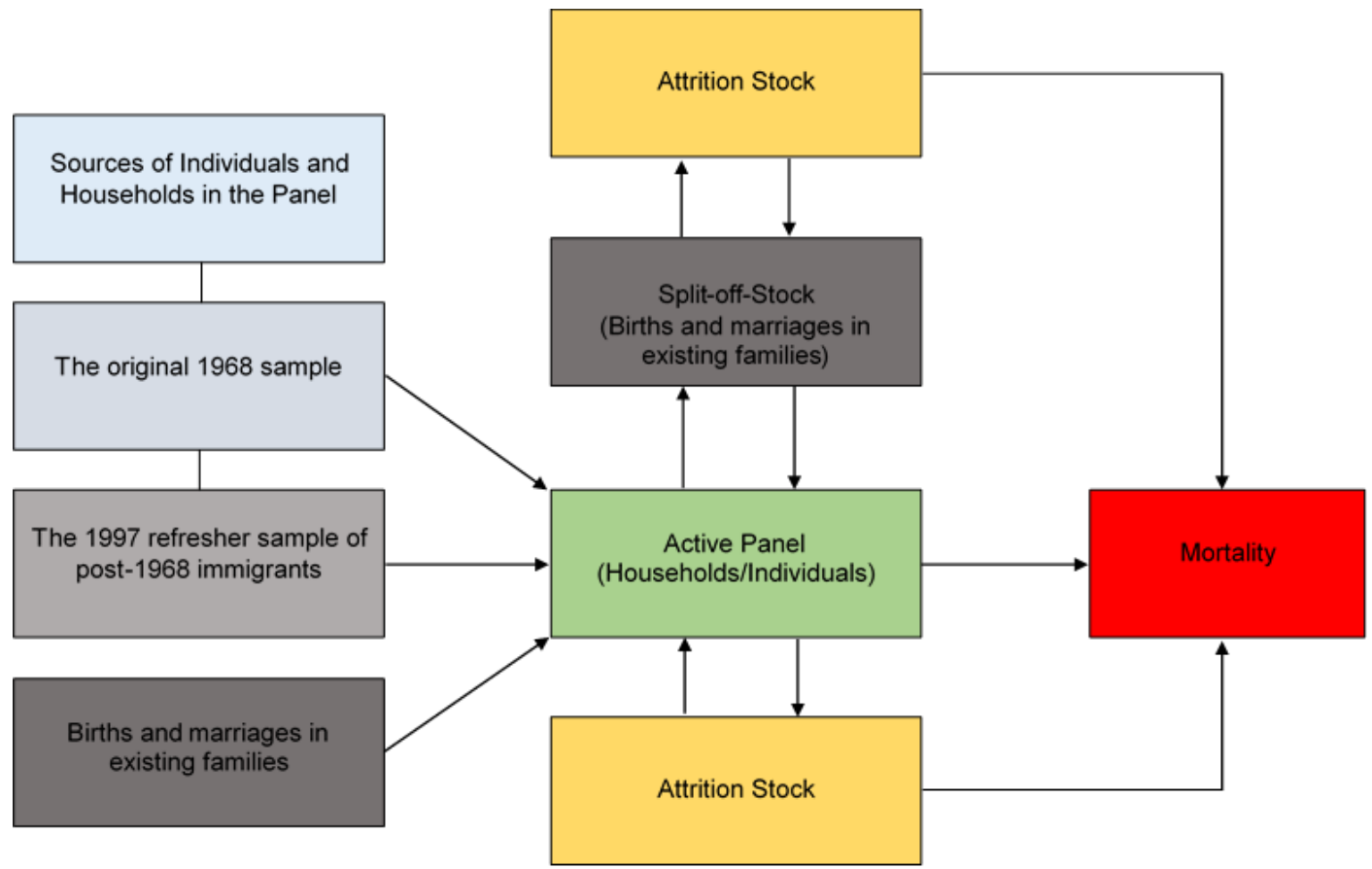

Interview data are released with five different files: family file, cross-year individual file, birth history file, marriage history file, and parent identification file (84). In this dissertation, both family and cross-year individual files, which are publicly available, will be used to gather information on households. Most of the information about households' heads and their wives are available in the family file. Information on demographic, education, family composition, health behavior, health care utilization, health history, health insurance, health status, economic indicators are all available in the family file (84). On the contrary, limited information on every person who was ever in an interviewed family at any point is available in the cross-year individual file. It should be noted that the PSID provides other supplemental studies including child development supplement, transition into adulthood supplement, disability and use of time, and intergenerational transfer (84). For the purpose of the current study, we restricted our 
analyses to the households' heads who were continuously in the panel between 1999 and 2013.

Figures 1.2 and 1.3 depict the panel design of PSID.

Figure 1.3: Split-Offs Family Units

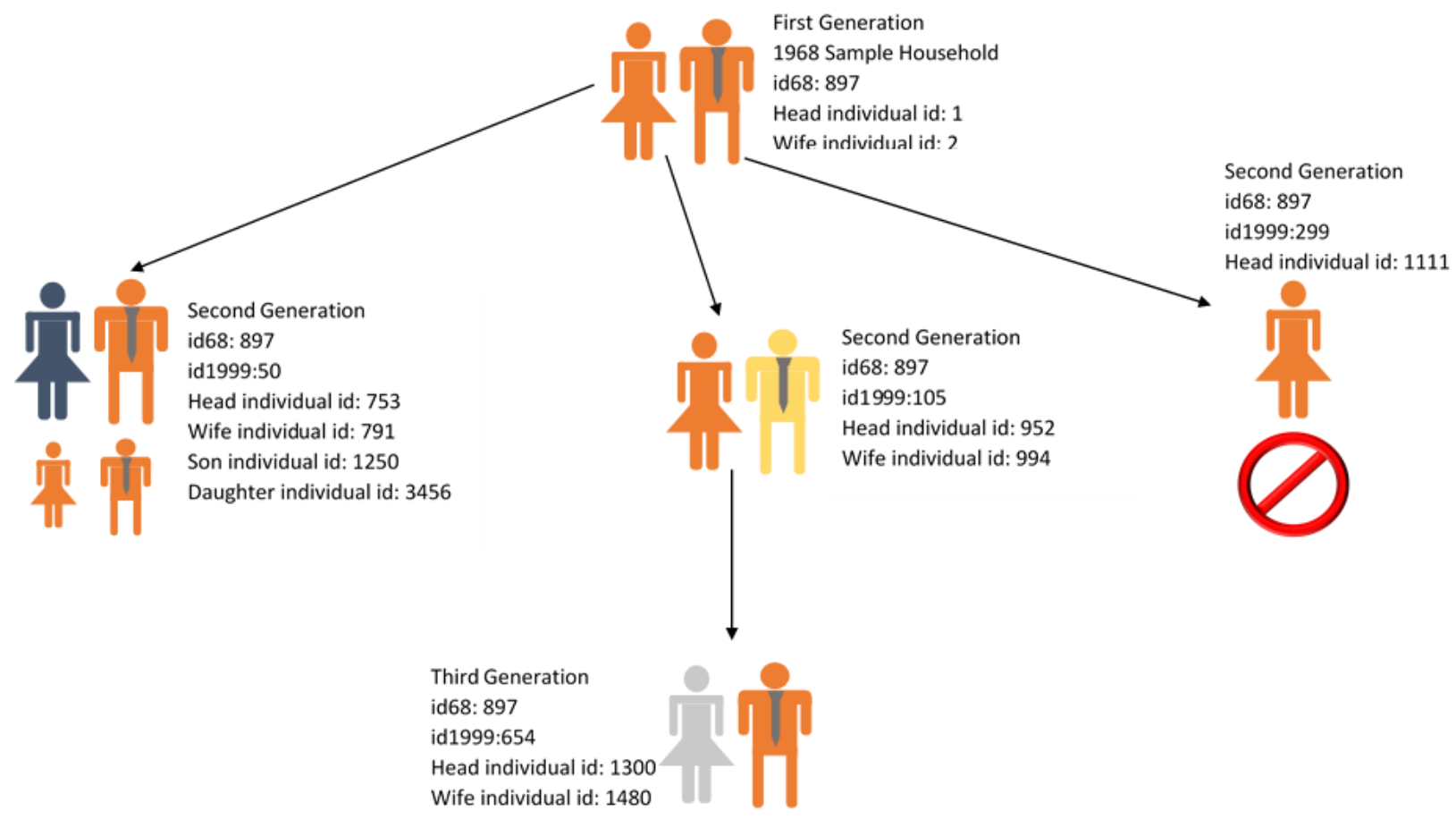

\section{The Area Health Resource File (AHRF)}

Unemployment rates were derived from the AHRF, provided by the Department of Health and Human Services (85). This information was linked to the PSID by using five-digit Federal Information Processing Standard (FIPS) codes at the metro-level. 


\section{REFERENCES}

(1) Fiscella K, Franks P. Individual income, income inequality, health, and mortality: what are the relationships? Health services research 2000;35(1 pt2):307-318.

(2) McDonough P, Berglund P.. Histories of poverty and self-rated health trajectories. Journal of Health and Social Behavior 2003;44(2):198-214.

(3) Meer J, Miller DL, Rosen HS. Exploring the health-wealth nexus. . Journal of health economics 2003;22(5):713-730.

(4) Berry B. Does money buy better health? Unpacking the income to health association after midlife. Health(London) 2007;11(2):199-226.

(5) Hajat A, Kaufman JS, Rose KM, Siddiqi A, Thomas JC. Do the wealthy have a health advantage? Cardiovascular disease risk factors and wealth. Social Science and Medicine 2010;71(11):1935-1942.

(6) Hajat A, Kaufman JS, Rose KM, Siddiqi A, Thomas JC. Long-term effects of wealth on mortality and self-rated health status. American Journal of Epidemiology 2011;173(2):192-200.

(7) Michaud PC, van Soest A. Health and wealth of elderly couples: causality tests using dynamic panel data models. Journal of Health Economics 2008;27(5):1312-1325.

(8) Halliday TJ. Earnings Growth and Movements in Self-Reported Health. Review of Income and Wealth 2016.

(9) Sareen J, Afifi TO, McMillan KA, Asmundson GJ. Relationship between household income and mental disorders: findings from a population-based longitudinal study. Archives of General Psychiatry 2011;68(4):419-427.

(10) Lorant V, Deliège D, Eaton W, Robert A, Philippot P, Ansseau M. Socioeconomic inequalities in depression: a meta-analysis. American Journal of Epidemiology 2003;157(2):98112 .

(11) McMillan KA, Enns MW, Asmundson GJ, Sareen J. The association between income and distress, mental disorders, and suicidal ideation and attempts: findings from the collaborative psychiatric epidemiology surveys. . The Journal of clinical psychiatry 2010;71(9):1168-1175.

(12) Yilmazer T, Babiarz P, Liu F. The impact of diminished housing wealth on health in the United States: Evidence from the Great Recession. Social science \& medicine 2015;130:234241.

(13) Case A, Deaton A. Broken down by work and sex: How our health declines. Analyses in the Economics of Aging, University of Chicago Press. 2005:185-212.

(14) Adams P, Hurd MD, McFadden DL, Merrill A, Ribeiro T. Healthy, wealthy, and wise? Tests for direct causal paths between health and socioeconomic status. Journal of Econometrics 2003;112(1):3-56. 
(15) Robert SA, Cherepanov D, Palta M, Dunham NC, Feeny D, Fryback DG. Socioeconomic status and age variations in health-related quality of life: Results from the national health measurement study. Journal of Gerontology: Social Sciences 2009;64B(3):378-389.

(16) Braveman PA, Cubbin C, Egerter S, Williams DR, Pamuk E. Socioeconomic disparities in health in the United States: what the patterns tell us. American journal of public health 2010;100(S1):S186-S196.

(17) Do DP, Frank R, Finch BK. Does SES explain more of the black/white health gap than we thought? Revisiting our approach toward understanding racial disparities in health. Social science \& medicine 2012;74(9):1385-1393.

(18) Golberstein E. The effects of income on mental health: evidence from the social security notch. The journal of mental health policy and economics 2015;18(1):27-37.

(19) Preamble to the Constitution of the World Health Organization as adopted by the International Health Conference. ; 1948.

(20) Turnock B J. Chapter 2: Understanding and Measuring Health. Public Health: what it is and how it works turnock. 6th ed. Burlington, MA, USA: Jones \& Bartlett Publishers; 2011. p. 21-47.

(21) Kennedy BP, Kawachi I, Glass R, Prothrow-Stith D. Income distribution, socioeconomic status, and self rated health in the United States: multilevel analysis. BMJ 1998;317(7163):917921.

(22) Halliday T. Income volatility and health. Discussion Paper No 3234, IZA 2007.

(23) Halliday T. Earnings Growth and Movements in Self-Reported Health. IZA 2012;6367:151.

(24) Meyer OL, Castro-Schilo L, Aguilar-Gaxiola S. Determinants of mental health and selfrated health: a model of socioeconomic status, neighborhood safety, and physical activity. . American journal of public health 2014;104(9):1734-1741.

(25) Banks J, Marmot M, Oldfield Z, Smith JP. Disease and disadvantage in the United States and in England. JAMA 2006;295(17):2037-2045.

(26) Chung Y. Chronic Health Conditions and Economic Outcomes. Unpublished mimeo 2013 http://www.sole-jole.org/14225.pdf.

(27) Grafova IB. Financial status and chronic conditions onset among non-elderly adults. Review of Economics of the Household 2015;13(1):53-72.

(28) Idler EL BY. Self-rated health and mortality: a review of twenty-seven community studies. Journal of Health and Social Behavior 1997;38(1):21-37.

(29) Alecxih L, Shen S, Chan I, Taylor D, Drabek J. Individuals Living in the Community with Chronic Conditions and Functional Limitations: A Closer Look. 2010.

(30) Anesetti-Rothermel A SU. Physical and mental illness burden: disability days among working adults. Population health management 2011;14(5):223-230. 
(31) Xu JQ, Murphy SL, Kochanek KD, Bastian BA. Deaths: Final data for 2013. National vital statistics reports. National Center for Health Statistics 2016;64(2).

(32) Zajacova A DJ. Reliability of self-rated health in US adults. American Journal of Epidemiology 2011;174(8):977-983.

(33) Bombak AE. Self-Rated Health and Public Health: A Critical Perspective. Front Public Health 2013;1(15).

(34) Allore HG, Zhan Y, Tinetti M, Trentalange M, McAvay G. Longitudinal average attributable fraction as a method for studying time-varying conditions and treatments on recurrent self-rated health: the case of medications in older adults with multiple chronic conditions. Annals of epidemiology 2015;25(9):681-686.

(35) Hays RD, Spritzer KL, Thompson WW, Cella D. US general population estimate for "excellent" to "poor" self-rated health item. Journal of general internal medicine 2015;30(10):1511-1516.

(36) Chamberlain AM, Manemann SM, Dunlay SM, Spertus JA, Moser DK, Berardi C, Kane RL, Weston SA, Redfield MM, Roger VL. Self-rated health predicts healthcare utilization in heart failure. Journal of the American Heart Association 2014;3(3):1-8.

(37) Wagner DC. Longitudinal predictors of self-rated health and mortality in older adults. Preventing chronic disease 2014.

(38) Zack MM, Moriarty DG, Stroup DF, Ford ES, Mokdad AH. Worsening trends in adult health-related quality of life and self-rated health-United States, 1993-2001. Public health reports 2004;119(5):493-505.

(39) Blackwell DL LJ. Tables of Summary Health Statistics for U.S. Adults: 2014 National Health Interview Survey. 2015.

(40) Franks P, Gold MR, Fiscella K. Sociodemographics, self-rated health, and mortality in the US. Social science \& medicine 2003;56(12):2505-2514.

(41) Ward BW. Multiple chronic conditions and labor force outcomes: A population study of U.S. adults. American Journal of Industrial Medicine 2015;58(9):943-954.

(42) Egede LE, Zheng D, Simpson K. Comorbid depression is associated with increased health care use and expenditures in individuals with diabetes. Diabetes Care 2002 Mar;25(3):464-470.

(43) Weissman J, Pratt LA, Miller EA, Parker JD. Serious psychological distress among adults: United States, 2009-2013. National Center for Health Statistics 2015;NCHS data brief(203).

(44) Adams PF BV. Tables of Summary Health Statistics for the U.S. Population: 2014 National Health Interview Survey. . 2015.

(45) DeVol R BA. An unhealthy America: The economic burden of chronic disease--charting a new course to save lives and increase productivity and economic growth. 2007. 
(46) Vuong TD, Wei F, Beverly CJ. Absenteeism due to Functional Limitations Caused by Seven Common Chronic Diseases in US Workers. . Journal of Occupational and Environmental Medicine 2015;57(7):779-784.

(47) Herman H, Saxena S, Moodie R. Promoting Mental Health: Concepts, Emerging Evidence, Practice. Geneva, Switzerland: World Health Organization; 2005.

(48) Center for Behavioral Health Statistics and Quality. Behavioral health trends in the United States: Results from the 2014 National Survey on Drug Use and Health. Available at: http://www.samhsa.gov/data/. Accessed 07/22, 2016.

(49) Murray CJ, Abraham J, Ali MK, Alvarado M, Atkinson C, Baddour LM, Bartels DH, Benjamin EJ, Bhalla K, Birbeck G, Bolliger I. The state of US health, 1990-2010: burden of diseases, injuries, and risk factors. JAMA 2013;310(6):591-606.

(50) Levit KR, Kassed CA, Coffey RM, Mark TL, McKusick DR, King E, Vandivort R, Buck J, Ryan K, Stranges E. Projections of National Expenditures for Mental Health Services and

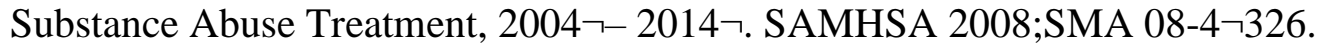

(51) Greenberg PE, Fournier AA, Sisitsky T, Pike CT, Kessler RC. The economic burden of adults with major depressive disorder in the United States (2005 and 2010). The Journal of clinical psychiatry 2015;76(2):155-162.

(52) Stewart WF, Ricci JA, Chee E, Hahn SR, Morganstein D. Cost of lost productive work time among US workers with depression. JAMA 2003;289(23):3135-3144.

(53) Prause J, Dooley D, Huh J. Income volatility and psychological depression. . American Journal of Community Psychology 2009;43(1-2):57-70.

(54) Messias E, Eaton WW, Grooms AN. Income inequality and depression prevalence across the United States: an ecological study. Psychiatric Services 2011;62(7):710-712.

(55) Bogan VL FA. Portfolio choice and mental health. Review of Finance 2013;17(3):955-992.

(56) Pabayo R, Kawachi I, Gilman SE. Income inequality among American states and the incidence of major depression. Journal of epidemiology and community health 2013;jech2013:1-6.

(57) Ettner, S., R. Frank, and R. Kessler. The Impact of Psychiatric Disorders on Labor Market Outcomes. Industrial and Labor Relations Review 2007;51(1):64-81.

(58) Dooley, D., J. Prause, and K.A. Ham-Rowbottom. Underemployment and Depression: Longitudinal Relationships. Journal of Health Social Behavior 2000;41(4):421-436.

(59) Chatterji, P., M. Alegria, M. Lu, and D. Takeuchi. Psychiatric Disorders and Labor Market Outcomes: Evidence from the National Latino and Asian American Study. Health Economics 2007;16(10):1069-1090.

(60) Chatterji, P., M. Alegria, and D. Takeuchi. Psychiatric Disorders and Labor Market Outcomes: Evidence from the National Comorbidity Survey-Replication. Journal of Health Economics 2011;30(5):858-868. 
(61) Baldwin, M., and S. Marcus. The impact of mental and substance-use disorders on employment transitions. Health Economics 2014;23(3):332-344.

(62) Mitra S JK. The impact of recent mental health changes on employment: new evidence from longitudinal data. Applied Economics 2016:1-4.

(63) Duncan GJ, Daly MC, McDonough P, Williams DR. Optimal indicators of socioeconomic status for health research. American Journal of Public Health 2002;92(7):1151-1157.

(64) Keister LA. Wealth in America: Trends in wealth inequality. Cambridge, UK: Press Syndicate of the University of Cambridge.; 2000.

(65) Shapiro TM, \& Wolff EN. Assets for the poor: The benefits of spreading asset ownership. New York: Russell Sage Foundation.; 2001.

(66) Galama TJ. A contribution to health-capital theory. Rand Working Paper 2011:1-47.

(67) Galama TJ, Van Kippersluis H. Health inequalities through the lens of health-capital theory: issues, solutions, and future directions. Research on economic inequality 2013;21:263-284.

(68) Marmot M. The influence of income on health: views of an epidemiologist. . Health affairs 2002;21(2):31-46.

(69) Toossi M. Labor force projections to 2014: Retiring boomers. Labor Force 2005(128):2544.

(70) West L, Cole S, GoodkinD, He W. 65+ in the United States: 2010. U S Census Bureau, U S Government Printing Office 2014:23-212.

(71) Bosworth B BK. Changing Sources of Income among the Aged Population. Center for Retirement Research at Boston College 2012;CRR WP 2012-27:1-34.

(72) Claxton G, Rae M, Long M,Panchal N, Damico A. (Kaiser Family Foundation). Employer Health Benefits, 2015. Kaiser Family Foundation and Health Research and Educational Trust 2015:1-233.

(73) National Center for Health Statistics. Health, United States, 2015: With Special Feature on Racial and Ethnic Health Disparities. U S Department of Health and Human Services 2015.

(74) Shapiro TM, Meschede T, Sullivan L. The racial wealth gap increases fourfold. Waltham, MA: Institute on Assets and Social Policy, Brandeis University 2010.

(75) Williams DR JP. Social sources of racial disparities in health. . Health Affairs 2005;24(2):325-334.

(76) Shea DG, Miles T, Hayward M. The health-wealth connection: Racial differences. The Gerontologist 1996;36(3):342-349.

(77) Pollack CE, Cubbin C, Sania A, Hayward M, Vallone D, Flaherty B, Braveman PA. Do wealth disparities contribute to health disparities within racial/ethnic groups? Journal of epidemiology and community health 2013;67(5):439-445. 
(78) Orsi JM, Margellos-Anast H, Whitman S. Black-White health disparities in the United States and Chicago: a 15-year progress analysis. . American Journal of Public Health 2010;100(2):349-356.

(79) Musu-Gillette L, Robinson J, McFarland J, KewalRamani, A, Zhang A, Wilkinson-Flicker S. Status and Trends in the Education of Racial and Ethnic Groups 2016 (NCES 2016-007). U S Department of Education, National Center for Education Statistics Washington, DC 2016.

(80) Grossman M. On the concept of health capital and the demand for health. . Journal of Political economy 1972;80(2):223-255.

(81) Strauss J, Thomas D. Health over the life course. Handbook of development economics 2007;31(4):3375-3474.

(82) McGonagle KA, Schoeni RF. The Panel Study of Income Dynamics: Overview and summary of scientific contributions after nearly 40 years. . Survey Research Center - Institute for Social Research University of Michigan 2006;06-01.

(83) McGonagle KA, Schoeni RF, Sastry N, Freedman VA. The Panel Study of Income Dynamics: overview, recent innovations, and potential for life course research. Longitudinal and Life Course Studies 2012;3(2):268-284.

(84) Dascola M, Freedman V, Insolera N, Pfeffer F, McGonagle K, Sastry N. PSID Main Interview User Manual: Release 2015. Institute for Social Research, University of Michigan 2015.

(85) Department of Health and Human Services. Area health and resources files (AHRF). 2015 . 


\section{Chapter 2 \\ The Dynamic Relationships between Economic Indicators and Physical Health Measures among Working-Age Adults in the United States}

ABSTRACT

We examined the dynamic relationships between economic indicators and health measures utilizing data from 8 waves of the Panel Study of Income Dynamics from 1999 to 2013. Health measures were self-rated health (SRH) and functional limitations; economic indicators were family income, labor income and net wealth. Four approaches of panel models:1) System-Generalized Method of Moment (system-GMM); 2) first-difference; 3) first-difference with instrumental variables (IV); 4) Lagged fixed effects; and two standard models: 1) ordinary least squares regression (OLS) and 2) IV OLS were used to evaluate the dynamic relationships between economic indicators and health measures. Standard models revealed significant positive relationships between all economic indicators and SRH and negative relationships between all economic indicators and functional limitations. System-GMM estimators revealed a significant positive relationships between all economic indicators and SRH. Nevertheless, only labor income and net wealth were associated with functional limitations. SRH declined due to losses in family income and labor income; decreases in SRH resulted in losses in family income, labor income and net wealth. Results highlight the need for integrating the economic and health policies and programs to prevent the adverse effects on health whenever an individual experiences a decline in economic status or health. 


\section{INTRODUCTION}

The relationships between economic indicators and health measures among adults living in the United States (US) have been documented extensively in economic, epidemiological and sociological studies (1-14). For example, in the US, Chetty and colleagues reported that men in the top $1 \%$ of income distribution can live 15 years longer than the men in the $1 \%$ bottom of income distribution. Similarly, women in the top $1 \%$ of income distribution can live 10 years longer than the women in the $1 \%$ bottom of income distribution (13). While this study highlighted the impact of economic status on mortality, there is a need for studies that evaluate the effect of changes in economic status over time on health states other than mortality (15). Also, further research is needed to evaluate how changes in income affect changes in health over time and vice versa. As changes can consist of both declines and improvements in income and health, the dynamic relationships between economic loss and health decline as well as economic improvement and health improvement warrant examination.

The relationships between economic indicators and health may be bidirectional. Therefore, the endogeneity between economic indicators and health need to be addressed in estimating the effect of economic indicators on health (16,17). From an economic perspective, healthier individuals may have access to greater economic resources because of their ability to participate in the labor force and earn an income (16-18). On the other hand, from an epidemiological and health policy perspectives, individuals with higher financial resources may have better health because they have the ability to invest in their health (16-18). Some studies have addressed this endogeneity by using statistical techniques such as instrumental variables (IV) $(3,6,12)$. However, it is very challenging to find valid instrument variables that have an effect on health only through economic indicators $(3,6,14)$. 
Therefore, recent efforts have focused on using information available in the panel data (example: past histories) as instrumental variables after the panel-level effects have been removed by first-differencing (19). These models were further refined by Arellano and Bond (20), who used the panel structure of the data and derived procedures to determine the optimal number of lagged endogenous and exogenous variables as instruments $(20,21)$. These estimators have become powerful econometric tools to address the effects of endogeneity and used in many disciplines $(22,23)$.

Two studies $(6,14)$ examined the causal relationships between economic indicators and health using the Arellano-Bond dynamic panel data estimators. These two studies have reported mixed results with one of them indicating causal effect of economic status on health (14) and the other indicating no causal effect of economic status on health (6). Halliday reported better selfrated health due to increases in labor income among working-age adults (21-64 years) using data from the Panel Study of Income Dynamics. Michaud and Soest used wealth to represent the economic status and various measures of mental and physical health as well as a composite index to measure health based on data from the Health and Retirement Study (HRS). They concluded that economic status did not affect health (6). The differences in findings may be due to differences in age groups, measures of health, and economic indicators. In fact, Halliday attributed the discrepancy in findings between his study and the study by Michaud and Soest to differences in age group of the samples. However, it is plausible that the differences in findings could be due to differing measurements of economic indicators and health. A major limitation of both studies is that they did not control for other factors that may affect economic status, health or both. Furthermore, these studies analyzed any change and did not distinguish between economic gain and economic loss. 
Therefore, the objective of the current study is to examine the dynamic relationships between various measures of economic status and physical health using a sample of working-age adults (18-64 years) in the US. The study examined the effect of positive and negative changes in economic status on health, and improvement and decline in health on economic status.

\section{CONCEPTUAL FRAMEWORK}

This study was guided by several economic frameworks in which health capital, human capital and financial capital interact with each other. From a health economics perspective, an individual is born with a fixed health capital stock (health capital), which declines with age because of biological processes (15). However, according to Grossman, health of an individual can be improved by investing in education (human capital) because educated individuals are more likely to improve their healthcare or effectively address/reverse a health decline. Therefore, education rather than income or wealth is the primary driver of health (24). Case and Deaton further suggested that the link between economic indicators and health is affected by both education (human capital) and financial resources (financial capital). In all these models, it is further assumed that there is an equitable distribution of health, but not human and financial capital, at the time of birth. Individuals with lower human and financial capital may thus be more likely to suffer earlier and more rapid declines in health, and to have poorer health at any given point in time than those with higher human and financial capital. Galama expanded these concepts and suggested that health may also affect economic indicators. Under his framework, "unhealthy individuals drop out of the labor force sooner, and lose income as a result". Case and Deaton also acknowledged that other factors such as age may affect both health and financial capital. In the present study, we have integrated all these frameworks and hypothesize that lower economic status will lead to decline in health and subsequent improvement in health can lead to 
higher economic status after adjusting for other factors that affect both economic indicators and health.

\section{METHODS}

\section{Study Design}

The study utilized a retrospective observational longitudinal design with repeated measures of economic indicators and health for a period of 14 years using 8 waves of the Panel Study of Income Dynamics: 1999, 2001, 2003, 2005, 2007, 2009, 2011, and 2013. These waves were selected due to the availability of the same sets of health variables. Data were pooled across years and thus, each individual had 8 repeated observations.

\section{Study Sample}

The study sample consisted of heads of households $(\mathrm{N}=2,693)$, who participated in all the waves of the PSID between 1999 and 2013 and who were aged between 18-50 years in 1999.

\section{Data Sources}

\section{The Panel Study of Income Dynamics (PSID):}

The PSID was created in 1966 to help President Lyndon Johnson’s War on Poverty $(25,26)$. The original PSID 1968 sample was drawn from two independent samples: an oversample of 1,872 low-income families from the Survey of Economic Opportunity; and a nationally representative sample of 2,930 families. The two samples constituted a national probability sample of U.S. families in $1968(25,26)$. Currently, the individuals in any panel come from three sources: the original 1968 sample; the 1997 refresher sample of post-1968 
immigrants; and births and marriages in existing families (25-27). In this study, both family and cross-year individual files were combined to gather information on households.

\section{The Area Health Resource File (AHRF):}

Unemployment rates were derived from the AHRF provided by the Department of Health and Human Services (28). We linked the state-specific metro-level unemployment rate to the PSID by state and metro status by using five-digit Federal Information Processing Standard (FIPS) codes.

\section{Measures}

\section{Health Status Measures}

Self-rated health (SRH): PSID queried each respondent about "say your health in general is excellent, very good, good, fair, or poor?" This SRH was coded on a scale of 1 to 5 (5 for excellent, 4 for very good, 3 for good, 2 for fair, and 1 for poor). Ware and colleagues transformed the SRH to a 0-100 scale using a linear relationship between item scores and the underlying health concept (29). Thus, higher scores in SRH indicate better health.

Functional limitations: PSID participants are asked about the functional limitations due to any reported chronic condition. PSID asks respondents "How much does this condition limit your normal daily activities?" The response is a 4-point scale: "not at all", "just a little", "somewhat", and "a lot". Since the degree of the limitations is the purpose of this physical measure, we coded the response of each limitation as follow: 0 for "not at all", 1 for "just a little", 2 for "somewhat", and 3 for "A lot". Then, we summed the responses for all the functional limitations due to asthma, arthritis, cancer, chronic obstructive pulmonary disease, diabetes, heart disease, hypertension, stroke, memory loss and psychological disorders. Finally, 
we standardized the sum by transforming the sum of the raw scores to a 0 to 100 scale using the following formula:

Functional Limitation score $=\frac{(\text { Actual raw score })-(\text { Minimum score })}{(\text { Maximum score })-(\text { Minimum Score })} \times 100$

The functional limitations scores ranged from 0 to 100, with higher scores representing higher functional limitations.

Change in Health: a) Increases in SRH: A binary indicator variable with the value of 1 representing improvements in SRH from one wave to the next and zero representing no change or decreases in SRH scores from one wave to the next. b) Decreases in SRH: A binary indicator variable with the value of 1 representing decreases in SRH from one wave to the next and zero representing no change in SRH or increases in SRH scores from one wave to the next. c) Better functional status: A binary indicator variable with the value of 1 representing a decline in functional limitation scores from one wave to the next and zero representing no change or increases in functional limitation scores from one wave to the next. d) Worsening functional status: A binary indicator variable with the value of 1 representing an increase in functional limitation scores from one wave to the next and zero representing no change or decreases in functional limitation scores from one wave to the next.

\section{Economic Indicators}

Family Income: In the PSID, total family income is calculated as the sum of "head/wife" taxable income (earnings, interest and dividends), head/wife transfer income, taxable or transfer income of other family unit members, head/wife social security income, and other family unit member's social security income. The participants reported the incomes they received in the prior year. 
Labor income: We measured labor income of the head of the household. Labor income included all money earned from wages and salaries, bonuses, overtime, tips, commissions, professional practice or any job-related income including farm or business income.

Total net wealth: In PSID, total net wealth is derived as the sum of home equity, farm or business assets, checking or savings accounts, vehicles, stocks and bonds and net debts. Some individuals in our study sample reported negative or zero family income $(n=15(1999)-$ 22(2013)), labor income $(n=154(1999)-435(2013))$ or net wealth $(n=444(1999)-458(2013))$. In the current study, we recoded negative values to zero and added a small positive amount (\$1) to zero values.

Quintiles of Economic Indicators: We categorized family income, labor income, and net wealth into quintiles based on the distribution of these variables in each wave. When economic indicators were used as continuous measures, all the economic indicators were transformed into a natural logarithmic scale.

Other Exogenous Explanatory variables: Prior literature has established that self-related health and chronic conditions are affected by health behavior and obesity $(30,31)$. Therefore, for each head of the household, we measured the following variables in each wave: number of chronic conditions categories (no condition, one condition, $>=2$ chronic conditions), body mass index (BMI) $\left(\mathrm{kg} / \mathrm{m}^{2}\right)$ (underweight< 18.5], normal [18.5 - 24.9], overweight [25.0 - 29.9], or obese [ $\geq 30.0]$ ), smoking status (smoker, not a smoker) and alcohol use (user, non-user). Other factors that may affect the economic status of the participants were age, marital status (married, widowed, separated or divorced, and never married), number of children under 18 years of age, health insurance, external financial support, and financial liabilities to others. Time-invariant 
variables were excluded from all models because they contradict the specifications of the fixed effects models.

Instrumental Variables: Instrumental variables (IV) were used to address the endogeneity between economic indicators and physical health measures. For family and labor income, unemployment rates at the metro level were used. Unfortunately, information on county of residence is not available in PSID. However, information on Beale-Ross Rural-Urban Continuum codes were available for all PSID participants. From AHRF (28), we derived the average unemployment rate for each of the Beale-Ross Rural-Urban Continuum group and linked it with PSID. We used the responses (yes/no) to big settlement from an insurance company, or an inheritance as an instrumental variable for net-wealth.

\section{STATISTICAL ANALYSES}

Ordinary Least Squares (OLS) Regression: The specifications of this model is as follows:

$\mathrm{h}_{\mathrm{it}}=\beta_{0}+\beta_{1} \mathrm{Y}_{\mathrm{it}}+\beta_{2} \mathrm{X}_{\mathrm{it}}+\mu_{\mathrm{it}}(1)$

Where $h_{i t}$ is the health of individual $i$ at time $t . Y_{i t}$ is the $\log$ transformed values or quintile categories of the economic indicators. $\mathrm{X}_{\mathrm{it}}$ is the matrix of the other explanatory variable. In these models, we accounted for repeated observations.

IV OLS Regression: This statistical technique was applied to address the endogeneity between economic indicators and physical health measures due to simultaneity, omitted variables and measurement errors. We used metropolitan area unemployment rate and inheritance as instrumental variables for income and wealth respectively. Following is the specification of the model: 
$Y_{\text {it }}=\gamma_{0}+\gamma_{1} Z_{i t}+\epsilon_{i t}$

$\mathrm{h}_{\mathrm{it}}=\beta_{0}+\beta_{1} \widehat{Y}_{i t}+\beta_{2} X_{i t}+\mu_{\text {it }}(2)$

Where $Z_{\text {it }}$ represents the instrumental variables.

First-difference (FD) estimator: We used the first-difference estimator to analyze changes in health due to change in economic status and to mitigate the concerns due to individual fixed effects. Static linear panel data models may be inconsistent due to the time-invariant individual's characteristics (Fixed-effects). Those fixed-effects may be correlated with the explanatory variables which may introduce the omitted variables bias. The first-difference estimator can solve this problem by using the one-period changes for each individual. Using the first-difference estimator removes the fixed individual-specific effects because they do not change with time. The proposed model for this estimator is as follows:

$\Delta \mathrm{h}_{\mathrm{it}}=\beta_{1} \Delta \mathrm{Y}_{\mathrm{it}}+\beta_{2} \Delta \mathrm{X}_{\mathrm{it}}+\Delta \mu_{\mathrm{it}}(3)$

IV FD: Combining the first-difference estimator with IVs could remove the bias due to endogeneity between economic indicators and health measures. We used this estimator to remove the effect of the endogeneity between economic indicators and health measures due to reverse causality. The specification of this model is:

$\Delta \mathrm{Y}_{\text {it }}=\gamma_{1} \Delta \mathrm{Z}_{\text {it }}+\Delta \varepsilon_{\text {it }}$

$\Delta \mathrm{h}_{\text {it }}=\beta_{1} \Delta \widehat{\mathrm{Y}}_{\mathrm{it}}+\beta_{2} \Delta \mathrm{X}_{\mathrm{it}}+\Delta \mu_{\mathrm{it}}(4)$

In the above models, we allow for clustering on the individual level in the statistical inference.

Lagged-fixed effect estimator: Based on Michael Grossman's conceptual framework, the current status of health is a function of one's past health and past economic status (i.e. t-1). To test this, we estimated the following model:

$h_{\text {it }}=\beta_{0}+\beta_{1} h_{\text {it }-1}+\beta_{2} Y_{i t-1}+\beta_{3} X_{i t-1}+\mu_{\text {it }}(5)$ 
Arellano-Bond generalized method of moments (GMM) estimator (20): It is possible that current health state is influenced by past health and current economic status and other exogenous variables.

$h_{\text {it }}=\beta_{0}+\beta_{1} h_{i t-1}+\beta_{2} Y_{i t}+\beta_{2} X_{i t}+\mu_{i t}(6)$

Equation 6 does not account for: 1) the endogeneity between economic indicators and health measures; 2) individual-specific fixed effects; 3 ) the endogeneity between current state of health and lagged health status; 4) heteroscedasticity and autocorrelation within individuals; and 5) the small time dimension compared to the large individual dimension (21). To solve these problems, we can transform the previous equation to the following:

$\Delta \mathrm{h}_{\mathrm{it}}=\beta_{1} \Delta \mathrm{h}_{\mathrm{it}-1}+\beta_{2} \Delta \mathrm{h}_{\mathrm{it}}+\beta_{3} \Delta \mathrm{X}_{\mathrm{it}}+\Delta \mu_{\mathrm{it}}(7)$

In equation 7 , the first-difference estimation can address limitations 1 and 2 . The Arellano and Bond system-GMM can address limitations 3, 4, and 5. Under the Arellano and Bond approach, lags of the dependent variable are used as instruments to compute unbiased consistent estimates of equation (7). However, weak instruments problem may occur in the Arellano-Bond approach because lagged values of the endogenous variables may be weakly correlated with the regressors in the first-difference model. Thus, Blundell and Bond (Blundell \& Bond 1998) proposed a system-GMM estimator. System-GMM estimator uses lagged differences as instruments for the level model and lagged levels as instruments for the firstdifference model. Under system-GMM estimator, economic status is considered as a predetermined variable and all the feasible lags of economic status and health measures (t-1 and thereafter) are used as instrumental variables. However, we found that using only four lags of health measures as IVs increased the efficiency of the models (Based on the second order autocorrelation test and the Hansen $\mathrm{J}$ statistics on overidentifying restrictions). We also applied 
finite sample correction to the robust two-step covariance matrix calculated for system-GMM estimator to reduce over-identification caused by too many IVs (21).

\section{The effect of economic loss on health decline and economic gain on health}

improvement: Lagged-fixed effects and first-difference estimators were used to examine the dynamic relationships between economic loss and decline in health as well as economic gain and health improvement. Appendix 2.1 displays the specifications of these models. All analyses were weighted using 2013 PSID-provided longitudinal weights.

\section{RESULTS}

Characteristics of the study sample: The study sample consisted of 2,693 heads of households, who were between ages 18 and 50 in 1999. In the study sample, $18.5 \%$ were women and $81.5 \%$ were men. The majority of the adults in the study sample were white $(75.1 \%)$ and married (59.8\%). Most lived in a metropolitan area (76.2\%). Fifty-two percent were between 18-

39 years old in 1999. In the study sample, 808 adults had chronic conditions and were eligible to respond to the functional limitations due to chronic conditions questions in 1999. The number of adults who had chronic conditions steadily increased to 1,585 in 2013 . Thus, the panel was not balanced for functional limitations. Table 2.1 displays the weighted percentages across the 8 waves.

Economic indicators and physical health measures over time: Table 2.2 displays the means and standard errors of actual and natural logarithmic values of labor income of the heads of households, family income, net wealth, SRH and functional limitations across the eight waves. There were fluctuations in the average values of economic indicators across waves. On the other hand, SRH and functional limitations steadily deteriorated over time. 


\section{The adjusted relationships between economic indicators and physical health}

measures: Table 2.3 summarizes the parameter estimates and standard errors of the economic indicators (family income, labor income, net wealth) on physical health measures (SRH and functional limitations) from the adjusted OLS, IVOLS, FD, IVFD and lagged fixed effects. Tables 2.4 and 2.5 summarize the Arellano-Bond system-GMM estimators for SRH and functional limitations respectively.

\section{Labor income and health measures:}

Labor income and SRH: Adjusted OLS regression that accounted for repeated observations indicated a significant positive relationship between labor income and SRH. When labor income was measured in terms of quintiles, SRH was higher in labor income quintiles 2 through 5 as compared to the lowest labor income quintile. These relationships between labor income and SRH persisted in IV OLS regressions. For example, in the adjusted analyses, SRH

was higher for higher levels of labor income $(\hat{\beta}=3.945, \mathrm{p}<0.01)$. Similarly, in the lagged fixed effects models labor income (in quintiles) showed a significant, positive relationship with SRH. As illustrated in Table 2.4, models using the system-GMM estimator likewise indicated a strong positive relationship between labor income and $\mathrm{SRH}(\hat{\beta}=0.868 \mathrm{p}<0.001)$. In contrast, in analyses using FD with or without IV, no significant associations between labor income and SRH were observed.

\section{Labor income and functional limitations: The adjusted OLS indicated significant} negative relationships between labor income and functional limitations that persisted regardless of whether labor income was assessed as a continuous variable or in quintiles. For example, functional limitations declined progressively with rising quintile of labor income. Parameter estimates and standard errors of labor income from the system-GMM estimator indicated a 
significant negative relationship between labor income and functional limitations $(\hat{\beta}=-0.515, \mathrm{p}<$ 0.001) (Table 2.5). Likewise, in models using either lagged fixed effects or FD without IV, functional limitations declined significantly with increasing labor income regardless of measurement. However, there was no significant relationship between labor income and functional limitations in FD models with IV.

\section{Family income and health measures}

Family income and SRH: Adjusted OLS, indicated significant positive relationships between family income, family income quintiles and SRH. These relationships between family income and SRH persisted in IV OLS regressions. For example, in the adjusted analyses, SRH was higher as for higher levels of family income $(\hat{\beta}=10.70, \mathrm{p}<0.01)$. Likewise, parameter estimates and standard errors of family income from the system-GMM estimators (Table 2.4) indicated that there was a significant relationship between family income and SRH $(\hat{\beta}=0.871, \mathrm{p}$ $<0.05)$. In contrast, analyses using lagged fixed effects and FD with and without IV indicated that there was no significant relationship between family income and SRH.

Family Income and functional limitations: The adjusted OLS indicated significant negative relationships between family income and functional limitations that persisted regardless of whether family income was assessed as a continuous variable or in quintiles. For example, functional limitations declined progressively with rising quintile of family income. In models using lagged fixed effects and FD with and without IV, there were no significant relationships between family income and functional limitations. Likewise, parameter estimates and standard errors of family income from the Arellano-Bond system-GMM estimators (Table 2.5) indicated that there was no relationship between family income and functional limitations. 
Net wealth and health measures:

Net wealth and SRH: Adjusted OLS suggested a significant positive relationship between net wealth (continuous or in quintiles) and SRH. We also observed a significant relationship between net wealth and SRH $(\hat{\beta}=0.317, \mathrm{p}<0.001)$ using system-GMM estimators. However, the relationships between net wealth and SRH were not significant in IV OLS regressions, lagged fixed effects models, or FD models with IV.

Net wealth and functional limitations: Adjusted OLS revealed a significant negative relationship between net wealth (continuous or in quintiles) and functional limitations. However, IV OLS regressions revealed a significant positive relationship between net wealth and functional limitations. Lagged fixed effects models indicated a significant negative relationship between net wealth and functional limitation. System-GMM estimators indicated that there was a significant negative relationship between net wealth and functional limitations $(\hat{\beta}=-0.142, \mathrm{p}<$ $0.05)$.

\section{Health improvement due to gain in economic status:}

In the adjusted FD analyses, increases in net wealth were associated with a 1.8 percentage point increase in the probability of SRH improvement. In the adjusted FD analyses, the transitioning from a lower net wealth quintile to an upper quintile was associated with a 3.8 percentage point increase in the probability of SRH improvement. In the adjusted lagged fixed effects, gains in family $(\hat{\beta}=0.78, \mathrm{p}<0.05)$ or labor income $(\hat{\beta}=0.89, \mathrm{p}<0.05)$ had a positive impact on SRH; similar results were observed when labor income was measured as quintiles.

Gains in labor income were also associated with better functional status $(\hat{\beta}=-0.936, \mathrm{p}<0.001)$. 


\section{Decline in health due to decline in economic status:}

In the adjusted FD analyses, decreases in family income, labor income and net wealth were associated respectively with $1.76,2.1$ and 2.2 percentage point increase in the probability of SRH decline. The transition from an upper labor income quintile to a lower quintile was associate with a 2.1 percentage point increase in the probability of SRH decline. Additionally, the transition from an upper net wealth quintile to a lower quintile was associated with a 4.2 percentage point increase in the probability of SRH decline. In the adjusted FD analyses, decreases in family income were associated with a 4.2 percentage point increase in the probability of higher functional limitations. Furthermore, decreases in labor income or the transition from an upper labor income quintile to a lower quintile were associated with 3.8 and 6.3 percentage points increase in the probability of higher functional limitations. In the adjusted lagged fixed effects, the loss in family $(\hat{\beta}=-0.81, \mathrm{p}<0.05)$ or labor income $(\hat{\beta}=-0.75, \mathrm{p}<0.05)$ was associated with declines in SRH; assessing labor and family income as quintiles yielded similar findings. However, functional limitations worsened only with decline in labor income $(\hat{\beta}=0.863, \mathrm{p}<0.001)$.

\section{The effects of health improvement and health decline on economic status:}

In the adjusted FD analyses, SRH improvement was associated with significant gains in family income and net wealth. SRH improvement increased the probability of gains in family income and net wealth by 2.4 and 2.3 percentage points respectively. In lagged fixed effects models, SRH improvement was associated with gains in all measures of economic status (Table 2.7). Conversely, reduction in SRH was associated with significant declines in all measures of 
economic status in the adjusted FD analyses, but only with decreases in labor income in the lagged fixed effect model (Table 2.7).

\section{DISCUSSION}

The current study examined the dynamic relationships between economic indicators (family income, labor income, and net wealth) and two physical health measures (SRH and functional limitations). Using the standard OLS models, all economic indicators showed significant positive relationships with SRH and significant negative relationships with functional limitations. Using the Arellano-bond system-GMM estimators, we found positive relationships between SRH and all measures of economic status. However, we did not find a significant relationship between family income and functional limitations. Our study results suggest that the relationship between economic indicators and health is dependent on the health measures that used to examine the relationship. Health is a multidimensional concept and economic indicators seem to have different dynamic relationships with different components of health.

When changes in economic indicators were examined by economic loss and economic gain, we found strong relationships between losses in family or labor income and health decline. Although we do not know the reasons for economic loss, one could speculate that decline in labor income may be due to reduced work hours or a job loss. Future studies need to examine the reasons for decline in labor income because policy prescriptions for protection against job loss and reduced work hours differ. It is plausible that many adults in the US experienced income losses due to job losses because our study period overlapped with the great 2007-2009 recession (32). Decline in labor income (or family income) due to loss of employment has important potential implications for the future health of these adults and their families. Although unemployment insurance may provide some relief in the short-term (33), it may not cover all the 
hardships. For example, the majority of employed adults (58\%) in the US receive employersponsored health insurance (34) and may lose health insurance coverage due to loss of employment. Such loss of insurance coverage may contribute to further deterioration in health status due to the lack of access to medical care.

We also found that improvement in SRH led to increases in family income, labor income and net wealth after adjusting for other factors; conversely, decreases in SRH led to declines in family income, labor income, and net wealth. In the US, adults with chronic health conditions are more likely to report that their health is fair or poor (35), suggesting that policies and interventions that decrease the burden of chronic disease among working-age adults could have significant positive effects on economic status in this population. In addition, given that SRH is widely considered to be an excellent measure of healthcare quality in the US (36), improving the healthcare quality in the US may likewise promote/lead to improvement in economic well-being.

The current study has several strengths. First, we examined the potential reciprocal relationships between economic status and health using a variety of economic and health measures. Second, this study assessed the relationship of health to both continuous and categorical measures of economic status. Third, we controlled for a comprehensive list of other exogenous explanatory variables, including age, number of chronic conditions, body mass index, alcohol use, smoking status, light physical activity, marital status, number of children under 18 years of age, health insurance status, external financial support, and financial liabilities to others. Also, by tracking individuals over a 14-year period, we were able to analyze causal relationships between economic status and health, including bidirectional relationships. We also used dynamic panel data estimators, specifically Arellano-Bond estimators, to overcome the limitations of lack of readily available valid instrumental variables. 
This study also suffers from some limitations. First, information on all variables was based on self-reported data, raising the possibility of recall bias. Second, self-rated health status and functional limitations may not capture the whole aspects of health. Third, although we employed statistical techniques to remove the effects of endogeneity due to reverse causality and omitted variables, we cannot completely eliminate these biases. Fourth, although we controlled for fixed effects due to time-invariant factors such as sex, race/ethnicity and other contextual factors, we did not provide the estimates of the effects of these factors. Also, the generalizability is limited because we restricted our sample to those who were followed in all 8 waves of the study.

\section{CONCLUSION}

Findings of this cohort study suggest a strong, bidirectional relationship between economic status and health. Our findings suggest the need for integrating the economic and health policies and programs to prevent the adverse effects on health whenever an individual experiences either a decline in economic status or decline in health. 


\section{REFERENCES}

(1) Fiscella K Franks P. Individual income, income inequality, health, and mortality: what are the relationships? Health services research 2000;35(1 pt2):307-318.

(2) McDonough P Berglund P. Histories of poverty and self-rated health trajectories. Journal of Health and Social Behavior 2003;44(2):198-214.

(3) Meer J, Miller DL, Rosen HS. Exploring the health-wealth nexus. . Journal of health economics 2003;22(5):713-730.

(4) Adams P, Hurd MD, McFadden DL, Merrill A, Ribeiro T. Healthy, wealthy, and wise? Tests for direct causal paths between health and socioeconomic status. Journal of Econometrics 2003;112(1):3-56.

(5) Berry B. Does money buy better health? Unpacking the income to health association after midlife. Health(London) 2007;11(2):199-226.

(6) Michaud PC, van Soest A. Health and wealth of elderly couples: causality tests using dynamic panel data models. Journal of Health Economics 2008;27(5):1312-1325.

(7) Robert SA, Cherepanov D, Palta M, Dunham NC, Feeny D, Fryback DG. Socioeconomic status and age variations in health-related quality of life: Results from the national health measurement study. Journal of Gerontology: Social Sciences 2009;64B(3):378-389.

(8) Braveman PA, Cubbin C, Egerter S, Williams DR, Pamuk E. Socioeconomic disparities in health in the United States: what the patterns tell us. American journal of public health 2010;100(S1):S186-S196.

(9) Hajat A, Kaufman JS, Rose KM, Siddiqi A, Thomas JC. Do the wealthy have a health advantage? Cardiovascular disease risk factors and wealth. Social Science and Medicine 2010;71(11):1935-1942.

(10) Hajat A, Kaufman JS, Rose KM, Siddiqi A, Thomas JC. Long-term effects of wealth on mortality and self-rated health status. American Journal of Epidemiology 2011;173(2):192-200.

(11) Do DP, Frank R, Finch BK. Does SES explain more of the black/white health gap than we thought? Revisiting our approach toward understanding racial disparities in health. Social science \& medicine 2012;74(9):1385-1393.

(12) Golberstein E. The effects of income on mental health: evidence from the social security notch. The journal of mental health policy and economics 2015;18(1):27-37.

(13) Chetty R, Stepner M, Abraham S, Lin S, Scuderi B, Turner N, Bergeron A, Cutler D. The association between income and life expectancy in the United States, 2001-2014. JAMA 2016;315(16):1750-1766.

(14) Halliday TJ. Earnings Growth and Movements in Self-Reported Health. Review of Income and Wealth 2016.

(15) Case A, Deaton A. Broken down by work and sex: How our health declines. Analyses in the Economics of Aging, University of Chicago Press. 2005:185-212. 
(16) Galama TJ. A contribution to health-capital theory. Rand Working Paper 2011:1-47.

(17) Galama TJ, Van Kippersluis H. Health inequalities through the lens of health-capital theory: issues, solutions, and future directions. Research on economic inequality 2013;21:263-284.

(18) Halliday T. Income volatility and health. Discussion Paper No 3234, IZA 2007.

(19) Anderson TW, Hsiao C. Estimation of dynamic models with error components. Journal of the American Statistical Association 1981;76(375):598-606.

(20) Arellano M Bond S. Some tests of specification for panel data: Monte Carlo evidence and an application to employment equations. The review of economic studies 1991;58(2):277-297.

(21) Roodman D. How to do xtabond2: An introduction to difference and system GMM in Stata. The Stata Journal 2009;9(1):86-136.

(22) Wawro G. Estimating dynamic panel data models in political science. . Political Analysis 2002;10(1):25-48.

(23) Piernas C, Ng SW, Mendez MA, Gordon-Larsen P, Popkin BM. A dynamic panel model of the associations of sweetened beverage purchases with dietary quality and food-purchasing patterns. American journal of epidemiology 2015;181(9):661-671.

(24) Grossman M. On the concept of health capital and the demand for health. . Journal of Political economy 1972;80(2):223-255.

(25) McGonagle KA, Schoeni RF. The Panel Study of Income Dynamics: Overview and summary of scientific contributions after nearly 40 years. . Survey Research Center - Institute for Social Research University of Michigan 2006;06-01.

(26) McGonagle KA, Schoeni RF, Sastry N, Freedman VA. The Panel Study of Income Dynamics: overview, recent innovations, and potential for life course research. Longitudinal and Life Course Studies 2012;3(2):268-284.

(27) Dascola M, Freedman V, Insolera N, Pfeffer F, McGonagle K, Sastry N. PSID Main Interview User Manual: Release 2015. Institute for Social Research, University of Michigan 2015.

(28) Department of Health and Human Services. Area health and resources files (AHRF). 2015 .

(29) Ware J Jr, Snow KK, Kosinski M, Gandek B. SF-36 Health Survey manual and interpretation guide. . The Health Institute, New England Medical Center 1993.

(30) Okosun IS, Choi S, Matamoros T, Dever GA. Obesity is associated with reduced self-rated general health status: evidence from a representative sample of white, black, and Hispanic Americans. Preventive medicine 2001;32(5):429-436.

(31) Tsai J, Ford ES, Li C, Zhao G, Pearson WS, Balluz LS. Multiple healthy behaviors and optimal self-rated health: findings from the 2007 Behavioral Risk Factor Surveillance System Survey. Preventive medicine 2010;51(3):268-274.

(32) Goodman CJ, Mance SM.. Employment loss and the 2007-09 recession: an overview. Monthly Labor Review 2011;134(4):3-12. 
(33) East CN, Kuka E. Reexamining the consumption smoothing benefits of Unemployment Insurance. Journal of Public Economics 2015;132:32-50.

(34) State Health Access Data Assistance Center. State-Level Trends in Employer-Sponsored Health Insurance. SHADAC Report 2013.

(35) Blackwell DL, Lucas J.. Tables of Summary Health Statistics for U.S. Adults: 2014 National Health Interview Survey. 2015.

(36) Frosch DL. Patient-Reported Outcomes as a Measure of Healthcare Quality. . Journal of general internal medicine 2015;30(10):1383-1384. 
Table 2.1

Weighted Percentages of Selected Characteristics of Working-Age Adults (18-64 Years) Panel Study of Income Dynamics, 1999-2013, (N=2,693)

\begin{tabular}{|c|c|c|c|c|c|c|c|c|}
\hline & 1999 & 2001 & 2003 & 2005 & 2007 & 2009 & 2011 & 2013 \\
\hline \multicolumn{9}{|c|}{ Time Invariant Characteristics } \\
\hline \multicolumn{9}{|l|}{ Sex } \\
\hline Women & 18.5 & - & - & - & - & - & - & - \\
\hline Men & 81.5 & - & - & - & - & - & - & - \\
\hline \multicolumn{9}{|l|}{ Race/ethnicity } \\
\hline White & 75.1 & - & - & - & - & - & - & - \\
\hline AA & 13.2 & - & - & - & - & - & - & - \\
\hline Latino & 7.8 & - & - & - & - & - & - & - \\
\hline Other & 3.9 & - & - & - & - & - & - & - \\
\hline \multicolumn{9}{|c|}{ Time Varying Characteristics } \\
\hline \multicolumn{9}{|l|}{ Age in years } \\
\hline 18-39 years & 52.2 & 43.2 & 36.1 & 28.9 & 23.0 & 17.7 & 11.8 & 7.1 \\
\hline $40-49$ years & 42.8 & 42.5 & 41.1 & 38.9 & 37.3 & 34.1 & 31.5 & 29.0 \\
\hline $50-64$ years & 5.0 & 14.3 & 22.8 & 32.3 & 39.8 & 48.2 & 56.7 & 63.4 \\
\hline \multicolumn{9}{|l|}{ Marital Status } \\
\hline Married & 59.8 & 61.0 & 61.6 & 62.1 & 62.8 & 61.7 & 61.1 & 60.2 \\
\hline Widowed & 1.0 & 1.1 & 1.2 & 1.1 & 1.3 & 1.5 & 1.5 & 1.8 \\
\hline Separated/Divorced & 16.4 & 17.0 & 17.7 & 18.2 & 18.2 & 19.7 & 20.5 & 21.4 \\
\hline Never Married & 22.8 & 20.9 & 19.6 & 18.7 & 17.8 & 17.2 & 17.0 & 16.6 \\
\hline \multicolumn{9}{|l|}{ Education } \\
\hline LE High School & 15.2 & 15.2 & 14.0 & 14.0 & 14.0 & 12.4 & 12.5 & 12.4 \\
\hline High School & 27.9 & 27.8 & 30.1 & 30.1 & 30.1 & 27.8 & 27.7 & 27.1 \\
\hline Some College & 23.8 & 23.8 & 22.4 & 22.3 & 22.3 & 22.9 & 22.9 & 23.4 \\
\hline College,+ & 33.1 & 33.1 & 33.5 & 33.6 & 33.6 & 36.9 & 36.9 & 37.1 \\
\hline \multicolumn{9}{|l|}{ Employment Status } \\
\hline Employed & 91.1 & 90.2 & 89.7 & 88.9 & 87.6 & 81.7 & 79.3 & 75.9 \\
\hline Not employed & 8.9 & 9.8 & 10.3 & 11.1 & 12.5 & 18.4 & 20.7 & 24.1 \\
\hline \multicolumn{9}{|l|}{ Smoking Status } \\
\hline Smoker & 24.0 & 24.3 & 24.1 & 22.5 & 21.2 & 20.5 & 19.8 & 17.8 \\
\hline Non-smoker & 76.0 & 75.7 & 75.9 & 77.5 & 78.8 & 79.5 & 80.2 & 82.2 \\
\hline \multicolumn{9}{|l|}{ Alcohol Use } \\
\hline Yes & 69.6 & 70.1 & 69.6 & 69.0 & 68.5 & 68.9 & 69.7 & 68.1 \\
\hline No & 30.4 & 30.0 & 30.4 & 31.0 & 31.5 & 31.1 & 30.3 & 31.9 \\
\hline \multicolumn{9}{|c|}{ Body Mass Index Categories } \\
\hline Under weight & 0.7 & 0.8 & 0.9 & 0.8 & 0.7 & 0.6 & 0.9 & 0.8 \\
\hline Normal & 33.3 & 30.1 & 28.5 & 25.9 & 24.5 & 22.7 & 23.1 & 21.9 \\
\hline Over-weight & 42.6 & 43.3 & 42.4 & 44.5 & 43.2 & 43.0 & 42.7 & 43.5 \\
\hline Obese & 23.3 & 25.9 & 28.2 & 28.9 & 31.6 & 33.8 & 33.4 & 33.7 \\
\hline \multicolumn{9}{|l|}{ Light Physical Activity } \\
\hline GE 3 times/week & 64.3 & 64.6 & 65.1 & 58.8 & 55.6 & 56.8 & 56.5 & 56.4 \\
\hline LT 3 times/week & 35.7 & 35.5 & 34.9 & 41.2 & 44.4 & 43.3 & 43.5 & 43.6 \\
\hline \multicolumn{9}{|l|}{ Heavy Physical Activity } \\
\hline GE 3 times/week & 32.5 & 32.1 & 31.5 & 40.9 & 40.6 & 41.6 & 42.3 & 39.8 \\
\hline LT 3 times/week & 67.5 & 67.9 & 68.5 & 59.1 & 59.5 & 58.4 & 57.7 & 60.2 \\
\hline \multicolumn{9}{|c|}{ Chronic Physical Conditions } \\
\hline No Conditions & 70.2 & 66.7 & 61.4 & 57.8 & 52.3 & 48.1 & 44.6 & 41.4 \\
\hline One condition & 21.1 & 22.7 & 25.3 & 25.6 & 27.8 & 28.8 & 28.7 & 28.7 \\
\hline GE 2 conditions & 8.7 & 10.6 & 13.3 & 16.6 & 19.9 & 23.2 & 26.7 & 29.8 \\
\hline
\end{tabular}


Table 2.1

Weighted Percentages of Selected Characteristics of Working-Age Adults (18-64 Years) Panel Study of Income Dynamics, 1999-2013, (N=2,693)

\begin{tabular}{lrrrrrrrr}
\hline & $\mathbf{1 9 9 9}$ & $\mathbf{2 0 0 1}$ & $\mathbf{2 0 0 3}$ & $\mathbf{2 0 0 5}$ & $\mathbf{2 0 0 7}$ & $\mathbf{2 0 0 9}$ & $\mathbf{2 0 1 1}$ & $\mathbf{2 0 1 3}$ \\
\hline Metro Status & & & & & & & & \\
Metro & 76.2 & 76.3 & 76.2 & 76.3 & 76.5 & 76.2 & 75.4 & 75.1 \\
Urban & 20.7 & 20.7 & 20.6 & 20.2 & 20.2 & 20.5 & 21.2 & 21.7 \\
Rural & 3.1 & 3.0 & 3.3 & 3.4 & 3.4 & 3.4 & 3.4 & 3.2 \\
Region of Residence & & & & & & & & \\
Northeast & 19.1 & 19.2 & 19.0 & 18.6 & 18.6 & 18.4 & 18.3 & 18.1 \\
North central & 26.8 & 26.7 & 26.7 & 26.8 & 26.8 & 26.4 & 26.6 & 26.5 \\
South & 30.1 & 30.1 & 30.6 & 30.9 & 31.4 & 32.0 & 32.3 & 32.7 \\
West & 23.0 & 22.9 & 23.0 & 22.9 & 22.6 & 22.4 & 22.3 & 22.1 \\
Alaska, Hawaii & 0.3 & 0.4 & 0.2 & 0.2 & 0.2 & 0.1 & 0.1 & 0.1 \\
Other & 0.6 & 0.7 & 0.6 & 0.6 & 0.4 & 0.6 & 0.4 & 0.5 \\
\hline
\end{tabular}

Note: Based on 2,693 head of household participants of the Panel Study of Income Dynamics and for whom data were available for all years between 1999 and 2013.

GE: Greater than or equal to; LE: Less than or equal to; LT: Less than. 
Table 2.2

Mean and Standard Errors (SE) of Economic Indicators and Health Measures

Working-Age Adults (18-64 Years)

Panel Study of Income Dynamics, panels 1999-2013, (N=2,693)

\begin{tabular}{|c|c|c|c|c|c|c|}
\hline \multicolumn{7}{|c|}{ Economic Indicators } \\
\hline Year & $\begin{array}{l}\text { Family Income } \\
\text { Mean (SE) }\end{array}$ & $\begin{array}{c}\text { Ln Family } \\
\text { Income } \\
\text { Mean (SE) }\end{array}$ & $\begin{array}{l}\text { Labor Income } \\
\text { Mean (SE) }\end{array}$ & $\begin{array}{l}\text { Ln Labor Income } \\
\text { Mean (SE) }\end{array}$ & $\begin{array}{l}\text { Net Wealth } \\
\text { Mean (SE) }\end{array}$ & $\begin{array}{l}\text { Ln Net Wealth } \\
\text { Mean (SE) }\end{array}$ \\
\hline 1999 & $90,677(2,071)$ & $11.033(0.026)$ & $60,036(1,685)$ & $10.171(0.061)$ & $198,721(15,410)$ & $9.486(0.102)$ \\
\hline 2001 & $98,953(2,479)$ & $11.106(0.03)$ & $64,380(1,774)$ & $10.286(0.057)$ & $246,772(29,259)$ & $9.763(0.1)$ \\
\hline 2003 & $98,773(2,622)$ & $11.112(0.027)$ & $64,553(2,132)$ & $10.165(0.066)$ & $301,094(31,739)$ & $10.032(0.097)$ \\
\hline 2005 & $105,174(4,022)$ & $11.123(0.029)$ & $67,858(2,651)$ & $10.053(0.074)$ & $358,671(30,163)$ & $10.23(0.102)$ \\
\hline 2007 & $106,781(2,840)$ & $11.131(0.032)$ & $69,816(2,337)$ & $9.966(0.077)$ & $434,167(42,197)$ & $10.449(0.103)$ \\
\hline 2009 & $104,211(2,727)$ & $11.074(0.039)$ & $67,132(2,242)$ & $9.823(0.081)$ & $366,855(26,126)$ & $9.864(0.112)$ \\
\hline 2011 & $99,858(2,806)$ & $11.060(0.030)$ & $61,904(2,111)$ & $9.378(0.09)$ & $362,236(27,604)$ & $9.769(0.11)$ \\
\hline 2013 & $101,666(3,686)$ & $11.006(0.035)$ & $63,065(3,374)$ & $9.046(0.101)$ & $37,7623(26,483)$ & $9.929(0.107)$ \\
\hline \multicolumn{7}{|c|}{ Health Measures } \\
\hline & & $\begin{array}{c}\text { Self-rated Healt } \\
\text { Mean (SE) }\end{array}$ & & \multicolumn{3}{|c|}{$\begin{array}{c}\text { Functional Limitations }^{\dagger} \\
\text { Mean (SE) }\end{array}$} \\
\hline 1999 & & $76.76(0.55)$ & & \multicolumn{3}{|c|}{$3.50(0.27)$} \\
\hline 2001 & & $75.89(0.58)$ & & \multicolumn{3}{|c|}{$3.79(0.3)$} \\
\hline 2003 & & $75.15(0.61)$ & & \multicolumn{3}{|c|}{$3.54(0.26)$} \\
\hline 2005 & & $72.60(0.61)$ & & \multicolumn{3}{|c|}{$3.71(0.24)$} \\
\hline 2007 & & $71.96(0.63)$ & & \multicolumn{3}{|c|}{$3.94(0.27)$} \\
\hline 2009 & & $69.92(0.64)$ & & \multicolumn{3}{|c|}{$4.49(0.29)$} \\
\hline 2011 & & $68.36(0.66)$ & & \multicolumn{3}{|c|}{$4.80(0.3)$} \\
\hline 2013 & & $67.31(0.66)$ & & \multicolumn{3}{|c|}{$5.64(0.33)$} \\
\hline
\end{tabular}

Note: Based on 2,693 head of household participants of the Panel Study of Income Dynamics and for whom data were available for all years between 1999 and 2013.

'Functional Limitations (N): 1999 (808), 2001 (922), 2003 (1,027), 2005 (1,148), 2007 (1,296), 2009 (1,396), 2011 (1,490), $2013(1,585)$.

Ln: Natural Log. 


\section{Table 2.3}

Adjusted Parameter Estimates and Standard Errors of Economic Indicators on Self-Reported Health and Functional Limitations ${ }^{\dagger}$ among Working-age Adults in the United States The Panel Study of Income Dynamics, 1999-2013, (N=2,693)

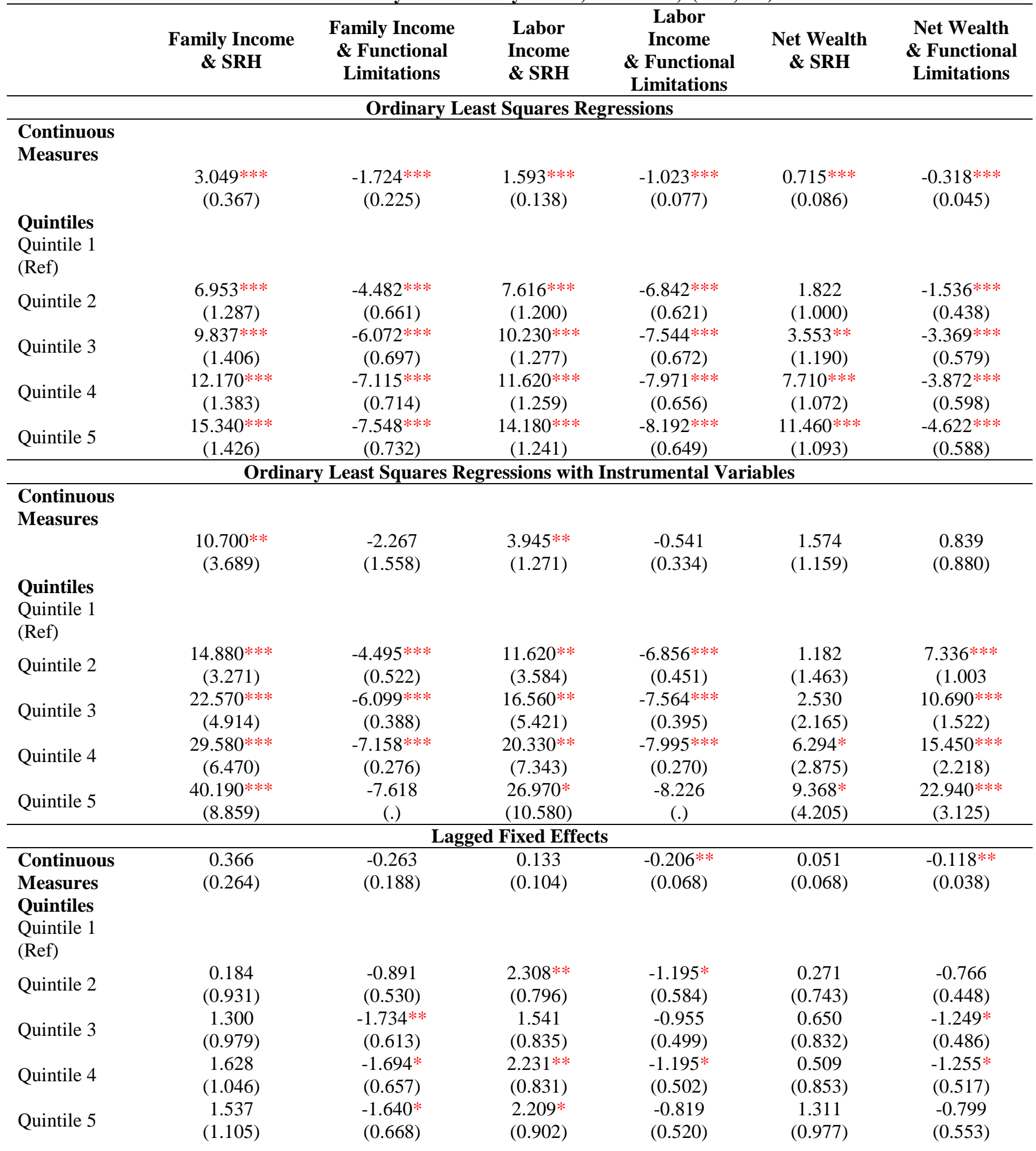


Table 2.3

Adjusted Parameter Estimates and Standard Errors of Economic Indicators

on Self-Reported Health and Functional Limitations ${ }^{\dagger}$ among Working-age Adults in the United States

The Panel Study of Income Dynamics, 1999-2013, (N=2,693)

\begin{tabular}{lcccccc}
\hline & $\begin{array}{c}\text { Family Income } \\
\text { \& SRH }\end{array}$ & $\begin{array}{c}\text { Family Income } \\
\text { \& Functional } \\
\text { Limitations }\end{array}$ & $\begin{array}{c}\text { Labor } \\
\text { Income } \\
\text { \& SRH }\end{array}$ & $\begin{array}{c}\text { Labor } \\
\text { Income } \\
\text { \& Functional } \\
\text { Limitations }\end{array}$ & $\begin{array}{c}\text { Net Wealth } \\
\text { \& SRH }\end{array}$ & $\begin{array}{c}\text { Net Wealth } \\
\text { \& Functional } \\
\text { Limitations }\end{array}$ \\
\hline Continuous & 0.294 & -0.170 & 0.192 & $-0.296^{* * *}$ & $0.204^{* *}$ & -0.052 \\
Measures & $(0.263)$ & $(0.298)$ & $(0.117)$ & $(0.068)$ & $(0.073)$ & $(0.035)$ \\
Quintiles & -0.091 & -0.181 & -0.0507 & $-0.384 * * *$ & $0.929 * * *$ & -0.201 \\
& $(0.279)$ & $(0.125)$ & $(0.242)$ & $(0.103)$ & $(0.270)$ & $(0.127)$ \\
\hline Continuous & 7.673 & First Differences with Instrumental Variables & & -3.075 \\
Measures & $(10.63)$ & $(7.796$ & -43.090 & 10.970 & 2.292 & $(6.497)$ \\
Quintiles & 10.66 & $(254.2)$ & $(108.1)$ & $(4.610)$ & -8.395 \\
& $(14.30)$ & $(3.572)$ & $(10.55$ & 1.617 & 5.128 & $(12.05)$ \\
\hline
\end{tabular}

Note: Based on 2,693 households' head participants of the Panel Study of Income Dynamics and for whom data were available for all years between 1999 and 2013.

$* * * \mathrm{p}<.001 ; * * .001 \leq \mathrm{p}<.01 ; * .01 \leq \mathrm{p}<.05$.

$\dagger$ Functional Limitations due to chronic conditions were based on individuals who had chronic conditions and the number varied across waves: (N): 1999 (808), 2001 (922), 2003 (1,027), 2005 (1,148), 2007 (1,296), 2009 (1,396), 2011 (1,490), 2013 (1,585).

OLS and IVOLS adjusted with age, number of chronic conditions (only SRH), body mass index, alcohol use, smoking status, light physical activity, marital status, number of children under 18 years of age, health insurance, external financial support, and financial liabilities to others. Individuals with missing data on any of these variables were not included in the analyses $(n=80)$.

FD and IVFD adjusted with the change in age, number of chronic conditions (only SRH), body mass index, alcohol use, smoking status, light physical activity, marital status, number of children under 18 years of age, health insurance, external financial support, and financial liabilities to others.

In lagged fixed effects models, the outcome is the SRH at time $t$ (or functional limitation at time $t$ ). Lagged fixed effect model included the following variables measured at t-1: SRH, economic indicator, age, number of chronic conditions (only SRH), body mass index, alcohol use, smoking status, light physical activity, marital status, number of children under 18 years of age, health insurance, external financial support, and financial liabilities to others.

SRH: Self-rated health 


\section{Table 2.4}

The Dynamic Relationships between Economic Indicators and Self-rated Health Arellano-Bond (System-GMM)

Working-age Adults in the United States

The Panel Study of Income Dynamics, 1999-2013, (N=2,693)

\begin{tabular}{|c|c|c|c|}
\hline \multirow{2}{*}{\multicolumn{4}{|c|}{ Continuous Measures }} \\
\hline & & & \\
\hline Economic Indicator & $\begin{array}{l}0.871^{*} \\
(0.352)\end{array}$ & $\begin{array}{c}0.868 * * * \\
(0.121)\end{array}$ & $\begin{array}{c}0.317 * * * \\
(0.086)\end{array}$ \\
\hline $\mathrm{SRH}_{\mathrm{t}-1}$ & $\begin{array}{c}0.246 * * * \\
(0.021)\end{array}$ & $\begin{array}{c}0.238 * * * \\
(0.020)\end{array}$ & $\begin{array}{c}0.266^{* * * *} \\
(0.020)\end{array}$ \\
\hline $\mathrm{SRH}_{\mathrm{t}-2}$ & $\begin{array}{c}0.115^{* * * *} \\
(0.019)\end{array}$ & $\begin{array}{c}0.115^{* * * *} \\
(0.019)\end{array}$ & $\begin{array}{c}0.126^{* * * *} \\
(0.019)\end{array}$ \\
\hline $\mathrm{SRH}_{\mathrm{t}-3}$ & $\begin{array}{c}0.064 * * * \\
(0.019)\end{array}$ & $\begin{array}{r}0.053^{* *} \\
(0.019)\end{array}$ & $\begin{array}{c}0.054^{* *} \\
(0.019)\end{array}$ \\
\hline $\begin{array}{l}\text { \#IV } \\
\text { Hansen } \mathrm{J}\end{array}$ & $\begin{array}{c}64 \\
\operatorname{chi}^{2}(34): 44.03 ; P=0.116\end{array}$ & $\begin{array}{c}64 \\
\operatorname{chi}^{2}(34): 40.74 ; P=0.198\end{array}$ & $\begin{array}{c}64 \\
\operatorname{chi}^{2}(34): 33.63 ; P=0.486\end{array}$ \\
\hline \multicolumn{4}{|l|}{ Quintiles } \\
\hline Quintile 1 (Ref) & & & \\
\hline Quintile 2 & $\begin{array}{r}3.539^{* *} \\
(1.258)\end{array}$ & $\begin{array}{c}5.575^{* * * *} \\
(1.006)\end{array}$ & $\begin{array}{c}1.623 \\
(0.873)\end{array}$ \\
\hline Quintile 3 & $\begin{array}{r}3.958^{* * *} \\
(1.378)\end{array}$ & $\begin{array}{c}5.892 * * * \\
(1.087)\end{array}$ & $\begin{array}{c}2.746^{* * *} \\
(1.045)\end{array}$ \\
\hline Quintile 4 & $\begin{array}{l}4.063 * * \\
(1.503)\end{array}$ & $\begin{array}{c}3.754 * * * \\
(1.101)\end{array}$ & $\begin{array}{c}5.349^{* * *} \\
(1.175)\end{array}$ \\
\hline Quintile 5 & $\begin{array}{l}4.105^{*} \\
(1.614)\end{array}$ & $\begin{array}{c}4.227 * * * \\
(1.174)\end{array}$ & $\begin{array}{c}5.925^{* * *} * \\
(1.338)\end{array}$ \\
\hline $\mathrm{SRH}_{\mathrm{t}-\mathbf{1}}$ & $\begin{array}{c}0.275^{* * * *} \\
(0.019)\end{array}$ & $\begin{array}{c}0.271^{* * * *} \\
(0.018)\end{array}$ & $\begin{array}{c}0.244 * * * \\
(0.019)\end{array}$ \\
\hline $\mathrm{SRH}_{\mathrm{t}-2}$ & $\begin{array}{l}0.120 * * * \\
(0.0182)\end{array}$ & $\begin{array}{l}0.135 * * * \\
(0.0174)\end{array}$ & $\begin{array}{c}0.124 * * * \\
(0.018)\end{array}$ \\
\hline $\mathrm{SRH}_{\mathrm{t}-3}$ & $\begin{array}{c}0.064 * * * \\
(0.017)\end{array}$ & $\begin{array}{c}0.067 * * * \\
(0.017)\end{array}$ & $\begin{array}{c}0.059^{* * *} \\
(0.017)\end{array}$ \\
\hline $\begin{array}{l}\text { \#IV } \\
\text { Hansen J }\end{array}$ & $\begin{array}{c}145 \\
\operatorname{chi}^{2}(111): 99.23 ; \mathrm{P}=0.781\end{array}$ & $\begin{array}{c}145 \\
\operatorname{chi}^{2}(111): 133.78 ; P=0.070\end{array}$ & $\begin{array}{c}145 \\
\operatorname{chi}^{2}(111): 124.28 ; \mathrm{P}=0.183\end{array}$ \\
\hline
\end{tabular}

Note: Based on 2,693 households' head participants of the Panel Study of Income Dynamics and for whom data were available for all years between 1999 and 2013.

$* * * \mathrm{p}<.001 ; * * .001 \leq \mathrm{p}<.01 ; * .01 \leq \mathrm{p}<.05$.

Adjusted model includes age, number of chronic conditions, body mass index, alcohol use, smoking status, light physical activity, marital status, number of children under 18 years of age, health insurance, external financial support, and financial liabilities to others. 


\section{Table 2.5}

The Dynamic Relationship between Economic Indicators and Functional Limitations ${ }^{\dagger}$ Arellano-Bond (System-GMM)

Working-age Adults in the United States

The Panel Study of Income Dynamics, 1999-2013, (N=2,693)

\begin{tabular}{|c|c|c|c|}
\hline \multirow{2}{*}{\multicolumn{4}{|c|}{ Continuous Measures }} \\
\hline & & & \\
\hline Economic Indicator & $\begin{array}{l}-0.535 \\
(0.471)\end{array}$ & $\begin{array}{c}-0.515 * * * \\
(0.097)\end{array}$ & $\begin{array}{r}-0.142 * \\
(0.062)\end{array}$ \\
\hline Functional Limitation $\mathbf{t}-\mathbf{1}$ & $\begin{array}{l}0.572 * * * \\
(0.039)\end{array}$ & $\begin{array}{c}0.484 * * * \\
(0.050)\end{array}$ & $\begin{array}{c}0.582 * * * \\
(0.043)\end{array}$ \\
\hline Functional Limitation $\mathbf{t}-\mathbf{2}$ & $\begin{array}{l}0.242 * * * \\
(0.0445)\end{array}$ & $\begin{array}{l}0.216^{* * * *} \\
(0.047)\end{array}$ & $\begin{array}{l}0.266^{* * * *} \\
(0.045)\end{array}$ \\
\hline Functional Limitation $\mathbf{t}-\mathbf{3}$ & $\begin{array}{l}0.172 * * \\
(0.057)\end{array}$ & $\begin{array}{l}0.132 * \\
(0.064)\end{array}$ & $\begin{array}{c}0.193 * * * \\
(0.057)\end{array}$ \\
\hline $\begin{array}{l}\text { \#IV } \\
\text { Hansen J }\end{array}$ & $\begin{array}{c}62 \\
\operatorname{chi}^{2}(35): 45.90 ; P=0.103\end{array}$ & $\begin{array}{c}62 \\
\operatorname{chi}^{2}(35): 52.70 ; P=0.028\end{array}$ & $\begin{array}{c}62 \\
\operatorname{chi}^{2}(35): 50.54 ; P=0.043\end{array}$ \\
\hline \multicolumn{4}{|l|}{ Quintiles } \\
\hline Quintile 2 & $\begin{array}{l}-1.008 \\
(0.876)\end{array}$ & $\begin{array}{c}-3.653^{* * *} \\
(0.755)\end{array}$ & $\begin{array}{l}-1.329^{*} \\
(0.545)\end{array}$ \\
\hline Quintile 3 & $\begin{array}{l}-0.976 \\
(0.999)\end{array}$ & $\begin{array}{c}-3.304 * * * \\
(0.746)\end{array}$ & $\begin{array}{r}-1.582^{*} \\
(0.638)\end{array}$ \\
\hline Quintile 4 & $\begin{array}{l}-1.227 \\
(1.152)\end{array}$ & $\begin{array}{c}-2.682^{* * * *} \\
(0.806)\end{array}$ & $\begin{array}{l}-1.619^{*} \\
(0.644)\end{array}$ \\
\hline Quintile 5 & $\begin{array}{l}-1.980 \\
(1.222)\end{array}$ & $\begin{array}{c}-3.409^{* * * *} \\
(0.827)\end{array}$ & $\begin{array}{l}-1.788^{*} \\
(0.739)\end{array}$ \\
\hline Functional Limitation $\mathbf{t}-\mathbf{1}$ & $\begin{array}{c}0.595^{* * * *} \\
(0.046)\end{array}$ & $\begin{array}{c}0.565^{* * * *} \\
(0.047)\end{array}$ & $\begin{array}{c}0.576 * * * \\
(0.040)\end{array}$ \\
\hline Functional Limitation $\mathbf{t}-\mathbf{2}$ & $\begin{array}{c}0.252 * * * \\
(0.045)\end{array}$ & $\begin{array}{c}0.208 * * * \\
(0.043)\end{array}$ & $\begin{array}{c}0.207 * * * \\
(0.040)\end{array}$ \\
\hline Functional Limitation $\mathbf{t}-\mathbf{3}$ & $\begin{array}{c}0.160 * * \\
(0.052)\end{array}$ & $\begin{array}{r}0.172 * * \\
(0.056)\end{array}$ & $\begin{array}{r}0.143 * * \\
(0.051)\end{array}$ \\
\hline $\begin{array}{l}\text { \#IV } \\
\text { Hansen J }\end{array}$ & $\begin{array}{c}143 \\
\operatorname{chi}^{2}(112): 117.64 ; P=0.339\end{array}$ & $\begin{array}{c}143 \\
\operatorname{chi}^{2}(112): 123.41 ; P=0.217\end{array}$ & $\begin{array}{c}143 \\
\operatorname{chi}^{2}(112): 112.83 ; P=0.460\end{array}$ \\
\hline
\end{tabular}

Note: Based on 2,693 households' head participants of the Panel Study of Income Dynamics and for whom data were available for all years between 1999 and 2013.

$* * * \mathrm{p}<.001 ; * * .001 \leq \mathrm{p}<.01 ; * .01 \leq \mathrm{p}<.05$.

${ }^{\dagger}$ Functional Limitations due to chronic conditions were based on individuals who had chronic conditions and the number varied across waves: (N): 1999 (808), 2001 (922), 2003 (1,027), 2005 (1,148), 2007 (1,296), 2009 (1,396), 2011 (1,490), 2013 (1,585).

Adjusted model includes age, number of chronic conditions, body mass index, alcohol use, smoking status, light physical activity, marital status, number of children under 18 years of age, health insurance, external financial support, and financial liabilities to others. 
Table 2.6

Changes in Economic Status (Gain and Loss) and Changes in Health Measures (Decline or Improvement) Working-Age Adults in the United States

The Panel Study of Income Dynamics, 1999-2013, (N=2,693)

\begin{tabular}{|c|c|c|c|c|}
\hline & \multicolumn{2}{|c|}{ SRH } & \multicolumn{2}{|c|}{ 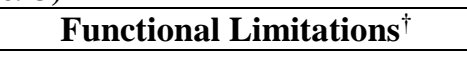 } \\
\hline \multicolumn{5}{|c|}{ Gain in Economic Status and Improvement in SRH and Decreases in Functional Limitations } \\
\hline & $\begin{array}{c}\text { FD } \\
\text { (Adjusted) }\end{array}$ & $\begin{array}{l}\text { Lagged Fixed } \\
\text { Effect }\end{array}$ & $\begin{array}{c}\text { FD } \\
\text { (Adjusted) }\end{array}$ & $\begin{array}{c}\text { Lagged Fixed } \\
\text { Effect }\end{array}$ \\
\hline Ln Family Income & $\begin{array}{c}0.013 \\
(0.008)\end{array}$ & $\begin{array}{l}0.781^{*} \\
(0.354)\end{array}$ & $\begin{array}{c}0.008 \\
(0.014)\end{array}$ & $\begin{array}{l}-0.186 \\
(0.205)\end{array}$ \\
\hline Change in Family Income Quintile & $\begin{array}{c}0.005 \\
(0.009)\end{array}$ & $\begin{array}{l}0.606 \\
(0.516)\end{array}$ & $\begin{array}{c}0.020 \\
(0.017)\end{array}$ & $\begin{array}{c}-0.842 * * \\
(0.309)\end{array}$ \\
\hline Ln Labor Income & $\begin{array}{l}0.010 \\
(0.007)\end{array}$ & $\begin{array}{l}0.890^{* *} \\
(0.323)\end{array}$ & $\begin{array}{l}-0.007 \\
(0.013)\end{array}$ & $\begin{array}{c}-0.936 * * * \\
(0.177)\end{array}$ \\
\hline $\begin{array}{l}\text { Change in Income Labor Income } \\
\text { Ouintile }\end{array}$ & $\begin{array}{l}0.0174 \\
(0.010)\end{array}$ & $\begin{array}{l}1.285^{*} \\
(0.520)\end{array}$ & $\begin{array}{c}0.024 \\
(0.017)\end{array}$ & $\begin{array}{c}-0.863 * * \\
(0.265)\end{array}$ \\
\hline Ln Net Wealth & $\begin{array}{l}0.018^{*} \\
(0.007)\end{array}$ & $\begin{array}{c}0.458 \\
(0.317)\end{array}$ & $\begin{array}{c}0.003 \\
(0.012)\end{array}$ & $\begin{array}{l}-0.323 \\
(0.175)\end{array}$ \\
\hline Change in Net Wealth Quintile & $\begin{array}{c}0.038 * * * \\
(0.010) \\
\end{array}$ & $\begin{array}{l}1.075^{*} \\
(0.501) \\
\end{array}$ & $\begin{array}{c}0.027 \\
(0.016) \\
\end{array}$ & $\begin{array}{l}-0.496 \\
(0.275) \\
\end{array}$ \\
\hline & \multicolumn{2}{|c|}{ SRH } & \multicolumn{2}{|c|}{ Functional Limitations ${ }^{\dagger}$} \\
\hline \multicolumn{5}{|c|}{ Loss in Economic Status and Decline in SRH and Increases in Functional Limitations } \\
\hline & $\begin{array}{c}\text { FD } \\
\text { (Adjusted) }\end{array}$ & $\begin{array}{l}\text { Lagged Fixed } \\
\text { Effect }\end{array}$ & $\begin{array}{c}\text { FD } \\
\text { (Adjusted) }\end{array}$ & $\begin{array}{l}\text { Lagged Fixed } \\
\text { Effect }\end{array}$ \\
\hline Ln Family Income & $\begin{array}{c}0.0176^{*} \\
(0.008)\end{array}$ & $\begin{array}{l}-0.810^{*} \\
(0.354)\end{array}$ & $\begin{array}{l}0.042 * * \\
(0.014)\end{array}$ & $\begin{array}{c}0.204 \\
(0.207)\end{array}$ \\
\hline Change in Family Income Quintile & $\begin{array}{c}0.009 \\
(0.010)\end{array}$ & $\begin{array}{l}-0.981 * \\
(0.472)\end{array}$ & $\begin{array}{c}0.020 \\
(0.018)\end{array}$ & $\begin{array}{l}0.555^{*} \\
(0.274)\end{array}$ \\
\hline Ln Labor Income & $\begin{array}{c}0.021^{* *} \\
(0.008)\end{array}$ & $\begin{array}{l}-0.748^{*} \\
(0.321)\end{array}$ & $\begin{array}{l}0.038^{* *} \\
(0.0136)\end{array}$ & $\begin{array}{c}0.863 * * * \\
(0.169)\end{array}$ \\
\hline $\begin{array}{l}\text { Change in Income Labor Income } \\
\text { Quintile }\end{array}$ & $\begin{array}{c}0.0211^{*} \\
(0.011)\end{array}$ & $\begin{array}{l}-1.556 * * * \\
(0.472)\end{array}$ & $\begin{array}{c}0.063 * * * \\
(0.018)\end{array}$ & $\begin{array}{c}1.427 * * * \\
(0.277)\end{array}$ \\
\hline Ln Net Wealth & $\begin{array}{c}0.022^{* *} \\
(0.008)\end{array}$ & $\begin{array}{l}-0.512 \\
(0.330)\end{array}$ & $\begin{array}{c}0.005 \\
(0.014)\end{array}$ & $\begin{array}{c}0.160 \\
(0.189)\end{array}$ \\
\hline Change in Net Wealth Quintile & $\begin{array}{c}0.042 * * * \\
(0.010)\end{array}$ & $\begin{array}{l}-1.008 * \\
(0.481) \\
\end{array}$ & $\begin{array}{c}0.030 \\
(0.018)\end{array}$ & $\begin{array}{c}0.400 \\
(0.274)\end{array}$ \\
\hline
\end{tabular}

Note: Based on 2,693 households' head participants of the Panel Study of Income Dynamics and for whom data were available for all years between 1999 and 2013.

$* * * \mathrm{p}<.001 ; * * .001 \leq \mathrm{p}<.01 ; * .01 \leq \mathrm{p}<.05$.

Economic Gain: One-period positive change or transition from a lower quintile to un upper quintile.

Health Improvement (SRH): A binary indicator variable measuring one-period change in SRH with the value of 1 representing improvements in SRH and zero representing no change or worsening health.

Economic Loss: One-period negative change or transition from an upper quintile to a lower quintile.

Health Decline (SRH): A binary indicator variable measuring one-period change in SRH with the value of 1 representing a decline in SRH and zero representing no change or health improvement. 
Functional Limitation improvement: A binary indicator variable measuring one-period change in functional limitation with the value of 1 representing improvements in functional limitation and zero representing no change or worsening functional limitation.

Worsening functional status: A binary indicator variable measuring one-period change in functional limitation with the value of 1 representing increases in functional limitation and zero representing no change or functional limitation improvement.

$\dagger$ Functional Limitations due to chronic conditions were based on individuals who had chronic conditions and the number varied across waves: (N): 1999 (808), 2001 (922), 2003 (1,027), 2005 (1,148), 2007 (1,296), 2009 (1,396), 2011 (1,490), 2013 (1,585).

In FD model, the outcome is health improvement (or decline) and the key endogenous variable is economic gain (or loss). FD adjusted for one-period changes in age, number of chronic conditions (only SRH), body mass index, alcohol use, smoking status, light physical activity, marital status, number of children under 18 years of age, health insurance, external financial support, and financial liabilities to others.

In lagged fixed effect model, the outcome is the SRH at time $t$ (or functional limitation at time $t$ ). The key independent variable is either economic gain or loss. Lagged fixed effect model included the following variables measured at t-1: health measure, economic indicator, age, number of chronic conditions (only SRH), body mass index, alcohol use, smoking status, light physical activity, marital status, number of children under 18 years of age, health insurance, external financial support, and financial liabilities to others.

SRH: Self-rated health; Ln: Natural Log. 
Table 2.7

Changes in Health (Decline or Improvement) and Changes in Economic Status (Gain or Loss)

Working-Age Adults (18-64 Years) in the United States

The Panel Study of Income Dynamics, 1999-2013, (N=2,693)

\begin{tabular}{|c|c|c|c|c|c|c|}
\hline \multicolumn{3}{|c|}{ Ln Family Income } & \multicolumn{2}{|c|}{ Ln Labor Income } & \multicolumn{2}{|c|}{ Net Wealth } \\
\hline \multicolumn{7}{|c|}{ Improvement in SRH and Decreases in Functional Limitations ${ }^{\dagger}$ and Gain in Economic Status } \\
\hline & $\begin{array}{c}\text { FD } \\
\text { (Adjusted) }\end{array}$ & $\begin{array}{c}\text { Lagged Fixed } \\
\text { Effect }\end{array}$ & $\begin{array}{c}\text { FD } \\
\text { (Adjusted) }\end{array}$ & $\begin{array}{c}\text { Lagged Fixed } \\
\text { Effect }\end{array}$ & $\begin{array}{c}\text { FD } \\
\text { (Adjusted) }\end{array}$ & $\begin{array}{c}\text { Lagged Fixed } \\
\text { Effect }\end{array}$ \\
\hline SRH & $\begin{array}{l}0.024^{*} \\
(0.011)\end{array}$ & $\begin{array}{c}0.058 * * \\
(0.022)\end{array}$ & $\begin{array}{c}0.018 \\
(0.011)\end{array}$ & $\begin{array}{c}0.284 * * * \\
(0.076)\end{array}$ & $\begin{array}{l}0.023^{*} \\
(0.011)\end{array}$ & $\begin{array}{l}0.143 * \\
(0.072)\end{array}$ \\
\hline $\begin{array}{l}\text { Functional } \\
\text { Limitations }\end{array}$ & $\begin{array}{c}0.012 \\
(0.017)\end{array}$ & $\begin{array}{c}0.018 \\
(0.035)\end{array}$ & $\begin{array}{l}-0.023 \\
(0.016) \\
\end{array}$ & $\begin{array}{c}0.710^{* * * *} \\
(0.113) \\
\end{array}$ & $\begin{array}{l}-0.011 \\
(0.016) \\
\end{array}$ & $\begin{array}{c}0.030 \\
(0.112) \\
\end{array}$ \\
\hline \multicolumn{3}{|c|}{ Ln Family Income } & \multicolumn{2}{|c|}{ Ln Labor Income } & \multicolumn{2}{|c|}{ Net Wealth } \\
\hline \multicolumn{7}{|c|}{ Decline in SRH and Increases in Functional Limitations ${ }^{\dagger}$ and Loss in Economic Status } \\
\hline & $\begin{array}{c}\text { FD } \\
\text { (Adjusted) }\end{array}$ & $\begin{array}{c}\text { Lagged Fixed } \\
\text { Effect }\end{array}$ & $\begin{array}{c}\text { FD } \\
\text { (Adjusted) }\end{array}$ & $\begin{array}{c}\text { Lagged Fixed } \\
\text { Effect }\end{array}$ & $\begin{array}{c}\text { FD } \\
\text { (Adjusted) }\end{array}$ & $\begin{array}{l}\text { Lagged Fixed } \\
\text { Effect }\end{array}$ \\
\hline $\begin{array}{l}\text { SRH } \\
\end{array}$ & $\begin{array}{c}0.032 * * \\
(0.011)\end{array}$ & $\begin{array}{l}-0.037 \\
(0.021)\end{array}$ & $0.030 * *(0.010)$ & $\begin{array}{c}-0.318^{* * * *} \\
(0.065)\end{array}$ & $\begin{array}{c}0.033 * * * * \\
(0.010)\end{array}$ & $\begin{array}{l}-0.039 \\
(0.066)\end{array}$ \\
\hline $\begin{array}{l}\text { Functional } \\
\text { Limitations }\end{array}$ & $\begin{array}{l}0.035^{*} \\
(0.015)\end{array}$ & $\begin{array}{l}-0.075^{*} \\
(0.030)\end{array}$ & $\begin{array}{c}0.022 \\
(0.015)\end{array}$ & $\begin{array}{c}-0.797 * * * \\
(0.106)\end{array}$ & $\begin{array}{c}0.002 \\
(0.015)\end{array}$ & $\begin{array}{l}-0.175 \\
(0.097)\end{array}$ \\
\hline
\end{tabular}

Note: Based on 2,693 households' head participants of the Panel Study of Income Dynamics and for whom data were available for all years between 1999 and 2013.

$* * * \mathrm{p}<.001 ; * * .001 \leq \mathrm{p}<.01 ; * .01 \leq \mathrm{p}<.05$.

Economic Gain: One-period positive change or transition from lower quintile to upper quintile.

Health Improvement (SRH): A binary indicator variable measuring one-period change in SRH with the value of 1 representing improvements in SRH and zero representing no change or worsening health.

Economic Loss: One-period negative change or transition from upper quintile to lower quintile.

Health Decline (SRH): A binary indicator variable measuring one-period change in SRH with the value of 1 representing decline in SRH and zero representing no change or health improvement.

Functional Limitation improvement: A binary indicator variable measuring one-period change in functional limitation with the value of 1 representing improvements in functional limitation and zero representing no change or worsening functional limitation.

Worsening Functional Status: A binary indicator variable measuring one-period change in functional limitation with the value of 1 representing increases in functional limitation and zero representing no change or functional limitation improvement.

${ }^{\dagger}$ Functional Limitations due to chronic conditions were based on individuals who had chronic conditions and the number varied across waves: (N): 1999 (808), 2001 (922), 2003 (1,027), 2005 (1,148), 2007 (1,296), 2009 (1,396), 2011 (1,490), 2013 (1,585).

In FD model, the outcome is economic gain (or loss) and the key endogenous variable is health improvement (or decline). FD adjusted for one-period changes in age, number of chronic conditions (only 
SRH), body mass index, alcohol use, smoking status, light physical activity, marital status, number of children under 18 years of age, health insurance, external financial support, and financial liabilities to others.

In lagged fixed effect model, the outcome is the economic indicator at time. Lagged fixed effect model included the following variables measured at $\mathrm{t}-1$ : health measure, economic indicator, age, number of chronic conditions (only SRH), body mass index, alcohol use, smoking status, light physical activity, marital status, number of children under 18 years of age, health insurance, external financial support, and financial liabilities to others.

SRH: Self-rated health; Ln: Natural Log. 


\begin{tabular}{|c|c|c|}
\hline \multicolumn{3}{|c|}{$\begin{array}{c}\text { Appendix 2.1 } \\
\text { Specifications of Economic Gain and Loss Models }\end{array}$} \\
\hline $\begin{array}{l}\text { First } \\
\text { Difference- } \\
\text { Health } \\
\text { improvement }\end{array}$ & $\Delta \mathrm{hi}_{\mathrm{it}}=\beta_{1} \Delta \mathrm{Yg}_{\mathrm{it}}+\beta_{2} \Delta \mathrm{X}_{\mathrm{it}}+\Delta \mu_{\mathrm{it}}$ & $\begin{array}{l}\mathrm{hi}_{\mathrm{it}} \text { : A binary indicator variable measuring one-period change in } \\
\text { health with the value of } 1 \text { representing improvements in health and } \\
\text { zero representing no change or worsening health. } \\
\mathrm{Yg}_{\mathrm{it}} \text { : One-period positive change or transition from lower quintile to } \\
\text { upper quintile. } \\
\Delta \mathrm{X}_{\mathrm{it}} \text { : the change in the matrix of time-variant control variables. } \\
\Delta \mu_{\mathrm{it}}: \text { The change in the error term. }\end{array}$ \\
\hline $\begin{array}{l}\text { First } \\
\text { Difference- } \\
\text { Health decline }\end{array}$ & $\Delta \mathrm{hd}_{\mathrm{it}}=\beta_{1} \Delta \mathrm{Yl}_{\mathrm{it}}+\beta_{2} \Delta \mathrm{X}_{\mathrm{it}}+\Delta \mu_{\mathrm{it}}$ & $\begin{array}{l}\mathrm{hd}_{\mathrm{it}} \text { : A binary indicator variable measuring one-period change in } \\
\text { health with the value of } 1 \text { representing decline in health and zero } \\
\text { representing no change or health improvement. } \\
\mathrm{Yl}_{\mathrm{it}} \text { : One-period negative change or transition from upper quintile to } \\
\text { lower quintile. } \\
\Delta \mathrm{X}_{\mathrm{it}} \text { the change in the matrix of time-varying control variables. } \\
\Delta \mu_{\mathrm{it}}: \text { The change in the error term. }\end{array}$ \\
\hline $\begin{array}{l}\text { Lagged-Fixed } \\
\text { effects- } \\
\text { Economic Gain }\end{array}$ & $\begin{array}{l}\mathrm{h}_{\mathrm{it}}=\beta_{0}+\beta_{1} \mathrm{~h}_{\mathrm{it}-1}+\beta_{2} \mathrm{Y}_{\mathrm{it}-1}+\beta_{3} \Delta \mathrm{Yg}_{\mathrm{it}}+ \\
\beta_{4} \mathrm{X}_{\mathrm{it}-1}+\mu_{\mathrm{it}}\end{array}$ & $\begin{array}{l}h_{\mathrm{it}} \text { is the health of individual } \mathrm{i} \text { at time } \mathrm{t} . \mathrm{h}_{\mathrm{it}-1} \text { is the health of individual } \\
\mathrm{i} \text { at time } \mathrm{t}-1 . \mathrm{Y}_{\mathrm{it}-1} \text { is the economic indicator at time } \mathrm{t}-1 . \mathrm{X}_{\mathrm{it}-1} \text { is the } \\
\text { matrix of the other exogenous variables at } \mathrm{t}-1 \text {. } \\
\mathrm{Yg}_{\mathrm{it}} \text { : One-period positive change or transition from lower quintile to } \\
\text { upper quintile. }\end{array}$ \\
\hline $\begin{array}{l}\text { Lagged-Fixed } \\
\text { effects- } \\
\text { Economic Loss }\end{array}$ & $\begin{array}{l}\mathrm{h}_{\mathrm{it}}=\beta_{0}+\beta_{1} \mathrm{~h}_{\mathrm{it}-1}+\beta_{2} \mathrm{Y}_{\mathrm{it}-1}+\beta_{3} \Delta \mathrm{Yl}_{\mathrm{it}}+ \\
\beta_{4} \mathrm{X}_{\mathrm{it}-1}+\mu_{\mathrm{it}}\end{array}$ & $\begin{array}{l}\mathrm{h}_{\mathrm{it}} \text { is the health of individual } \mathrm{i} \text { at time } \mathrm{t} . \mathrm{h}_{\mathrm{it}-1} \text { is the health of individual } \\
\mathrm{i} \text { at time } \mathrm{t}-1 . \mathrm{Y}_{\mathrm{it}-1} \text { is the economic indicator at time } \mathrm{t}-1 . \mathrm{X}_{\mathrm{it}-1} \text { is the } \\
\text { matrix of the other exogenous variables at } \mathrm{t}-1 \text {. } \\
\mathrm{Yl}_{\mathrm{it}} \text { : One-period negative change or transition from upper quintile to } \\
\text { lower quintile. }\end{array}$ \\
\hline
\end{tabular}




\section{Chapter 3 \\ The Dynamics of Economic status and Mental Health among Working-Age Adults in the United States}

\section{ABSTRACT}

We examined the dynamic relationships between economic status and mental health measures with data from 4 waves of the Panel Study of Income Dynamics (PSID) from 2007 to 2013 in the United States (US). Mental health was assessed using self-reported diagnosis of psychiatric disorders, as well as participant scores on the Kessler-6 Non-Specific Psychological Distress Scale; mental illness was defined as the presence of depression, anxiety, or serious psychological distress. Economic status was measured using family income, labor income and net wealth in quintiles. The study sample comprised 4,867 heads of households from the PSID. Probit and instrumental variable (IV) probit models were used to evaluate the relationships between economic indicators and mental illnesses. Further, ordinary least squares regression (OLS) and IV OLS were used to examine the relationships between economic indicators and psychological distress scores. First-difference estimators were used to assess the associations between changes in economic status and changes in mental health. After controlling for the endogeneity between economic status and mental health, we observed a significant relationship between net wealth and the presence of a mental illness. On the other hand, adjusted IV OLS revealed significant relationships between family income, net wealth and psychological distress. First-difference estimators indicated that a decline in economic status resulted in a decline in mental health. Similarly, a decline in mental health resulted in losses to net wealth, family and labor income. Our findings suggest that mental health and economic status have a strong bidirectional relationship. Therefore, US programs and policies to improve either mental health 
or economic status of individuals may need to take into account both mental health and economic sectors.

\section{INTRODUCTION}

The World Health Organization (WHO) defines health as "a state of complete physical, social and mental well-being, and not merely the absence of disease or infirmity (1)," suggesting that mental health is an important domain of population health, and an integral component of the overall health of an individual. Mental health is "a state of well-being in which every individual realizes his or her own potential, can cope with the normal stresses of life, can work productively and fruitfully, and is able to make a contribution to her or his community (2)." Under this broad definition, impaired mental health can encompass - mental illnesses (chronic conditions such as schizophrenia and post-traumatic stress disorder), episodic health conditions such as depression, anxiety, chronic stress, psychological distress, behavioral disorders, and substance abuse. Poor mental health can have profound adverse effects on health and cognitive function and is a significant contributor to disability (3). For example, depression is the second leading cause of disability in the United States (US) (3). Poor mental health also has economic consequences for the individuals, families, healthcare systems, and society. In 2009, mental health treatment spending from all public and private sources was $\$ 171.7$ billion (4). For individuals, mental health can lead to loss of productivity $(5,6)$, reduction in working hours and unemployment $(6$ 11).

Mental health is determined by multiple and interacting social, psychological, and economic factors. In 2011, 75\% of the American adults reported financial concerns as a significant source of stress (12). Many studies have examined the contemporaneous relationships between economic indicators and mental health (19-22). For example, several previous investigations 
have shown depression, anxiety and serious psychological distress to be more prevalent among adults with limited financial resources $(16,17,18)$. In addition, a meta-analysis of 50 crosssectional studies reported that individuals with low income were more likely to report depression compared to those with high income (23). These findings suggest that economic stress may lead to depression, anxiety and serious psychological distress (13-15). Recent longitudinal studies offer further evidence for a causal link between economic indicators and mental health $(15,20,24,25)$. For example, Yilmazer et al. reported that a decline in housing wealth was a significant, independent predictor of increased psychological distress during the great recession of 2007-2009 (15). McMillan et al. also reported a strong inverse association between income and subsequent psychological distress (25). Likewise, findings of two recent population-based studies suggest that lower income and wealth increase risk for the development of both depression and anxiety $(20,24)$. For example, in an investigation using the National Epidemiologic Survey of Alcohol and Related Conditions (NESARC), Sareen et al. reported that households with lowest income were more likely to report depression, and reduction in income from one wave to the next was associated with increased risk of depression (20). The effect of an economic shock (loss of employment or economic loss) on mental health has also has been studied $(15,26,27)$. Collectively, findings of these investigations suggest that financial well-being can have a profound effect on mental health.

Conversely, impairment in mental health may also lead to negative economic consequences. For example, numerous studies have shown that individuals with poor mental health are less likely to secure and maintain employment compared to those with better mental health (6-11). However, although the link between psychological and financial status/well-being appears strongly reciprocal, few studies have rigorously evaluated the bidirectional relationship between 
economic status and mental health. Moreover, with the exception of two studies in a sample of US elders $(22,28)$, few studies have addressed the potential endogeneity between economic status and mental health.

Two theories have been proposed to explain the relationship between economic status and mental health $(17,20)$ : social causation and social selection. The social causation theory assumes that economic status is a determinant of mental health and posits that experiencing an economic shock increases the risk of mental illness. Thus, a sudden loss of income or wealth can lead to incident mental illnesses. From an epidemiological perspective, social causation (economic status as a predictor of mental health) can explain the high prevalence of depression, anxiety, and other psychological disorders among individuals with low economic status (29-32). On the other hand, social selection theory assumes that mental health influences subsequent economic status, positing that environmental and genetic factors contribute to incident mental illness, which, in turn, leads to a reduction in economic resources (17). From an epidemiological perspective, social selection (mental health as a determinant of economic status) can explain low economic status among individuals with psychiatric disorders such as schizophrenia (29-32). From an economic point of view, mental illness can lead to a decline in income due to the inability to work; conversely, economic shocks can increase stress, which may lead to psychological disorders and distress $(6,14)$.

The objective of the current study is to evaluate the bidirectional relationships between economic indicators (family income, labor income and net wealth) and indices of mental health (mental illness and psychological distress), adjusting for the potential endogeneity between economic status and mental health. There are several points of departure between the current study and previous investigations. The current study used a comprehensive list of economic and 
mental health measures. We also addressed the endogeneity between economic indicators and mental health by employing instrument variables techniques. The current study focuses on working-age adults, since they have different economic resources and healthcare needs. In this study, we also controlled for other factors that may affect economic indicators, mental health or both such as age, self-rated health and other factors in previous studies (33-35).

\section{METHODS}

Study Design: The study utilized a retrospective observational longitudinal design with repeated measures of economic indicators and mental health measures for a period of 6 years using 4 waves of the Panel Study of Income Dynamics (PSID): 2007, 2009, 2011, and 2013. Psychological distress and mental health measures were continuously available in the PSID in these waves.

Study Sample: The study sample comprised heads of households who participated in all the waves of the PSID between 2007 and 2013 and who were aged between 18-58 years in 2007 (N $=4,867)$.

Data Sources: PSID: The PSID is a longitudinal study of the US population which began in 1968. The PSID 1968 sample was drawn from national probability sample of 1,872 low-income families from the Survey of Economic Opportunity and a nationally representative sample of 2,930 families (36-38). Currently, the individuals in any panel come from three sources: the original 1968 sample; the 1997 refresher sample of post-1968 immigrants; and births and marriages in existing families (36-38). In this study, both family and cross-year individual files were combined to gather information on households.

Measures: Mental Health Measures: Psychological Distress: Psychological distress was measured using the 6 item Kessler-6 Non-Specific Psychological Distress Scale (39), which 
included the following questions: "In the past 30 days, about how often did you feel: (1) so sad nothing could cheer you up? (2) nervous? (3) restless or fidgety? (4) hopeless? (5) that everything was an effort? (6) worthless?" The responses to these six questions are on a scale of 1 to 5: all of the time, most of the time, some of the time, a little of the time, none of the time. In the current study, the summary score from the Kessler- 6 scale was used to measure psychological distress. Mental Illness: Since 1999, the PSID has included a question regarding diagnosis of any emotional, nervous, or psychiatric problems. In 2005, PSID added a follow-up question about specific psychiatric disorder (depression, bipolar disorder, schizophrenia, anxiety, phobias, alcohol abuse, drug abuse, obsessive compulsive disorder and other) for those indicating diagnosed psychological problems. For the purposes of this study, mental illness was defined as present if participants 1) indicated a diagnosis of depression or anxiety and/or 2) scored 13 or greater on the Kessler- 6 scale, a cut point considered to reflect serious psychological distress, and to be a strong indicator of mental illness $(18,40,41)$.

Change in Mental Health Measures: a) Increases in psychological distress: A binary indicator variable with the value of 1 representing an increase in psychological distress scores from one wave to the next and zero representing no change or decreases in psychological distress scores from one wave to the next. b) Decreases in psychological distress: A binary indicator variable with the value of 1 representing improvements in mental health (i.e. decline in psychological distress scores from one wave to the next and zero representing no change or increases in psychological distress scores from one wave to the next. c) Mental illness onset: A binary indicator variable with the value of 1 representing mental illness onset and zero representing recovery from or no change in mental illness. d) Recovery from mental illness: A 
binary indicator variable with the value of 1 representing recovery from mental illness and zero representing no change in the mental illness status or onset of mental illness.

Economic Indicators: Family Income: In the PSID, total family income is calculated as the sum of head/wife taxable income (earnings, interest and dividends), head/wife transfer income, taxable or transfer income of other family unit members, head/wife social security income, and other family unit member's social security income. The participants reported the incomes they received in the prior year. Labor income: We measured labor income of the head of the household. Labor income included all money earned from wages and salaries, bonuses, overtime, tips, commissions, professional practice or any job-related income including farm or business income. Total net wealth: In PSID, total net wealth was calculated as the sum of home equity, farm or business assets, checking or savings accounts, vehicles, stocks and bonds and net debts. For purposes of analysis, we categorized family income, labor income, and net wealth into quintiles based on the distribution of these variables in each wave.

Other Exogenous Explanatory variables: For each head of the household, we measured the following variables in each wave: self-rated health (continuous variable, 0-100); obesity (yes/no); smoking status (smoker, not a smoker) and alcohol use (user, non-user). Other factors that may affect the financial ability of the households were: age; marital status (married, widowed, separated or divorced, and never married); number of children under 18 years of age; health insurance; external financial support and financial liabilities to others.

Instrumental Variables (IV): Instrumental variables were used to address the endogeneity between economic indicators and mental health measures. We used family economic background (poor, average, better well-off) and father's education as IVs for family and labor income and wealth. We employed several IV diagnostic tests to evaluate the IVs' 
validity and strength including Kleibergen-Paap F-statistic which is the heteroscedasticity robust version of the Cragg-Donald statistic (42), and Anderson-Rubin test for significance of endogenous regressors (43). Both tests indicated that our IVs were satisfactory.

\section{STATISTCAL ANALYSES}

Ordinary Least Squares (OLS) regression: We used unadjusted and adjusted OLS regressions to evaluate the associations between economic indicators and psychological distress. IV OLS Regression: This statistical technique was applied to address the endogeneity between economic indicators and psychological distress due to simultaneity, omitted variables and measurement errors. We used family economic background and father's education as IVs for income and wealth. Probit regression estimator: Because mental illness measure in this study is a binary variable, we used unadjusted and adjusted probit regression models to examine the relationships between economic indicators (family income, labor income and wealth) and mental illness. IV probit regression: Family economic background and father's education were used as IVs to address the endogeneity between economic indicators and mental illness. First-difference estimators were used to examine the dynamic relationships between economic loss and decline in mental health as well as between economic gain and mental health improvement and vice versa. In all the above models, we accounted for clustering of observations within an individual in the statistical inference. All analyses were weighted using 2013 longitudinal weights provided by the PSID investigators. 


\section{RESULTS}

\section{Characteristics of the study sample:}

The study sample comprised 4,867 heads of households who were between 18 and 58 years of age in 2007 . A majority of the study sample were male $(76.5 \%)$, white $(71.1 \%)$, married (52.7\%), and living in metropolitan areas (76.3\%). Forty-percent of the adults were between 1839 years old in 2007 and $32.6 \%$ had completed at least 4 years of college. Table 3.1 displays the weighted percentages across the 4 waves.

\section{Economic Indicators and mental health measures over time:}

Table 3.2 displays the means and standard errors of actual and natural logarithmic values of family income, labor income of the head of household and family net wealth across the four waves. There were fluctuations in the averages of family income and net wealth across the waves. On the other hand, labor income steadily decreased over time. Table 3.3 presents the weighted percentages of onset of mental illness and the means and standard errors of psychological distress across the 4 waves and by quintiles. In $2007,4.5 \%$ of the study sample had a new onset of mental illness (depression/anxiety/serious psychological distress).

\section{The relationship between economic indicators and mental health measures:}

\section{Economic Indicators and Psychological Distress:}

Family income and psychological distress: In the adjusted OLS, family income showed a significant, negative association with psychological distress scores. Adults in quintiles $2(\hat{\beta}=-$ 1.2, $\mathrm{p}<0.001), 3(\hat{\beta}=-1.6, \mathrm{p}<0.001), 4(\hat{\beta}=-1.7, \mathrm{p}<0.001)$ and $5(\hat{\beta}=-1.8, \mathrm{p}<0.001)$ had lower psychological distress scores than adults in the lowest quintile of family income. After adjusting for endogeneity, adults in quintiles $2(\hat{\beta}=-2.0, \mathrm{p}<0.001), 3(\hat{\beta}=-2.9, \mathrm{p}<0.001), 4(\hat{\beta}=$ 
$-3.5, \mathrm{p}<0.001)$ and $5(\hat{\beta}=-4.4, \mathrm{p}<0.001)$ had significantly lower psychological distress scores than adults in the lowest quintile of family income.

Labor income and psychological distress: In adjusted OLS, adults in higher quintiles from 2-5 had lower psychological distress scores as compared to adults in the lowest quintile of labor income. After adjusting for endogeneity, only adults in the second $(\hat{\beta}=-1.4, \mathrm{p}<0.05)$ and third $(\hat{\beta}=-2.4, \mathrm{p}<0.05)$ quintile of labor income had significantly lower psychological distress score than those in the lowest quintile of labor income.

Net Wealth and psychological distress: net wealth was significantly and inversely associated with psychological distress scores in both the adjusted OLS and IV OLS regressions. Adults in net wealth quintiles $3(\hat{\beta}=-0.7, \mathrm{p}<0.001), 4(\hat{\beta}=-1.1, \mathrm{p}<0.001)$ and $5(\hat{\beta}=-1.1, \mathrm{p}<$ 0.001) had significantly lower psychological distress scores than adults in the lowest quintile of net wealth. Adjustment for endogeneity and other explanatory variables strengthened these associations, with adults in quintiles $2(\hat{\beta}=-0.9, \mathrm{p}<0.001), 3(\hat{\beta}=-1.7, \mathrm{p}<0.001), 4(\hat{\beta}=-2.4, \mathrm{p}$ $<0.001)$ and $5(\hat{\beta}=-3.1, \mathrm{p}<0.001)$ showing significantly lower psychological distress scores than those in the lowest quintile of net wealth. Table 3.4 summarizes parameter estimates and standard errors of economic indicators on psychological distress scores from OLS and IV OLS regressions.

\section{Economic Indicators and Mental Illness:}

Table 3.5 displays the estimated marginal effects at representative values of economic indicators (family income, labor income and net wealth) on mental illness probabilities from adjusted probit and IV probit models. All the marginal effects were computed for reference levels of other explanatory variables (non-obese, non-smoker, non-alcohol user, have no financial liabilities and does not receive any financial support, have health insurance, and 
exercise more than three times weekly), and at means of the continuous variables (economic indicators, age, self-rated health and number of children).

Family income and mental illness: In the adjusted probit analyses, adults in higher family income quintiles 2, 3, 4 and 5 had lower probabilities of mental illness $(2.0 \%, 2.7 \%, 2.8 \%$ and $3.5 \%$ respectively) as compared to adults in the lowest quintile. However, after adjusting for endogeneity between family income and mental health, the relationship became statistically insignificant. Labor Income and mental illness: In the adjusted probit models, adults in labor income quintiles 2, 3, 4 and 5 had lower probabilities of mental illness $(1.8 \%, 2.7 \%, 2.6 \%$ and $3.1 \%$ respectively) compared to those in the lowest quintile of labor income. However, there was no relationship between labor income and mental illness after adjusting for endogeneity between the two. Net Wealth and mental illness: In the adjusted probit and IV probit models, adults in higher net wealth quintiles - 2, 3, 4 and 5- had lower probabilities of mental illness compared to adults in the lowest quintile of net wealth.

Increase in economic status and mental health improvement: Psychological Distress: In the adjusted FD analyses, the transition from lower labor income and net wealth quintile to upper increased the probability of mental health improvement by 3.5 percentage points (Table 3.6). Mental Illness: However, there was no significant relationship between the transition from lower economic status to higher and mental illness.

Loss in economic status and decline in mental health: Psychological Distress: In the adjusted FD analyses, the transition from upper quintiles of family income, labor income and net wealth quintile to lower quintiles increased the probability of mental health decline by $2.8,4.5$ and 3.0 percentage points respectively. Mental Illness: The transition from higher quintiles of 
labor income and net wealth to lower quintiles significantly increased the probability of mental illness by 1.2 and 1.5 percentage points respectively (Table 3.6).

Mental health improvement and increase in economic status: Psychological Distress: In the adjusted FD analyses, improvements in mental health increased the probability of increases in labor income ( 2.3 percentage points) and net wealth ( 2.5 percentage points). Mental Illness: On the other hand, there were no relationships between mental illness recovery and economic status.

Mental health decline and loss in economic status: Increases in psychological distress scores increased the probability of decline in family income, labor income and net wealth by 1.8 , 2.9 and 2.0 percentage points respectively (Table 3.7). Furthermore, in the adjusted FD analyses, Mental Illness onset was associated with increased probability of a decline in labor income (7.2 percentage points) and net wealth (9.7 percentage points).

\section{DISCUSSION}

The current study examined the relationships between economic indicators (family income, labor income, and net wealth) and two mental health measures (mental illness and psychological distress scores). In adjusted probit models, all economic indicators had significantly negative relationships with mental illness. Similarly, in the adjusted OLS regression models, we observed inverse relationships between all economic indicators and psychological distress scores. However, in the adjusted IV probit models, we observed a significantly negative relationship only between net wealth and mental illness. Similarly, using the adjusted IV OLS, we found significant inverse associations only between family income and net wealth and psychological distress. These findings suggest that studies examining the relationship between 
economic status and mental health need to take into account the endogeneity between these factors.

Our results also revealed that working-age adults who experienced an economic loss were more likely to report a mental illness and indicate higher psychological distress. Our findings support results of the previous studies which indicated that reduction in income or wealth is associated with increased likelihood of mental illness and psychological distress $(15,20)$. However, our findings additionally showed that reduction in any economic measure (family income, labor income or net wealth) is strongly and positively associated with mental illnesses and psychological distress. A closer examination of our data revealed that $40-50 \%$ of adults were unemployed during the year of the mental illness onset. Further, approximately $50 \%$ of our sample had at least one child, 11-19\% had financial liabilities to other family members and 27$47 \%$ had negative wealth at the year of new onset mental illness. Taken together these findings suggest that adults in our sample were under financial duress from multiple sources and an economic shock may have increased the psychological stress.

Our study findings also confirmed the bidirectional relationship between mental health and economic status. In this sample, adults in the upper quintiles of the economic distribution were less likely to have mental illnesses relative to those in the lowest quintile, consistent with prior literature $(20,23)$. In agreement with the results of other published studies (44-47), we also found that adults who experienced a mental illness were more likely to experience a reduction in labor income and net wealth, and that a recovery from a mental illness increased the probability of economic gain.

The study findings have implications for strengthening existing policies and designing and implementing innovative and more effective economic development policies. Given the 
strong, reciprocal relationships between mental health and economic status confirmed in this study, policies targeting economic development may benefit from the incorporation of components addressing mental health issues. In the US, many existing policies and programs, including disability benefits for those with mental health impairment (48), mandated provision of mental health benefits by insurers, mental health parity and legislations (49) have specifically targeted financing and delivery of mental healthcare. However, there are no US policy initiatives targeting mental health improvement in all sectors of the economy such as those recently developed by a team of experts from Finland, Iceland, Norway, Portugal, United Kingdom and other European countries, which referred to as "mental health in all policies" (50). These experts concluded that social, economic, and physical environments have a significant impact on mental health and these effects should be considered in the development of all public policies and programs. This comprehensive initiative further recommended strengthening protective factors throughout an individual's life through affordable day-care centers for children, affordable housing, and return-to-work policies and programs (50). Although the US has disparate policies $(51,52)$, these policies need to be strengthened and include integrated and cohesive mental health components.

Our findings also have implications for improving access to mental healthcare and mental health treatment. Although provision of mental health services has been strengthened by Mental Health Parity Acts of 1996 and 2008 (53) which ensure equal care for mental health and substance use disorders in insurance plans, not all adults with poor mental health are insured. Nearly 1 in 5 working-age adults with severe mental illnesses was uninsured in a nationally representative sample of US adults (54). In addition, $30.4 \%$ of working-age adults with serious psychological distress were uninsured in the period from 2009-2013 (18). 
Even with insurance coverage, individuals with mental illness can face a high economic burden in terms of out-of-pocket spending. It has been reported that individuals with mental disorders have $25 \%$ higher out-of-pocket expenditures for the treatment than for treatment of physical chronic conditions such as heart conditions, cancer, trauma-related disorders, and asthma (54). Evidence also exists on cost as a barrier to receiving mental health services (55), which may lead to foregoing mental health care due to high-cost sharing and out-of-pocket spending burden. Lack of mental health treatment may further worsen the mental illness of adults, which can lead to further reductions in income. These findings again highlight the need for "mental health in all policies," recommended by the experts in the European countries (50).

Our study findings have also implications for healthcare professionals such as social workers and others who often coordinate care for those with low income and/or mental health conditions (16). For example, healthcare professionals need to take into account the economic status of the adults to treat a mental illness episode successfully and to increase the quality of the mental healthcare (16). Healthcare professionals need also to assess the adult's educational accomplishments and occupational progression when tailoring intervention programs that address mental illnesses.

The current study has several strengths. First, we used a large, nationally representative sample of working age adults and examined the dynamic, bidirectional relationships between economic indicators and mental health by tracking changes over a period of 8 years. Second, we tested the robustness of our findings by evaluating multiple measures of economic status and mental health and using rigorous, well-established statistical techniques. Third, we controlled for a comprehensive list of other exogenous explanatory variables including age, self-rated health, 
obesity, smoking status, alcohol use, marital status, number of children under 18 years of age, health insurance, external financial support, and financial liabilities to others.

However, our study has some limitations. First, information on all the variables is based on self-reported data, raising the possibility of recall bias. Second, although we employed statistical techniques to remove the effects of endogeneity due to reverse causality and omitted variables, we cannot completely eliminate these potential biases. Third, our mental health measures did not capture certain serious mental health conditions such as schizophrenia, which may affect employment as well income.

\section{CONCLUSION}

Our study findings confirmed strong, bidirectional relationships between economic status and mental health. These relationships should be considered in the development of programs and policies designed to improve the mental health and economic well-being of US residents. 


\section{REFERENCES}

(1) Preamble to the Constitution of the World Health Organization as adopted by the International Health Conference. ; 1948.

(2) Herman H, Saxena S, Moodie R. Promoting Mental Health: Concepts, Emerging Evidence, Practice. Geneva, Switzerland: World Health Organization; 2005.

(3) Murray CJ, Abraham J, Ali MK, Alvarado M, Atkinson C, Baddour LM, Bartels DH, Benjamin EJ, Bhalla K, Birbeck G, Bolliger I. The state of US health, 1990-2010: burden of diseases, injuries, and risk factors. JAMA 2013;310(6):591-606.

(4) Mark TL, Levit KR, Yee T, Chow CM. Spending on mental and substance use disorders projected to grow more slowly than all health spending through 2020. HEALTH AFFAIRS 2014;33(8):1407-1415.

(5) Stewart WF, Ricci JA, Chee E, Hahn SR, Morganstein D. Cost of lost productive work time among US workers with depression. JAMA 2003;289(23):3135-3144.

(6) Mitra S Jones K. The impact of recent mental health changes on employment: new evidence from longitudinal data. Applied Economics 2016:1-4.

(7) Ettner, S., R. Frank, and R. Kessler. The Impact of Psychiatric Disorders on Labor Market Outcomes. Industrial and Labor Relations Review 2007;51(1):64-81.

(8) Dooley, D., J. Prause, and K.A. Ham-Rowbottom. Underemployment and Depression: Longitudinal Relationships. Journal of Health Social Behavior 2000;41(4):421-436.

(9) Chatterji, P., M. Alegria, M. Lu, and D. Takeuchi. Psychiatric Disorders and Labor Market Outcomes: Evidence from the National Latino and Asian American Study. Health Economics 2007;16(10):1069-1090.

(10) Chatterji, P., M. Alegria, and D. Takeuchi. Psychiatric Disorders and Labor Market Outcomes: Evidence from the National Comorbidity Survey-Replication. Journal of Health Economics 2011;30(5):858-868.

(11) Baldwin, M., and S. Marcus. The impact of mental and substance-use disorders on employment transitions. Health Economics 2014;23(3):332-344.

(12) American Psychological Association:. Stress in America: Our Health at Risk, washington D.C. 2012.

(13) Cooper CL. Handbook of Stress Medicine and Health. Boca Raton, FL.: CRC Press; 2004.

(14) Strauss J, Thomas D. Health over the life course. Handbook of development economics 2007;31(4):3375-3474.

(15) Yilmazer T, Babiarz P, Liu F. The impact of diminished housing wealth on health in the United States: Evidence from the Great Recession. Social science \& medicine 2015;130:234241. 
(16) Hudson CG. Social Class and Mental Illness Correlation: Implications of the Research for Policy and Practice. The Journal of Sociology \& Social Welfare 1988;15(1):27-54.

(17) Hudson CG. Socioeconomic status and mental illness: tests of the social causation and selection hypotheses. American journal of Orthopsychiatry 2005;75(1):3-18.

(18) Weissman J, Pratt LA, Miller EA, Parker JD. Serious psychological distress among adults: United States, 2009-2013. National Center for Health Statistics 2015;NCHS data brief(203).

(19) Sturm R, Gresenz CR. Relations of income inequality and family income to chronic medical conditions and mental health disorders: national survey. Bmj 2002;324.

(20) Sareen J, Afifi TO, McMillan KA, Asmundson GJ. Relationship between household income and mental disorders: findings from a population-based longitudinal study. Archives of General Psychiatry 2011;68(4):419-427.

(21) Pabayo R, Kawachi I, Gilman SE. Income inequality among American states and the incidence of major depression. Journal of epidemiology and community health 2013;jech2013:1-6.

(22) Golberstein E. The effects of income on mental health: evidence from the social security notch. The journal of mental health policy and economics 2015;18(1):27-37.

(23) Lorant V, Deliège D, Eaton W, Robert A, Philippot P, Ansseau M. Socioeconomic inequalities in depression: a meta-analysis. American Journal of Epidemiology 2003;157(2):98112.

(24) Prause J, Dooley D, Huh J. Income volatility and psychological depression. . American Journal of Community Psychology 2009;43(1-2):57-70.

(25) McMillan KA, Enns MW, Asmundson GJ, Sareen J. The association between income and distress, mental disorders, and suicidal ideation and attempts: findings from the collaborative psychiatric epidemiology surveys. . The Journal of clinical psychiatry 2010;71(9):1168-1175.

(26) Dooley D, Catalano R, Wilson G. Depression and unemployment: panel findings from the Epidemiologic Catchment Area study. American journal of community psychology 1994;22(6):745-765.

(27) McKee-Ryan F, Song Z, Wanberg CR, Kinicki AJ. Psychological and physical well-being during unemployment: a meta-analytic study. Journal of applied psychology 2005;90(1):53.

(28) Ayyagari P. Evaluating the Impact of Social Security Benefits on Health Outcomes Among the Elderly. . Center for Retirement Research at Boston College: CRR WP 2015-25 2015.

(29) Goldberg EM, Morrison SL. Schizophrenia and social class. The British Journal of Psychiatry 1963;109(463):785-802.

(30) Muntaner C, Eaton WW, Miech R, O’Campo P. Socioeconomic position and major mental disorders. Epidemiologic reviews 2004;26(1):53-62.

(31) Saraceno B, Levav I, Kohn R. The public mental health significance of research on socioeconomic factors in schizophrenia and major depression. . World Psychiatry 2005;4(3):181-185. 
(32) Hanandita W, Tampubolon G. Does poverty reduce mental health? An instrumental variable analysis. Social Science \& Medicine 2014;113:59-67.

(33) Chaney EH, Chaney JD, Wang MQ, Eddy JM. Lifestyle behaviors and mental health of American adults. Psychological reports 2007;100(1):294-302.

(34) Scott KM, Bruffaerts R, Simon GE, Alonso J, Angermeyer M, de Girolamo G, Demyttenaere K, Gasquet I, Haro JM, Karam E, Kessler RC. Obesity and mental disorders in the general population: results from the world mental health surveys. . International journal of obesity 2008;32(1):192-200.

(35) Velten J, Lavallee KL, Scholten S, Meyer AH, Zhang XC, Schneider S, Margraf J. Lifestyle choices and mental health: a representative population survey. BMC psychology 2014;2(1).

(36) McGonagle KA, Schoeni R. The Panel Study of Income Dynamics: Overview and summary of scientific contributions after nearly 40 years. Survey Research Center - Institute for Social Research University of Michigan 2006;06-01.

(37) McGonagle KA, Schoeni RF, Sastry N, Freedman VA. The Panel Study of Income Dynamics: overview, recent innovations, and potential for life course research. Longitudinal and Life Course Studies 2012;3(2):268-284.

(38) Dascola M, Freedman V, Insolera N, Pfeffer F, McGonagle K, Sastry N. PSID Main Interview User Manual: Release 2015. Institute for Social Research, University of Michigan 2015.

(39) Kessler RC, Green JG, Gruber MJ, Sampson NA, Bromet E, Cuitan M, Furukawa TA, Gureje O, Hinkov H, Hu CY, Lara C. Screening for serious mental illness in the general population with the K6 screening scale: results from the WHO World Mental Health (WMH) survey initiative. . International journal of methods in psychiatric research 2010;19(1):4-22.

(40) Pratt LA. Serious psychological distress, as measured by the K6, and mortality. Annals of epidemiology 2009;19(3):202-209.

(41) Forman-Hoffman VL, Muhuri PK, Novak SP, Pemberton MR, Ault KL, Mannix D. Psychological distress and mortality among adults in the US household population. . CBHSQ Data Review: the Center for Behavioral Health Statistics and Quality, SAMHSA 2014.

(42) Baum, C., Schaffer, M. and Stillman, S. IVREG2: stata module for extended instrumental variables/2SLS and GMM estimation. Statistical Software Component, Boston College. 2002.

(43) Finlay, K., Magnusson, L. and Schaffer, M.E. WEAKIV: Stata module to perform weakinstrument-robust tests and confidence intervals for instrumental-variable (IV) estimation of linear, probit and tobit models. . Statistical Software Components 2015.

(44) Smith J. Consequences and predictors of new health events. Analyses in the Economics of Aging, University of Chicago Press 2005:213-240.

(45) Chung Y. Chronic Health Conditions and Economic Outcomes. Unpublished mimeo 2013 http://www.sole-jole.org/14225.pdf. 
(46) Grafova IB. Financial status and chronic conditions onset among non-elderly adults. Review of Economics of the Household 2015;13(1):53-72.

(47) Babiarz P, Widdows R, Yilmazer T. Borrowing to cope with adverse health events: liquidity constraints, insurance coverage, and unsecured debt. . Health economics 2013;22(10):1177-1198.

(48) Social Security Administration. Annual Statistical Report on the Social Security Disability Insurance Program. 2014.

(49) NAMI. State Mental Health Legislation 2015: Trends, Themes \& Effective Practices. 2015.

(50) EU Regional Conference Mental Health in All Policies - Supporting sustainability and growth in Europe. Mental Health in All Policies - A fundamental platform for sustainability and growth for people, communities and economies; May/11-12/2015; 2016.

(51) O'Hara A CE. 2 SECTION 8 MADE SIMPLE: Using The Housing Choice Voucher Program To Assist People With Disabilities. 2003.

(52) Section 811 Supportive Housing for Persons with Disabilities. Available at:

https://portal.hud.gov/hudportal/HUD?src=/program_offices/housing/mfh/progdesc/disab811. Accessed 1/1, 2017.

(53) CMS. The Mental Health Parity and Addiction Equity Act (MHPAEA). Available at: https://www.cms.gov/CCIIO/Programs-and-Initiatives/Other-InsuranceProtections/mhpaea_factsheet.html. Accessed 12/29, 2016.

(54) Soni A. The five most costly conditions, 1996 and 2006: Estimates for the US civilian noninstitutionalized population. American Journal of Psychiatry 2009;168(5):486-494.

(55) Rowan K, McAlpine DD, Blewett LA. Access and cost barriers to mental health care, by insurance status, 1999-2010. Health Affairs 2013;32(10):1723-1730. 


\begin{tabular}{|c|c|c|c|c|}
\hline \multicolumn{5}{|c|}{$\begin{array}{c}\text { Table } 3.1 \\
\begin{array}{c}\text { Weighted Percentages of Selected Characteristics of Working-Age Adults (18-64 Years) } \\
\text { Panel Study of Income Dynamics, 2007-2013, }(\mathrm{N}=4,867)\end{array}\end{array}$} \\
\hline & & 2009 & 2011 & 2013 \\
\hline \multicolumn{5}{|c|}{ Time Invariant Characteristics } \\
\hline Sex & & $(\%)$ & $(\%)$ & $(\%)$ \\
\hline Women & 23.5 & - & - & - \\
\hline Men & 76.5 & - & - & - \\
\hline \multicolumn{5}{|l|}{ Race/ethnicity } \\
\hline White & 71.1 & - & - & - \\
\hline AA & 16.7 & - & - & - \\
\hline Latino & 9.3 & - & - & - \\
\hline Other & 2.9 & - & - & - \\
\hline \multicolumn{5}{|c|}{ Time Varying Characteristics } \\
\hline \multicolumn{5}{|l|}{ Age in years } \\
\hline 18-39 years & 40.0 & 35.4 & 29.9 & 25.2 \\
\hline $40-49$ years & 30.5 & 28.5 & 27.3 & 25.9 \\
\hline 50-64 years & 29.5 & 36.1 & 42.9 & 49.0 \\
\hline \multicolumn{5}{|l|}{ Marital Status } \\
\hline Married & 52.7 & 52.9 & 53.1 & 52.9 \\
\hline Widowed & 1.8 & 1.9 & 1.9 & 2.1 \\
\hline Separated/Divorced & 19.2 & 20.4 & 21.2 & 21.9 \\
\hline Never Married & 26.4 & 24.9 & 23.9 & 23.1 \\
\hline \multicolumn{5}{|l|}{ Education } \\
\hline LE High School & 13.7 & 12.4 & 12.4 & 12.3 \\
\hline High School & 29.9 & 27.7 & 27.7 & 26.6 \\
\hline Some College & 23.9 & 24.8 & 24.8 & 25.2 \\
\hline College, + & 32.6 & 35.1 & 35.1 & 35.9 \\
\hline \multicolumn{5}{|l|}{ Employment Status } \\
\hline Employed & 86.1 & 80.6 & 79.1 & 77.5 \\
\hline Not employed & 13.9 & 19.4 & 20.9 & 22.5 \\
\hline \multicolumn{5}{|l|}{ Smoking Status } \\
\hline Smoker & 23.9 & 22.9 & 21.4 & 19.8 \\
\hline Non-smoker & 76.1 & 77.1 & 78.6 & 80.2 \\
\hline \multicolumn{5}{|l|}{ Alcohol Use } \\
\hline Yes & 69.4 & 70.3 & 71.3 & 69.3 \\
\hline No & 30.6 & 29.7 & 28.7 & 30.7 \\
\hline \multicolumn{5}{|l|}{ Body Mass Index Categories } \\
\hline Under weight & 1.0 & 0.7 & 0.9 & 0.9 \\
\hline Normal & 27.2 & 25.3 & 25.3 & 23.9 \\
\hline Over-weight & 41.5 & 41.0 & 41.4 & 41.8 \\
\hline Obese & 30.3 & 32.9 & 32.5 & 33.4 \\
\hline \multicolumn{5}{|l|}{ Light Physical Activity } \\
\hline GE 3 times/week & 57.6 & 58.0 & 58.0 & 57.7 \\
\hline LT 3 times/week & 42.4 & 42.0 & 42.0 & 42.3 \\
\hline \multicolumn{5}{|l|}{ Heavy Physical Activity } \\
\hline GE 3 times/week & 43.1 & 43.7 & 44.6 & 42.7 \\
\hline LT 3 times/week & 57.0 & 56.3 & 55.5 & 57.3 \\
\hline
\end{tabular}




\section{Table 3.1}

Weighted Percentages of Selected Characteristics of Working-Age Adults (18-64 Years) Panel Study of Income Dynamics, 2007-2013, (N=4,867)

\begin{tabular}{crrrr}
\hline & $\mathbf{2 0 0 7}$ & $\mathbf{2 0 0 9}$ & $\mathbf{2 0 1 1}$ & $\mathbf{2 0 1 3}$ \\
\hline Self-rated Health & & & & \\
Excellent & 22.8 & 18.9 & 16.7 & 16.6 \\
Very Good & 36.9 & 35.9 & 37.5 & 34.7 \\
Good & 27.8 & 31.1 & 29.9 & 31.9 \\
Fair & 9.9 & 11.2 & 12.4 & 12.6 \\
Poor & 2.7 & 2.9 & 3.6 & 4.2 \\
Metro Status & & & & \\
Metro & 76.3 & 76.3 & 76.1 & 75.8 \\
Urban & 20.7 & 20.6 & 20.8 & 21.1 \\
Rural & 3.1 & 3.1 & 3.2 & 3.1 \\
Northeast & & & & 18.0 \\
North central & 18.3 & 18.2 & 18.1 & 26.3 \\
South & 26.5 & 26.3 & 26.2 & 33.5 \\
West & 32.6 & 33.0 & 33.3 & 21.6 \\
Alaska, Hawaii & 21.8 & 21.8 & 21.9 & 0.2 \\
Other & 0.2 & 0.1 & 0.1 & 0.5 \\
\hline
\end{tabular}

Note: Based on 4,867 head of household participants of the Panel Study of Income Dynamics and for whom data were available for all years between 2007 and 2013.

GE: Greater than or equal to; LE: Less than or equal to; LT: Less than. 


\begin{tabular}{|c|c|c|c|c|}
\hline \multicolumn{5}{|c|}{$\begin{array}{c}\text { Table 3.2 } \\
\text { Mean and Standard Errors (SE) of Economic Indicators } \\
\text { Working-Age Adults (18-64 Years) } \\
\text { Panel Study of Income Dynamics, panels 2007-2013, }(\mathrm{N}=4,867) \\
\end{array}$} \\
\hline & 2007 & 2009 & 2011 & 2013 \\
\hline Family Income & $90,691(1,965)$ & $90,215(1,876)$ & $87,688(1,944)$ & $89,977(2,476)$ \\
\hline Ln Family Income & $10.93(0.025)$ & $10.93(0.028)$ & $10.91(0.023)$ & $10.87(0.029)$ \\
\hline Labor Income & $59,177(1,587)$ & $58,599(1,512)$ & $55,354(1,460)$ & $57,091(2,240)$ \\
\hline Ln Labor Income & $9.77(0.06)$ & $9.69(0.063)$ & $9.26(0.071)$ & $9.07(0.076)$ \\
\hline Net Wealth & $323,138(27,704)$ & $281,938(18,548)$ & $269,312(18,406)$ & $280,750(17,700)$ \\
\hline Ln Net Wealth & $9.4(0.09)$ & $8.90(0.09)$ & $8.83(0.09)$ & $9.01(0.09)$ \\
\hline
\end{tabular}

Note: Based on 4,867 head of household participants of the Panel Study of Income Dynamics and for whom data were available for all years between 2007 and 2013. 


\begin{tabular}{|c|c|c|c|c|}
\hline \multicolumn{5}{|c|}{$\begin{array}{c}\text { Table 3.3 } \\
\text { Mental Illness and Psychological Distress Descriptive Statistics } \\
\text { Working-Age Adults (18-64 Years) } \\
\text { Panel Study of Income Dynamics, 2007-2013, (N=4,867) } \\
\end{array}$} \\
\hline & 2007 & 2009 & 2011 & 2013 \\
\hline \multicolumn{5}{|l|}{ Mental Illness (Wt.\%) } \\
\hline Yes & 4.5 & 4.2 & 3.6 & 4.1 \\
\hline No & 95.5 & 95.8 & 96.4 & 95.9 \\
\hline Psychological Distress & 3.219 & 3.366 & 3.182 & 3.165 \\
\hline Score (Wt. Mean, SE) & $(0.076)$ & $(0.075)$ & $(0.074)$ & $(0.076)$ \\
\hline \multicolumn{5}{|c|}{ Psychological Distress by Family Income Quintiles (Wt. Mean, SE) } \\
\hline \multirow{2}{*}{ Quintile 1} & 5.252 & 5.628 & 5.300 & 5.324 \\
\hline & $(0.274)$ & $(0.261)$ & $(0.253)$ & $(0.265)$ \\
\hline \multirow{2}{*}{ Quintile 2} & 3.668 & 3.729 & 3.505 & 3.664 \\
\hline & $(0.188)$ & $(0.185)$ & $(0.181)$ & $(0.185)$ \\
\hline \multirow{2}{*}{ Quintile 3} & 3.254( & 3.170 & 2.879 & 2.810 \\
\hline & $0.158)$ & $(0.139)$ & $(0.147)$ & $(0.143)$ \\
\hline \multirow{2}{*}{ Quintile 4} & 2.494 & 2.721 & 2.681 & 2.469 \\
\hline & $(0.116)$ & $(0.131)$ & $(0.130)$ & $(0.121)$ \\
\hline \multirow{2}{*}{ Quintile 5} & 2.095 & 2.183 & 2.112 & 2.091 \\
\hline & $(0.095)$ & $(0.089)$ & $(0.091)$ & $(0.093)$ \\
\hline \multicolumn{5}{|c|}{ Psychological Distress by Labor Income Quintiles (Wt. Mean, SE) } \\
\hline \multirow{2}{*}{ Quintile 1} & 5.343 & 5.457 & 5.092 & 4.822 \\
\hline & $(0.280)$ & $(0.252)$ & $(0.253)$ & $(0.242)$ \\
\hline \multirow{2}{*}{ Quintile 2} & 3.588 & 3.954 & 3.669 & 3.628 \\
\hline & $(0.172)$ & $(0.185)$ & $(0.180)$ & $(0.198)$ \\
\hline \multirow{2}{*}{ Quintile 3} & 2.867 & 2.927 & 2.806 & 2.948 \\
\hline & $(0.148)$ & $(0.149)$ & $(0.135)$ & $(0.152)$ \\
\hline \multirow{2}{*}{ Quintile 4} & 2.859( & 2.718 & 2.506 & 2.665 \\
\hline & $0.140)$ & $(0.125)$ & $(0.125)$ & $(0.127)$ \\
\hline \multirow{2}{*}{ Quintile 5} & 2.126 & 2.325 & 2.320 & 2.166 \\
\hline & $(0.093)$ & $(0.099)$ & $(0.105)$ & $(0.104)$ \\
\hline \multicolumn{5}{|c|}{ Psychological Distress by Net Wealth Quintiles (Wt. Mean, SE) } \\
\hline \multirow{2}{*}{ Quintile 1} & 4.671 & 4.708 & 4.236 & 4.220 \\
\hline & $(0.235)$ & $(0.212)$ & $(0.205)$ & $(0.224)$ \\
\hline \multirow{2}{*}{ Quintile 2} & 3.941 & 4.370 & 4.306 & 4.222 \\
\hline & $(0.206)$ & $(0.222)$ & $(0.226)$ & $(0.222)$ \\
\hline \multirow{2}{*}{ Quintile 3} & 3.443 & 3.587 & 3.180 & 3.354 \\
\hline & $(0.188)$ & $(0.185)$ & $(0.160)$ & $(0.178)$ \\
\hline \multirow{2}{*}{ Quintile 4} & 2.554 & 2.628 & 2.505 & 2.624 \\
\hline & $(0.129)$ & $(0.132)$ & $(0.127)$ & (0.134) \\
\hline \multirow{2}{*}{ Quintile 5} & 2.245 & 2.316 & 2.277 & 2.094 \\
\hline & $(0.107)$ & $(0.099)$ & $(0.108)$ & $(0.098)$ \\
\hline
\end{tabular}

Note: Based on 4,867 head of household participants of the Panel Study of Income Dynamics and for whom data were available for all years between 2007 and 2013. Wt: weighted 
Table 3.4

Parameter Estimates and Standard Errors of Economic Indicators on Psychological Distress

Working-Age Adults (18-64 Years)

Panel Study of Income Dynamics, 2007-2013, (N=4,867)

OLS

(Adjusted)

\begin{tabular}{lcc} 
& (Adjusted) & (Adjusted) \\
\hline Family Income & & \\
Quintile 1 & Reference & $-2.011^{* * *}$ \\
Quintile 2 & $-1.200^{* * *}$ & $(0.465)$ \\
& $(0.197)$ & $-2.924 * * *$ \\
Quintile 3 & $-1.608^{* * *}$ & $(0.700)$ \\
& $(0.198)$ & $-3.522^{* * *}$ \\
Quintile 4 & $-1.727^{* * *}$ & $(0.942)$ \\
& $(0.197)$ & $-4.445^{* * *}$ \\
Quintile 5 & $-1.849^{* * *}$ & $(1.331)$ \\
Labor Income & $(0.192)$ & \\
Quintile 1 & & $-1.389^{*}$ \\
Quintile 2 & $-0.866^{* * *}$ & $(0.664)$ \\
Quintile 3 & $(0.196)$ & $-2.243 *$ \\
Quintile 4 & $-1.405^{* * *}$ & $(1.030)$ \\
Quintile 5 & $(0.183)$ & -2.565 \\
Net Wealth & $-1.412^{* * *}$ & $(1.393)$ \\
Quintile 1 & $(0.184)$ & -3.122 \\
Quintile 2 & $-1.446^{* * *}$ & $(2.023)$ \\
& $(0.178)$ & \\
Quintile 3 & & \\
Quintile 4 & & $-0.917 * *$ \\
Quintile 5 & -0.300 & $(0.314)$ \\
\hline & $(0.166)$ & $-1.676^{* * *}$ \\
& $-0.701^{* * *}$ & $(0.463)$ \\
& $(0.162)$ & $-2.447 * * *$ \\
& $-1.099^{* * *}$ & $(0.611)$ \\
& $(0.154)$ & $-3.069^{* * *}$ \\
& $-1.056^{* * *}$ & $(0.872)$ \\
\hline
\end{tabular}

IVOLS

(Adjusted)

$$
\begin{gathered}
-2.011 * * * \\
(0.465) \\
-2.924 * * * \\
(0.700) \\
-3.522 * * * \\
(0.942) \\
-4.445 * * *
\end{gathered}
$$

Note: Based on 4,867 head of household participants of the Panel Study of Income Dynamics and for whom data were available for all years between 2007 and 2013.

$* * * \mathrm{p}<.001 ; * * .001 \leq \mathrm{p}<.01 ; * .01 \leq \mathrm{p}<.05$.

IV: Instrumental Variable.

OLS and IV OLS adjusted for age, self-rated health, obesity, smoking status, alcohol use, marital status, number of children under 18 years of age, health insurance, external financial support, and financial liabilities to others. 


\begin{tabular}{|c|c|c|}
\hline \multicolumn{3}{|c|}{$\begin{array}{c}\text { Table } 3.5 \\
\text { Estimated Marginal effects of Economic Indicators on Mental Illness Probabilities } \\
\text { Working-Age Adults (18-64 Years) } \\
\text { Panel Study of Income Dynamics, 2007-2013, }(\mathrm{N}=4,867)\end{array}$} \\
\hline & $\begin{array}{c}\text { Probit } \\
\text { (Adjusted }\end{array}$ & $\begin{array}{l}\text { IV Probit } \\
\text { (Adjusted) }\end{array}$ \\
\hline $\begin{array}{l}\text { Family Income } \\
\text { Quintile } 1\end{array}$ & & \\
\hline Quintile 2 & $\begin{array}{c}-0.020 * * \\
(0.007)\end{array}$ & $\begin{array}{l}-0.081 \\
(0.052)\end{array}$ \\
\hline Quintile 3 & $\begin{array}{c}-0.027 * * * \\
(0.010)\end{array}$ & $\begin{array}{l}-0.105 \\
(0.065)\end{array}$ \\
\hline Quintile 4 & $\begin{array}{c}-0.028 * * * \\
(0.007)\end{array}$ & $\begin{array}{l}-0.113 \\
(0.071)\end{array}$ \\
\hline Quintile 5 & $\begin{array}{c}-0.035 * * * \\
(0.007)\end{array}$ & $\begin{array}{l}-0.125 \\
(0.073)\end{array}$ \\
\hline $\begin{array}{l}\text { Labor Income } \\
\text { Quintile 1 }\end{array}$ & & \\
\hline Quintile 2 & $\begin{array}{c}-0.018 * * \\
(0.006)\end{array}$ & $\begin{array}{l}-0.083 \\
(0.054)\end{array}$ \\
\hline Quintile 3 & $\begin{array}{c}-0.027 * * * \\
(0.006)\end{array}$ & $\begin{array}{l}-0.109 \\
(0.068)\end{array}$ \\
\hline Quintile 4 & $\begin{array}{c}-0.026^{* * * *} \\
(0.006)\end{array}$ & $\begin{array}{l}-0.117 \\
(0.074)\end{array}$ \\
\hline Quintile 5 & $\begin{array}{c}-0.031 * * * * \\
(0.007)\end{array}$ & $\begin{array}{l}-0.128 \\
(0.077)\end{array}$ \\
\hline $\begin{array}{l}\text { Net Wealth } \\
\text { Quintile } 1\end{array}$ & & \\
\hline Quintile 2 & $\begin{array}{l}-0.008 \\
(0.006)\end{array}$ & $\begin{array}{c}-0.196 * * \\
(0.064)\end{array}$ \\
\hline Quintile 3 & $\begin{array}{c}-0.018 * * \\
(0.006)\end{array}$ & $\begin{array}{c}-0.283^{* *} \\
(0.096)\end{array}$ \\
\hline Quintile 4 & $\begin{array}{c}-0.027 * * * \\
(0.007)\end{array}$ & $\begin{array}{c}-0.332 * * \\
(0.115)\end{array}$ \\
\hline Quintile 5 & $\begin{array}{c}-0.028^{* * * *} \\
(0.007)\end{array}$ & $\begin{array}{c}-0.355^{* *} \\
(0.124)\end{array}$ \\
\hline
\end{tabular}

Note: Based on 4,867 head of household participants of the Panel Study of Income Dynamics and for whom data were available for all years between 2007 and 2013.

$* * * \mathrm{p}<.001 ; * * .001 \leq \mathrm{p}<.01 ; * .01 \leq \mathrm{p}<.05$.

IV: Instrumental Variable.

Probit and IV probit adjusted with age, self-rated health, obesity, smoking status, alcohol use, marital status, number of children under 18 years of age, health insurance, external financial support, and financial liabilities to others 
Table 3.6

Changes in Economic Status (Gain and Loss) and Changes in Mental Health (Improvement and Decline)

Working-Age Adults (18-64 Years)

The Panel Study of Income Dynamics, 2007-2013, (N=4,867)

\begin{tabular}{|c|c|c|}
\hline 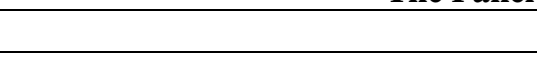 & Mental Illness & Psychological Distress \\
\hline \multicolumn{3}{|c|}{ Gain in Economic Status and Improvement in Mental Health } \\
\hline & $\begin{array}{c}\text { FD } \\
\text { (Adjusted) }\end{array}$ & $\begin{array}{c}\text { FD } \\
\text { (Adjusted) }\end{array}$ \\
\hline Change in Family Income Quintile & $\begin{array}{l}-0.005 \\
(0.004)\end{array}$ & $\begin{array}{c}0.008 \\
(0.014)\end{array}$ \\
\hline Change in Labor Income Quintile & $\begin{array}{l}-0.007 \\
(0.004)\end{array}$ & $\begin{array}{l}0.0353^{*} \\
(0.0137)\end{array}$ \\
\hline Change in Net Wealth Quintile & $\begin{array}{c}0.005 \\
(0.005)\end{array}$ & $\begin{array}{l}0.0352 * * \\
(0.0136)\end{array}$ \\
\hline \multicolumn{3}{|c|}{ Loss in Economic Status and Decline in Mental Health } \\
\hline & $\begin{array}{c}\text { FD } \\
\text { (Adjusted) }\end{array}$ & $\begin{array}{c}\text { FD } \\
\text { (Adjusted) }\end{array}$ \\
\hline Change in Family Income Quintile & $\begin{array}{c}0.001 \\
(0.004)\end{array}$ & $\begin{array}{l}0.028^{*} \\
(0.014)\end{array}$ \\
\hline Change in Labor Income Quintile & $\begin{array}{l}0.012 * \\
(0.005)\end{array}$ & $\begin{array}{l}0.045^{* * *} \\
(0.014)\end{array}$ \\
\hline Change in Net Wealth Quintile & $\begin{array}{c}0.015^{* *} \\
(0.005) \\
\end{array}$ & $\begin{array}{l}0.030^{*} \\
(0.014) \\
\end{array}$ \\
\hline
\end{tabular}

Note: Based on 4,867 head of household participants of the Panel Study of Income Dynamics and for whom data were available for all years between 2007 and 2013.

$* * * \mathrm{p}<.001 ; * * .001 \leq \mathrm{p}<.01 ; * .01 \leq \mathrm{p}<.05$.

Decline in mental health: 1) Mental illness onset: A binary indicator variable with the value of 1 representing mental illness onset and zero representing no change in mental illness or recovery. 2) Increase in psychological distress: A binary indicator variable with the value of 1 representing an increase in psychological distress scores from one wave to the next and zero representing no change or decreases in psychological distress scores from one wave to the next.

Mental health Improvement: 1) Mental illness recovery: A binary indicator variable with the value of 1 representing recovery from mental illness and zero representing no change in the mental illness status or onset of mental illness. 2) Decrease in psychological distress: A binary indicator variable with the value of 1 representing decline in psychological distress scores from one wave to the next and zero representing no change or increase in psychological distress scores from one wave to the next.

Economic Gain: The transition from lower quintile to upper quintile.

Economic Loss: The transition from upper quintile to lower quintile.

In FD model, the outcome is mental health improvement (or decline) and the key endogenous variable is economic gain (or loss). FD adjusted for one-period changes in age, self-rated health, obesity, smoking status, alcohol use, marital status, number of children under 18 years of age, health insurance, external financial support, and financial liabilities to others. 
Table 3.7

Changes in Mental Health (Decline or Improvement) and Changes in Economic Status (Gain or Loss)

Working-Age Adults (18-64 Years)

The Panel Study of Income Dynamics, 2007-2013, $(N=4,867)$

\begin{tabular}{|c|c|c|c|}
\hline & Family Income & Labor Income & Net Wealth \\
\hline \multicolumn{4}{|c|}{ Improvement in Mental Health and Gain in Economic Status } \\
\hline & -0.029 & -0.044 & 0.035 \\
\hline Mental Illness & $(0.025)$ & $(0.023)$ & $(0.030)$ \\
\hline Psychological & 0.005 & $0.023^{*}$ & $0.025^{* *}$ \\
\hline Distress & $(0.009)$ & $(0.009)$ & $(0.009)$ \\
\hline \multicolumn{4}{|c|}{ Decline in Mental Health and Loss in Economic Status } \\
\hline & 0.009 & $0.073^{*}$ & $0.097 * *$ \\
\hline Mental Illness & $(0.029)$ & $(0.031)$ & $(0.032)$ \\
\hline Psychological & $0.018^{*}$ & $0.029 * *$ & $0.020^{*}$ \\
\hline Distress & $(0.009)$ & $(0.009)$ & $(0.009)$ \\
\hline
\end{tabular}

Note: Based on 4,867 head of household participants of the Panel Study of Income Dynamics and for whom data were available for all years between 2007 and 2013.

$* * * \mathrm{p}<.001 ; * * .001 \leq \mathrm{p}<.01 ; * .01 \leq \mathrm{p}<.05$.

Decline in mental health: 1) Mental illness onset: A binary indicator variable with the value of 1 representing mental illness onset and zero representing no change in mental illness or recovery. 2) Increase in psychological distress: A binary indicator variable with the value of 1 representing an increase in psychological distress scores from one wave to the next and zero representing no change or decreases in psychological distress scores from one wave to the next.

Mental health Improvement: 1) Mental illness recovery: A binary indicator variable with the value of 1 representing recovery from mental illness and zero representing no change in the mental illness status or onset of mental illness. 2) Decrease in psychological distress: A binary indicator variable with the value of 1 representing decline in psychological distress scores from one wave to the next and zero representing no change or increase in psychological distress scores from one wave to the next.

Economic Gain: The transition from lower quintile to upper quintile.

Economic Loss: The transition from upper quintile to lower quintile.

In FD model, the outcome is economic gain (or loss) and the key endogenous variable is mental health improvement (or decline). FD adjusted for one-period changes in age, self-rated health, obesity, smoking status, alcohol use, marital status, number of children under 18 years of age, health insurance, external financial support, and financial liabilities to others. 


\section{Chapter 4 \\ Heterogeneous relationships between Labor Income and Health by Race/Ethnicity}

ABSTRACT

We examined the race-stratified relationships between labor income and measures of physical and mental health by following working-age adults up to 14 years using longitudinal data from the Panel study of Income Dynamics (PSID). System-Generalized Method of Moment and heteroscedasticity-based instrument regressions were used to examine the relationships between labor income and physical and mental health measures respectively. First-difference and lagged fixed effects models were used to examine the effect of loss in income on physical and mental health. We found that adults in higher labor income quartiles had better self-rated health (SRH) than those in the lowest quartile regardless of racial group. However, the relationship between labor income and psychological distress varied by race group; whites and African Americans in higher labor income quartiles had lower psychological distress scores than their counterparts in the lowest quartile. This was not the case with Hispanics. Reductions in labor income were associated with increases in psychological distress among whites only. These findings suggest heterogeneous relationships between labor income and physical and mental health across racial groups. Our results highlight the need for policies to provide safety nets for adults who experience a decline in income to prevent further deterioration in health. Our results also suggest that economic stability plays an important role in an individuals' physical and mental health. 


\section{INTRODUCTION}

The relationship between economic status and health has been documented in the previous literature (1-12). Economic, sociological and epidemiological studies have indicated that higher economic status is associated with better physical $(1-4,8,9)$ and mental health $(10-12)$.

Specifically, family and labor income and net wealth were found to be positively associated with physical health (self-rated health and functioning) $(1,4,9,13)$ and negatively associated with psychological distress and disorders $(10-12,14)$. Findings from some studies suggest the relationship between economic status and health may vary by age, sex and race $(8,9,15)$. However, investigations regarding the potential relationships between economic status and health within racial groups in the United States (US) are scarce. Understanding how the relation between health and economic well-being may vary by racial/ethnic group is essential for effective policy development and program planning, and may ultimately help better address disparities in both health and economic status in the US.

There are well-documented differences in financial capital, health capital and human capital among races in the US (16-19) because of the long history of racial discrimination, differential effect of poverty on health between whites and racial minorities (16-19). Certain racial/ethnic minorities, including African Americans and Hispanics, have low levels of human capital (education), health capital (poor health) and financial capital (economic resources) as compared to Non-Hispanic whites (16-19). In general, the limited financial capital can lead to poor health. However, the relationship between economic status and health outcomes within racial groups is inconsistent. For example, there is some evidence that the association of low income to chronic conditions is stronger among non-Hispanic white adults than among other racial/ethnic groups (20). Furthermore, Hispanics with low income generally report better mental and physical health 
than expected, which is referred to as the "Hispanic paradox" (21-23). Similarly, African Americans report better mental health than non-Hispanic whites in the same economic strata (24), often referred to as the "racial paradox of mental health". Several cross-sectional studies has reported differences in the relationships between economic indicators and health across different racial groups $(11,15,25,26)$. A large, population-based cross-sectional study in the US observed a strong association between income and health among white and African American adults but a weak relationship among Hispanics (26). Pollack et al. used two cross-sectional samples from the Survey of Consumer Finances (25-64 years) and the Health and Retirement Survey (50 years and older) to assess the relationship between net wealth and self-rated health (15). Pollack et al. reported that higher net wealth was associated with better health among African Americans and whites, no such relationship was observed among Hispanics (15). However, longitudinal studies are lacking, and to our knowledge, no systematic and rigorous investigation of the potential racial/ethnic variation in the relationship between economic indicators and health has yet been conducted. To help address this gap, the current study evaluates the relationship between labor income and two measures of physical and mental health, with analyses stratified by racial/ethnic groups. We also examine the effects of loss in labor income on mental and physical health by race/ethnicity. Because labor income is more sensitive to economic shocks (e.g. great recession of 2007-2009) (27), the current study focuses on labor income among working-age adults (18-64 years).

\section{CONCEPTUAL FRAMEWORK}

Various economic frameworks and psychosocial theories have been proposed to explain the link between economic status and health. From a health economics point of view, all individuals are born with a fixed health capital stock (health capital), which declines with age 
because of biological processes (28). According to Grossman, the health of an individual can be improved by investing in education (human capital) because educated individuals are more likely to improve their healthcare (29). Grossman further posits that individuals with lower human and financial capital may be more likely to suffer earlier and more rapid declines in health, and to have poorer health at any given point in time than those with higher human and financial capital. In the field of sociology, social causation and social selection have been proposed to explain the link between economic status and health (30). Social causation theory assumes that economic status is a causal determinant of health, positing that experiencing an economic shock increases the risk of health decline (30). On the other hand, social selection theory assumes that health is a causal determinant of economic status, positing that environmental and genetic factors contribute to the health decline, which, in turn, leads to a decrease in economic resources (30). In the current study, we investigate economic status as a potential causal determinant of health.

\section{METHODS}

Data Sources: PSID: The PSID is a longitudinal study of US population which started in 1968 with a national probability sample of US families (31-33). Currently, the individuals in any panel come from one of three sources: the original 1968 sample; the 1997 refresher sample of post-1968 immigrants; and births and marriages in existing families (31-33). In this study, both family and cross-year individual files were combined to derive information on households. The PSID has been including questions regarding self-rated health since 1984 and diagnosed chronic health conditions since 1999. Additional items regarding information on psychological distress and specific psychological illnesses were added beginning in 2005 .

Study Design: The study utilized a retrospective observational longitudinal design with repeated measures of labor income and health measures. To examine the relationship between 
labor income and self-rated health, a sample of heads of households was followed for a period of 14 years (1991-2013) using eight waves of the PSID. Further, another sample of household heads was followed for a period of 6 years (2007-2013) using 4 waves of the PSID to examine the relationship between labor income and psychological distress.

Study Sample: Two samples were used for the purpose of the current study. The first sample comprised heads of households who participated in all the 8 waves of the PSID from 1999 through 2013 and who were aged between 18-50 years in $1999(\mathrm{~N}=2,693)$. These waves were selected due to the availability of information on self-rated health and chronic conditions. The second sample comprised heads of households who participated in all the 4 waves of the PSID from 2007 through 2013 and who were aged between 18-58 years in $2007(\mathrm{~N}=4,867)$. We selected the 4 waves because psychological distress and mental health measures were continuously available only in these four waves.

\section{Measures}

\section{Health Measures:}

Self-rated health (SRH): PSID queried each respondent regarding their perceived health (“would you say your health in general is excellent, very good, good, fair, or poor?") The responses to the question were scored on a scale of 1 to 5 , with higher scores representing better health $(5=$ excellent, $4=$ very good, $3=$ good, $2=$ fair, and $1=$ poor $)$. Ware and colleagues transformed the SRH to a 0-100 scale using a linear relationship between item scores and the underlying health concept (34).

Psychological Distress: Psychological distress was measured using the Kessler-6 NonSpecific Psychological Distress Scale (35); this scale includes 6 items: "In the past 30 days, about how often did you feel: (1) so sad nothing could cheer you up? (2) nervous? (3) restless or 
fidgety? (4) hopeless? (5) that everything was an effort? (6) worthless?" Responses to these six questions are scored on a scale of 1 to 5 as follows $5=$ all of the time, $4=$ most of the time, $3=$ some of the time, $2=\mathrm{a}$ little of the time, and $1=$ none of the time. In the current study, the summary score from the Kessler-6 scale was used to measure psychological distress.

Change in Health Measures: $\underline{\text { SRH: }}$ a) Increases in SRH: A binary indicator variable with the value of 1 representing improvements in SRH from one wave to the next and zero representing no change or a decline in SRH scores from one wave to the next. b) Decreases in SRH: A binary indicator variable with the value of 1 representing declines in SRH from one wave to the next and zero representing no change in SRH or an increase in SRH scores from one wave to the next. Psychological distress: a) Increases in psychological distress: A binary indicator variable with the value of 1 representing increases in psychological distress scores from one wave to the next and zero representing no change or declines in psychological distress scores from one wave to the next. b) Decreases in psychological distress: A binary indicator variable with the value of 1 representing improvements in mental health (i.e. a decline in psychological distress scores from one wave to the next) and zero representing no change or increases in psychological distress scores from one wave to the next.

Labor Income: We measured labor income of the head of the household. Labor income included all money earned from wages and salaries, bonuses, overtime, tips, commissions, professional practice or any job-related income including farm or business income. In the current study, we categorized labor income into quartiles based on the distribution of this variable in each wave.

Other Exogenous Explanatory variables: included demographic, lifestyle, and other factors shown in prior studies to be associated with mental and physical health (36-38). For each 
head of the household, we measured the following health practices variables in each wave: number of chronic conditions categories (no condition, one condition, $>=2$ chronic conditions); body mass index (BMI) $(\mathrm{kg} / \mathrm{m} 2)$ (underweight [<18.5], normal [18.5 - 24.9], overweight [25.0 29.9], or obese [ $\geq 30.0]$ ); smoking status (smoker, not a smoker); and alcohol use (user, nonuser). Also considered in the analyses were other factors potentially affecting economic status including age, marital status (married, widowed, separated or divorced, and never married), number of children under 18 years of age, health insurance, external financial support, and financial liabilities to others.

\section{STATISTICAL ANALYSES}

Arellano-Bond generalized method of moments (GMM) estimator (39): Under the Arellano and Bond approach, lags of SRH are used as instruments to address the endogeneity between economic indicators and SRH. Nevertheless, weak instruments problem may occur in the Arellano-Bond approach because lagged values of the endogenous variables may be weakly correlated with the regressors in the first-difference model. Thus, Blundell and Bond proposed a system-GMM estimator (40). System-GMM estimator uses lagged differences as instruments for the level model and lagged levels as instruments for the first-difference model. Economic status is considered as a predetermined variable and all the feasible lags of economic status and health measures ( $\mathrm{t}-1$ and thereafter) are used as instrumental variables. However, we found that using only four lags of health measures as IVs increased the efficiency of the models (Based on the second order autocorrelation test and the Hansen J statistics on overidentifying restrictions). Further, we found that adjusting for three SRH lags increases the efficiency of system-GMM models. We also applied finite sample correction to the robust two-step covariance matrix 
calculated for system-GMM estimator to reduce over-identification caused by too many IVs (41).

Lewbel (2012) estimator using heteroskedastic errors as valid instruments $(42,43)$ : The main advantage of this technique is its ability to produce valid estimators where external instruments are unavailable or potentially weak. Due to the absence of suitable instruments, we used the Lewbel $(42,43)$ method to examine the association between labor income and psychological distress. This method generates external instruments which are associated with the endogenous variable, but not with the exogenous variables.

\section{The effect of economic loss on health decline and economic gain on health} improvement: First-difference and Lagged-fixed effect estimators were used to examine the dynamic relationships between economic loss and decline in health as well as economic gain and health improvement. All analyses were weighted using 2013 longitudinal weights provided by the PSID.

\section{RESULTS}

\section{Characteristics of the study samples:}

The first sample including data from waves 1999 to 2013 was used to examine the relationship between labor income and SRH. The sample consisted of 2,693 heads of households, who were between age 18 and 50 in 1999. Table 4.1 displays the weighted percentages of selected characteristics of the first sample in 1999. Participants were predominantly men (81.5\%) and non-Hispanic white (75.1\%); $13.2 \%$ of participants were African Americans and 7.8\% were Hispanics. Education level showed considerable variation by race/ethnicity, with $36.9 \%$ of nonHispanic white adults indicated a college degree vs. 15.4\% of African American and $11.1 \%$ of Hispanic participants. 
Data from the second sample (waves 2007 to 2013) were used to examine the relationship between labor income and psychological distress scores. Table 4.2 presents the weighted percentages of selected characteristics of the second sample in 2007. The sample comprised 4,867 heads of households aged 18 to 58 as of 2007. Again, participants in this sample were predominantly men $(76.5 \%)$ and non-Hispanic white (77.1\%). Seventeen percent were African Americans and 9.3\% were Hispanics. The vast majority of whites (72.6\%), African Americans (83.3\%) and Hispanics $(87.7 \%)$ lived in a metropolitan area.

\section{Labor income and health measures over time:}

Figure 4.1 presents the means of labor income of the heads of households by race and quartiles across the waves. White adults in the highest quartile had more averages values than African Americans and Hispanics in the highest quartile across the waves. Whites, African Americans and Hispanics in labor income quartiles 2, 3 and 4 had comparable averages values across the waves. There were fluctuations in the averages values across the waves for all racial groups. Figure 4.2 displays the means of SRH and psychological distress by race across the waves. Non-Hispanic white adults averaged higher SRH scores than did African Americans and Hispanics across all waves, although, mean SRH deteriorated over time in all racial/ethnic groups. White and African American adults averaged greater psychological distress than did Hispanic participants, although, psychological distress scores increased over time in the latter group.

\section{The relationship between labor income and SRH by race:}

Table 4.3 presents the parameter estimates and standard errors of labor income on SRH

from system-GMM by race. In system-GMM, there was a significant relationship between labor 
income quartiles and SRH across the racial groups. White adults in labor income quartiles $2(\hat{\beta}=$ 4.869, $\mathrm{p}<0.001), 3(\hat{\beta}=3.541, \mathrm{p}<0.001)$ and $4(\hat{\beta}=4.120, \mathrm{p}<0.001)$ had significantly better SRH than white adults in the lowest quartile. Similarly, African Americans in labor income quartiles $2(\hat{\beta}=3.687, \mathrm{p}<0.001), 3(\hat{\beta}=4.499, \mathrm{p}<0.001)$ and $4(\hat{\beta}=4.089, \mathrm{p}<0.001)$ had significantly better SRH than those in the lowest quartile. Hispanics in labor income quartiles 2 $(\hat{\beta}=6.306, \mathrm{p}<0.001), 3(\hat{\beta}=4.145, \mathrm{p}<0.01)$ and $4(\hat{\beta}=8.283, \mathrm{p}<0.001)$ had significantly better SRH than those in the lowest quartile.

\section{The relationship between labor income and psychological distress scores by race:}

Table 4.3 displays the parameter estimates and standard errors of labor income psychological distress scores from adjusted heteroscedasticity-based instruments regressions. After adjustment for the endogeneity, white adults in labor income quartiles $2(\hat{\beta}=-1.494, \mathrm{p}<$ $0.001), 3(\hat{\beta}=-1.457, \mathrm{p}<0.001)$ and $4(\hat{\beta}=-1.646, \mathrm{p}<0.01)$ had significantly lower scores than those in the lowest quartile. Similarly, African American adults in labor income quartiles 2 ( $\hat{\beta}=$ $1.708, \mathrm{p}<0.01), 3(\hat{\beta}=-2.538, \mathrm{p}<0.001)$ and $4(\hat{\beta}=-2.604, \mathrm{p}<0.001)$ had significantly lower psychological distress scores than those in the lowest quartile. Conversely, there was no relationship between labor income quartiles and psychological distress scores among Hispanics.

\section{Changes in labor income and changes in SRH by race:}

Increases in labor income and SRH by race:_Increases in labor income were not associated with SRH improvement among Non-Hispanic white, African American or Hispanic participants in adjusted FD analyses. Loss in labor income and SRH by race: In the adjusted FD analyses, the transition from a higher labor income quartile to a lower was associated with a 3.4 percentage point increase in the probability of SRH improvement among whites. Similarly, the transition 
from a higher labor income quartile to a lower had a negative impact on SRH among white $(\hat{\beta}=-$ 1.394, $\mathrm{p}<0.05)$ and African American adults $(\hat{\beta}=-4.542, \mathrm{p}<0.05)$.

Changes in labor income and changes in psychological distress scores by race:

Increases in labor income and psychological distress decreases by race:_Adjusted FD analyses revealed that gains in labor income were associated with a significantly with a 4.5 percentage point increase in the probability of mental health improvement (as measured by decline in psychological distress scores) among whites, but not African American or Hispanic adults (Table 4.4). Conversely, lagged fixed effects analyses indicated no association between increases in labor income and psychological distress scores. Loss in labor income and psychological distress increases by race: In the adjusted FD analyses, the transition from an upper labor income quartile to a lower quartile was associated with a 4.3 percentage point increase in the probability of increases in psychological distress scores among white adults. In lagged fixed effects analyses, the transition from an upper labor income quartile to a lower quartile was associated with increases in psychological distress scores $(\hat{\beta}=0.455, \mathrm{p}<0.01)$ among white adults.

\section{DISCUSSION}

We examined the relationships between labor income and two measures of health, stratified by race. Findings of this study suggest that labor income is strongly and positively associated with SRH in both white and African American adults. In these two racial groups, those who experienced a decline in labor income was significantly associated with a decline in SRH. This strong relationship between low labor income and ill health indicate that economic stability may play an important role in individual health. 
Collectively, the findings of this study support a need for policies that provide safety nets for adults experiencing income loss in order to prevent further deterioration in health. Our results also highlight the need for initiatives that improve individual health by incorporating health considerations into decision-making across all policy areas, referred to as "Health in All Policies" (44). Health in All Policies was developed by the public health facilitators of the California Health in All Policies Task Force (44). Under this approach re-shaping individuals' economic, physical, social, and service environments can help improving health (44). Our results revealed also that the economic stability plays an important role in individuals' health. Our results revealed a strong relationship between low labor income and ill health. However, the studies on the effect of income supplementation and state funded welfare programs are limited $(45,46)$. Clearly, further research on the effect of income supplementation programs on health outcome is warranted.

Among Hispanic participants, we found a significant positive relationship between labor income and SRH. However, Hispanics who experienced a decline in income did not show a corresponding decline in SRH. We also found that there was no relationship between labor income and psychological distress and no relationship between change in labor income and change in mental health among Hispanics. These findings may in part reflect baseline differences in overall mental health. In this study, Hispanic adults had lower psychological distress scores than whites or African Americans at all time points. Collectively, our results suggest the relationships of labor income to both physical and mental health are heterogeneous across racial/ethnic groups.

Although we did not control for social capital factors such as network of friends and families and religious affiliations, our findings appear consistent with prior literature supporting 
the "Hispanic Health Paradox". The Hispanic health paradox refers to the repeatedly documented observation that Hispanics living in the US have better health than expected given their high prevalence of poverty, poor education and lack of access to healthcare (47). For example, although Hispanics were more likely to have lower education and income than whites (47). A study by Dominguez et al. using four national data sets revealed that Hispanic adults have lower all-cause death rate and lower death rates for nine of the 15 leading causes of death in the US, although, they were more likely to have lower income and be more poorly educated than white adults (44). This apparent paradox may in part reflect certain protective factors characterizing Hispanic communities. For example, foreign-born immigrants are reported to have better mental health due to social support and family ties (23).

After adjustment for the endogeneity between labor income and psychological distress, we observed that whites who experienced a decline in labor income also experienced a decline in mental health. This was not the case with African Americans. These findings may be indicative of the "race mental health paradox". Race mental health paradox refers to the paradoxical observation of better mental health outcomes among African Americans compared to whites (24) despite being at high risk due to exposure to violence, poor educational outcomes, persistent poverty and discrimination (48). Again, this paradox may reflect certain protective factors typifying black communities, including higher social capital and better developed social networks (48).

The current study has several strengths, including the prospective, population-based design and relatively large sample size. To our knowledge, the current study is the first longitudinal study to examine the relationship between change in labor income and change in health status, and the first to investigate the potential variation in these relationships by race/ethnicity. The present 
study is also the first to investigate the effect of loss in labor income on SRH and psychological distress. We also employed a rigorous novel econometric approaches to address the endogeneity between labor income and health measures. In this study, we were able to control for multiple potential confounders, including demographic, socioeconomic, lifestyle, and health-related factors.

However, this investigation also has some limitations. First, our analyses were restricted to heads of households. Thus, our estimates may not be generalizable to other demographic groups under-represented in this sample, including married women. Second, we did not include time-invariant factors such as sex because inclusion of these factors contradict the specifications of the dynamic panel models. Third, neither SRH nor psychological distress can capture all domains of physical and mental health.

\section{CONCLUSION}

Findings of this cohort study suggest relationships between labor income and physical and mental health are heterogeneous across racial/ethnic groups. Additional rigorous prospective studies are needed to confirm these findings and to further investigate the effects of the social factors. Our results highlight the need for policies to provide safety nets for adults who experience a decline in income to prevent further deterioration in health. Our results also revealed that economic stability plays an important role in individuals' health. 


\section{REFERENCES}

(1) Fiscella K, Franks P. Individual income, income inequality, health, and mortality: what are the relationships? Health services research 2000;35(1 pt2):307-318.

(2) McDonough P, Berglund P. Histories of poverty and self-rated health trajectories. Journal of Health and Social Behavior 2003;44(2):198-214.

(3) Meer J, Miller DL, Rosen HS. Exploring the health-wealth nexus. . Journal of health economics 2003;22(5):713-730.

(4) Berry B. Does money buy better health? Unpacking the income to health association after midlife. Health(London) 2007;11(2):199-226.

(5) Hajat A, Kaufman JS, Rose KM, Siddiqi A, Thomas JC. Long-term effects of wealth on mortality and self-rated health status. American Journal of Epidemiology 2011;173(2):192-200.

(6) Hajat A, Kaufman JS, Rose KM, Siddiqi A, Thomas JC. Do the wealthy have a health advantage? Cardiovascular disease risk factors and wealth. Social Science and Medicine 2010;71(11):1935-1942.

(7) Golberstein E. The effects of income on mental health: evidence from the social security notch. The journal of mental health policy and economics 2015;18(1):27-37.

(8) Michaud PC, van Soest A. Health and wealth of elderly couples: causality tests using dynamic panel data models. Journal of Health Economics 2008;27(5):1312-1325.

(9) Halliday TJ. Earnings Growth and Movements in Self-Reported Health. Review of Income and Wealth 2016.

(10) Sareen J, Afifi TO, McMillan KA, Asmundson GJ. Relationship between household income and mental disorders: findings from a population-based longitudinal study. Archives of General Psychiatry 2011;68(4):419-427.

(11) McMillan KA, Enns MW, Asmundson GJ, Sareen J. The association between income and distress, mental disorders, and suicidal ideation and attempts: findings from the collaborative psychiatric epidemiology surveys. . The Journal of clinical psychiatry 2010;71(9):1168-1175.

(12) Yilmazer T, Babiarz P, Liu F. The impact of diminished housing wealth on health in the United States: Evidence from the Great Recession. Social science \& medicine 2015;130:234241.

(13) Meraya AM, Dwibedi N, Tan X, Innes K, Mitra S, Sambamoorthi U. The Dynamic Relationships between Economic Indicators and Physical Health Measures among Working-Age Adults in the United States. 2016.

(14) Meraya AM, Dwibedi N, Mitra S, Tan X, Innes K, Sambamoorthi U. The Dynamics of Economic status and Mental Health among Working-Age Adults in the United States. 2016.

(15) Pollack CE, Cubbin C, Sania A, Hayward M, Vallone D, Flaherty B, Braveman PA. Do wealth disparities contribute to health disparities within racial/ethnic groups? Journal of epidemiology and community health 2013;67(5):439-445. 
(16) Shapiro TM, Meschede T, Sullivan L. The racial wealth gap increases fourfold. Waltham, MA: Institute on Assets and Social Policy, Brandeis University 2010.

(17) Orsi JM, Margellos-Anast H, Whitman S. Black-White health disparities in the United States and Chicago: a 15-year progress analysis. . American Journal of Public Health 2010;100(2):349-356.

(18) Taylor P, Kochhar R, Fry R, Velasco G, Motel S. Wealth gaps rise to record highs between Whites, Blacks and Hispanics. . Pew Research Center; Washington, DC 2011 http://www.pewsocialtrends.org/2011/07/26/wealth-gaps-rise-to-record-highs-between-whitesblacks-hispanics/.

(19) Musu-Gillette L, Robinson J, McFarland J, KewalRamani, A, Zhang A, Wilkinson-Flicker S. Status and Trends in the Education of Racial and Ethnic Groups 2016 (NCES 2016-007). U S Department of Education, National Center for Education Statistics Washington, DC 2016.

(20) Crimmins EM, Hayward MD, Seeman TE. Race/ethnicity, socioeconomic status, and health. . In: Anderson NB, Bulatao RA, Cohen B., editor. Race/Ethnicity, Socioeconomic Status, and Health. Washington (DC): National Academies Press (US); 2004. p. 310-352.

(21) Abraido-Lanza AF, Dohrenwend BP, Ng-Mak DS, Turner JB. The Latino mortality paradox: a test of the" salmon bias" and healthy migrant hypotheses. American journal of public health 1999;89(10):1543-1548.

(22) Hummer RA, Powers DA, Pullum SG, Gossman GL, Frisbie WP. Paradox found (again): infant mortality among the Mexican-origin population in the United States. . Demography 2007;44(3):441-457.

(23) Viruell-Fuentes EA AF. Testing Immigrant Social Ties Explanations for Latino Health Paradoxes: The Case of Social Support and Depression Symptoms. Journal of Latino/Latin American Studies 2016;8(1):77-92.

(24) Barnes DM, Keyes KM, Bates LM. Racial differences in depression in the United States: how do subgroup analyses inform a paradox? Social psychiatry and psychiatric epidemiology 2013;48(12):1941-1949.

(25) Shea DG, Miles T, Hayward M. The health-wealth connection: Racial differences. The Gerontologist 1996;36(3):342-349.

(26) Braveman PA, Cubbin C, Egerter S, Williams DR, Pamuk E. Socioeconomic disparities in health in the United States: what the patterns tell us. American journal of public health 2010;100(S1):S186-S196.

(27) Tomaskovic-Devey D, Lin KH. Income dynamics, economic rents, and the financialization of the US economy. American Sociological Review 2011;76(4):538-559.

(28) Case A, Deaton A. Broken down by work and sex: How our health declines. Analyses in the Economics of Aging, University of Chicago Press. 2005:185-212.

(29) Grossman M. On the concept of health capital and the demand for health. . Journal of Political economy 1972;80(2):223-255. 
(30) Warren JR. Socioeconomic status and health across the life course: a test of the social causation and health selection hypotheses. Social Forces 2009;87(4):1-25.

(31) McGonagle KA, Schoeni RF. The Panel Study of Income Dynamics: Overview and summary of scientific contributions after nearly 40 years. . Survey Research Center - Institute for Social Research University of Michigan 2006;06-01.

(32) McGonagle KA, Schoeni RF, Sastry N, Freedman VA. The Panel Study of Income Dynamics: overview, recent innovations, and potential for life course research. Longitudinal and Life Course Studies 2012;3(2):268-284.

(33) Dascola M, Freedman V, Insolera N, Pfeffer F, McGonagle K, Sastry N. PSID Main Interview User Manual: Release 2015. Institute for Social Research, University of Michigan 2015.

(34) Ware J Jr, Snow KK, Kosinski M, Gandek B. SF-36 Health Survey manual and interpretation guide. . The Health Institute, New England Medical Center 1993.

(35) Kessler RC, Green JG, Gruber MJ, Sampson NA, Bromet E, Cuitan M, Furukawa TA, Gureje O, Hinkov H, Hu CY, Lara C. Screening for serious mental illness in the general population with the K6 screening scale: results from the WHO World Mental Health (WMH) survey initiative. . International journal of methods in psychiatric research 2010;19(1):4-22.

(36) Chaney EH, Chaney JD, Wang MQ, Eddy JM. Lifestyle behaviors and mental health of American adults. Psychological reports 2007;100(1):294-302.

(37) Scott KM, Bruffaerts R, Simon GE, Alonso J, Angermeyer M, de Girolamo G,

Demyttenaere K, Gasquet I, Haro JM, Karam E, Kessler RC. Obesity and mental disorders in the general population: results from the world mental health surveys. . International journal of obesity 2008;32(1):192-200.

(38) Velten J, Lavallee KL, Scholten S, Meyer AH, Zhang XC, Schneider S, Margraf J. Lifestyle choices and mental health: a representative population survey. BMC psychology 2014;2(1).

(39) Arellano M, Bond S. Some tests of specification for panel data: Monte Carlo evidence and an application to employment equations. The review of economic studies 1991;58(2):277-297.

(40) Blundell R, Bond S. Initial conditions and moment restrictions in dynamic panel data models. Journal of Econometrics 1998;87(1):115-143.

(41) Roodman D. How to do xtabond2: An introduction to difference and system GMM in Stata. The Stata Journal 2009;9(1):86-136.

(42) Lewbel A. Using heteroscedasticity to identify and estimate mismeasured and endogenous regressor models. Journal of Business \& Economic Statistics 2012.

(43) Baum CF, Schaffer M. IVREG2H: Stata module to perform instrumental variables estimation using heteroskedasticity-based instruments. 20152015.

(44) Rudolph L, Caplan J, Ben-Moshe K, Dillon L. Health in All Policies: A Guide for State and Local Governments. American Public Health Association and Public Health Institute 2013. 
(45) Connor J, Rodgers A, Priest P. Randomised studies of income supplementation: a lost opportunity to assess health outcomes. Journal of Epidemiology and Community Health 1999;53(11):725-730.

(46) Adams J, White M, Moffatt S, Howel D, Mackintosh J. A systematic review of the health, social and financial impacts of welfare rights advice delivered in healthcare settings. BMC Public Health 2006;6(81).

(47) Dominguez K, Penman-Aguilar A, Chang MH, Moonesinghe R, Castellanos T, RodriguezLainz A, Schieber R. Vital signs: leading causes of death, prevalence of diseases and risk factors, and use of health services among Hispanics in the United States-2009-2013. . Morbidity and Mortality Weekly Report 2015;64(17):469-478.

(48) Keyes CL. The Black-White paradox in health: Flourishing in the face of social inequality and discrimination. Journal of personality 2009;77(6):1677-1706. 


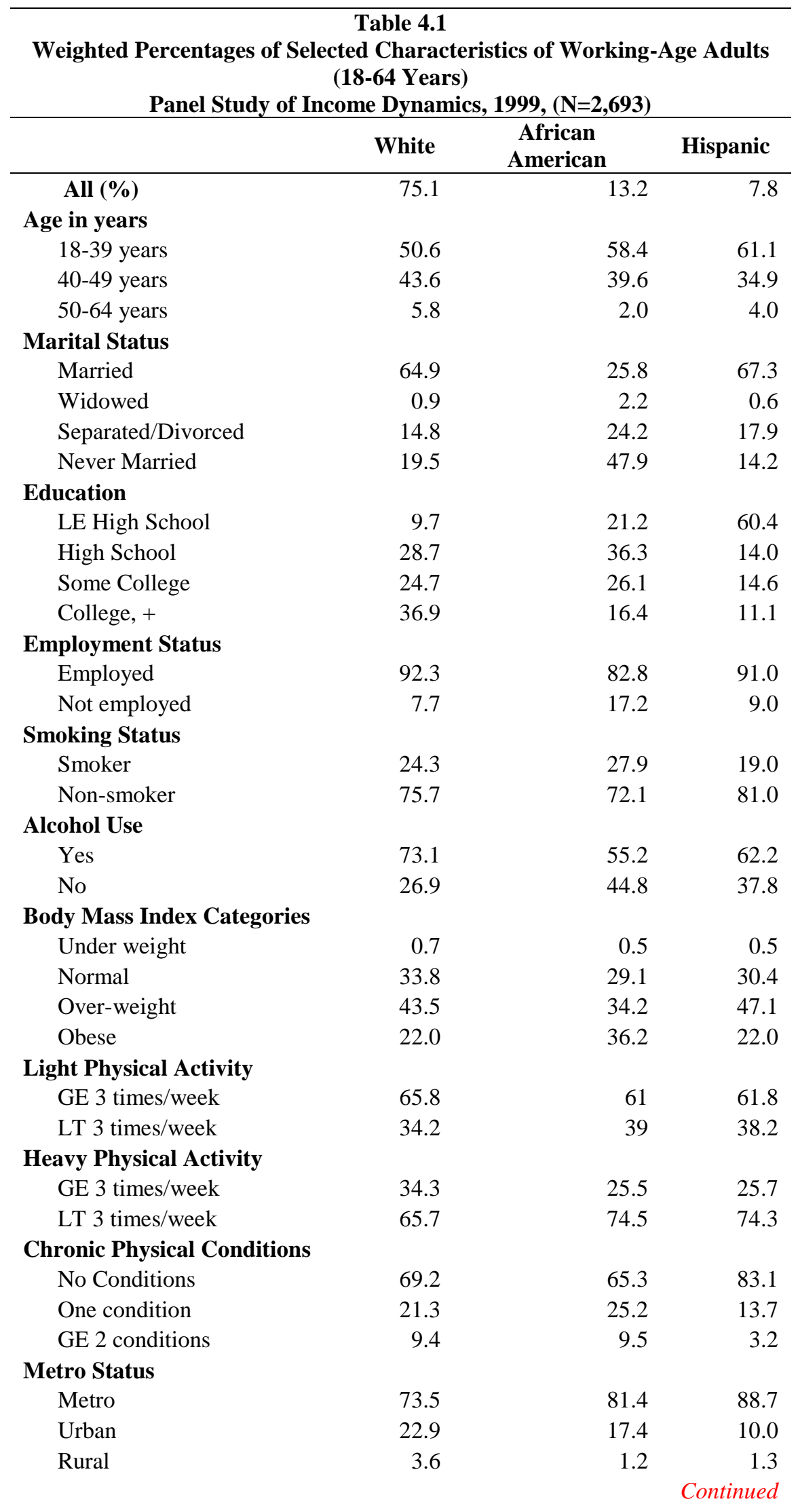




\begin{tabular}{lccr}
\hline \multicolumn{4}{c}{$\begin{array}{c}\text { Table } 4.1 \\
\text { Weighted Percentages of Selected Characteristics of Working-Age Adults } \\
\text { (18-64 Years) }\end{array}$} \\
\multicolumn{4}{c}{ Panel Study of Income Dynamics, } \\
White & $\begin{array}{c}\text { African } \\
\text { American }\end{array}$ & Hispanic \\
\hline Region of Residence & & & \\
Northeast & 21.2 & 15.5 & 4.0 \\
North central & 30.4 & 19.8 & 9.9 \\
South & 26.2 & 58.4 & 24.6 \\
West & 21.2 & 6.1 & 59.9 \\
Alaska, Hawaii & 0.4 & 0.0 & 0.0 \\
Other & 0.6 & 0.3 & 1.7
\end{tabular}

Note: Based on 2,693 head of household participants of the Panel Study of Income Dynamics and for whom data were available for all years between 1999 and 2013.

Whites: 1,576; African Americans: 848; Hispanics: 155.

GE: Greater than or equal to; LE: Less than or equal to; LT: Less than. 


\begin{tabular}{|c|c|c|c|}
\hline $\begin{array}{r}\text { Weighted Percentage } \\
\text { Age } \\
\text { Panel Study of Inc } \\
\end{array}$ & $\begin{array}{l}\text { Table } 4.2 \\
\text { elected C } \\
\text { Its (18-64 } \\
\text { Oynamics } \\
\end{array}$ & $\begin{array}{l}\text { racteristics o } \\
\text { ears) } \\
\text { 2007-2013, (N }\end{array}$ & $\begin{array}{l}\text { Working- } \\
4,867)\end{array}$ \\
\hline & White & $\begin{array}{c}\text { African } \\
\text { American }\end{array}$ & Hispanic \\
\hline All (\%) & 71.1 & 16.7 & 9.3 \\
\hline Age in years & & & \\
\hline 18-39 years & 39.4 & 43.4 & 41.7 \\
\hline $40-49$ years & 29.1 & 32.4 & 38.0 \\
\hline 50-64 years & 31.5 & 24.2 & 20.3 \\
\hline Marital Status & & & \\
\hline Married & 57.9 & 22.8 & 62.7 \\
\hline Widowed & 1.7 & 2.5 & 1.3 \\
\hline Separated/Divorced & 18.0 & 26.3 & 18.3 \\
\hline Never Married & 22.4 & 48.4 & 17.7 \\
\hline Education & & & \\
\hline LE High School & 9.0 & 18.0 & 43.0 \\
\hline High School & 29.0 & 37.0 & 26.0 \\
\hline Some College & 25.0 & 27.0 & 16.0 \\
\hline College, + & 37.0 & 17.0 & 15.0 \\
\hline Employment Status & & & \\
\hline Employed & 88.4 & 71.7 & 92.0 \\
\hline Not employed & 11.6 & 28.3 & 8.0 \\
\hline Smoking Status & & & \\
\hline Smoker & 24.3 & 26.5 & 17.4 \\
\hline Non-smoker & 75.7 & 73.5 & 82.6 \\
\hline Alcohol Use & & & \\
\hline Yes & 74.4 & 58.7 & 50.8 \\
\hline No & 25.6 & 41.4 & 49.2 \\
\hline Body Mass Index & & & \\
\hline Categories & & & \\
\hline Under weight & 0.9 & 1.1 & 1.3 \\
\hline Normal & 28.2 & 24.2 & 19.8 \\
\hline Over-weight & 42.7 & 34.8 & 45.5 \\
\hline Obese & 28.2 & 40.0 & 33.4 \\
\hline Light Physical Activity & & & \\
\hline GE 3 times/week & 62.3 & 49.1 & 38.4 \\
\hline LT 3 times/week & 37.7 & 50.9 & 61.6 \\
\hline Heavy Physical Activity & & & \\
\hline GE 3 times/week & 46.9 & 34.0 & 38.0 \\
\hline LT 3 times/week & 54.0 & 66.0 & 62.0 \\
\hline Chronic Physical & & & \\
\hline Conditions & & & \\
\hline No Conditions & 54.5 & 50.9 & 69.5 \\
\hline One condition & 27.6 & 26.8 & 19.7 \\
\hline GE 2 conditions & 17.9 & 22.3 & 10.8 \\
\hline Metro Status & & & \\
\hline Metro & 72.6 & 83.3 & 87.7 \\
\hline Urban & 23.4 & 15.5 & 12.1 \\
\hline Rural & 4.0 & 1.2 & 0.2 \\
\hline
\end{tabular}




\begin{tabular}{lccr}
\hline \multicolumn{4}{c}{ Table $\mathbf{4 . 2}$} \\
Weighted Percentages of Selected Characteristics of Working- \\
Age Adults (18-64 Years) \\
\multicolumn{4}{c}{ Panel Study of Income Dynamics, 2007-2013, (N=4,867) } \\
\hline Region of Residence \\
Northeast & 20.8 & 14.3 & 5.4 \\
North central & 30.5 & 21.9 & 8.3 \\
South & 28.0 & 56.5 & 29.0 \\
West & 20.1 & 7.3 & 55.2 \\
Alaska, Hawaii & 0.2 & 0.0 & 0.2 \\
Other & 0.5 & 0.0 & 1.9
\end{tabular}

Note: Based on 4,867 head of household participants of the Panel Study of Income Dynamics and for whom data were available for all years between 2007 and 2013.

Whites: 2,568; African Americans: 1,782; Hispanics: 375.

GE: Greater than or equal to; LE: Less than or equal to; LT: Less than. 


\section{Figure 4.1 Mean Labor Income by Quartiles}

Sample 1, 1999-2013
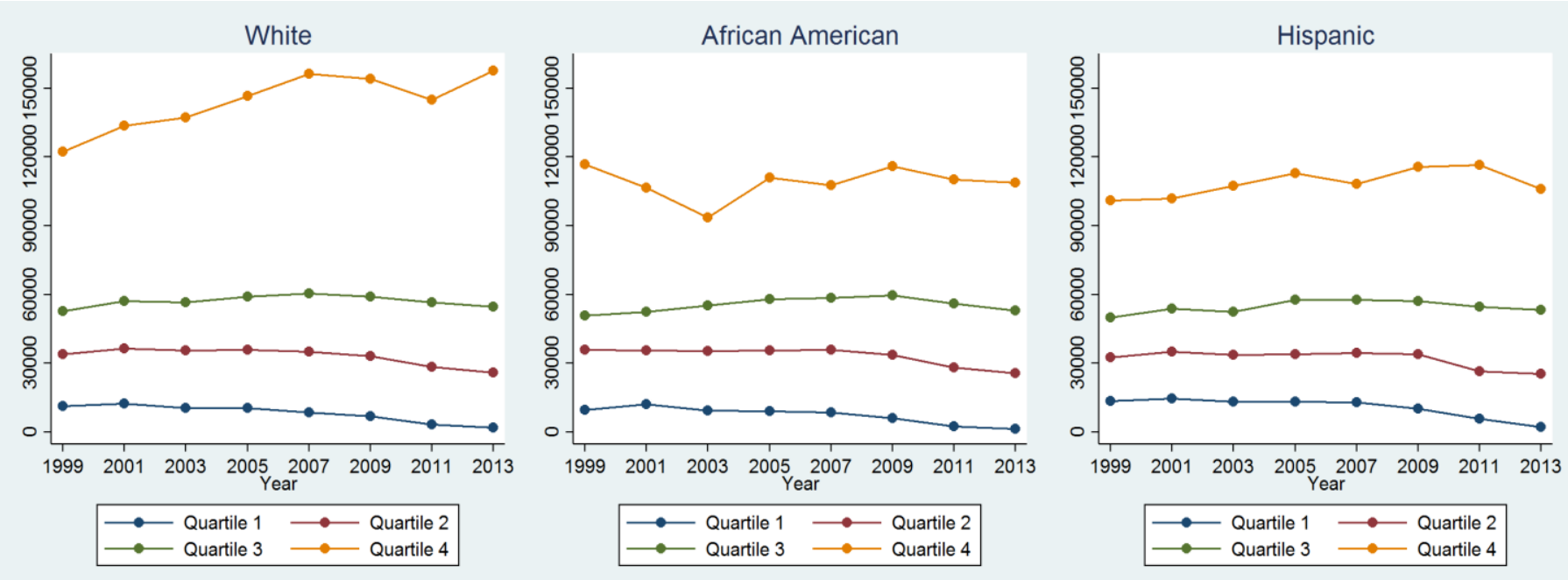

Sample 2, 2007-2013
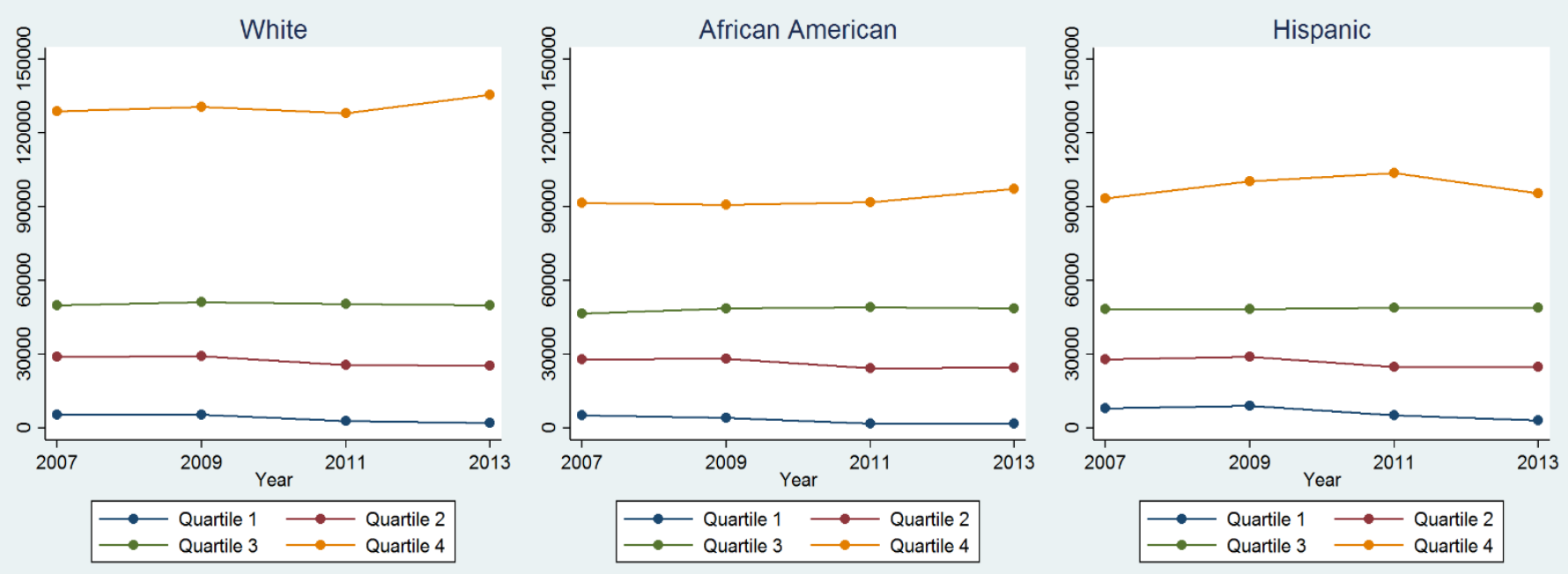

Note: Sample 1 is based on 2,693 head of household participants of the Panel Study of Income Dynamics and for whom data were available for all years between 1999 and 2013.

White: 1,576; African Americans: 848; Hispanics: 155.

Sample 2 is based on 4,867 head of household participants of the Panel Study of Income Dynamics and for whom data were available for all years between 2007 and 2013.

White: 2,568; African Americans: 1,782; Hispanics: 375. 


\section{Figure 4.2: Mean Self-Rated Health and Psychological Distress by Race}

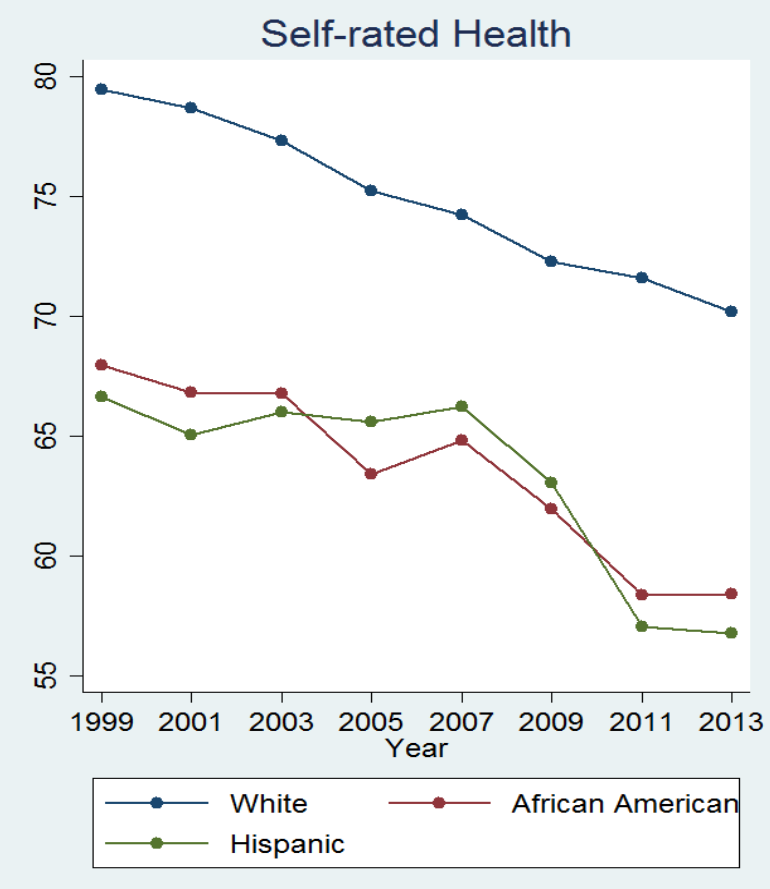

Psychological Distress

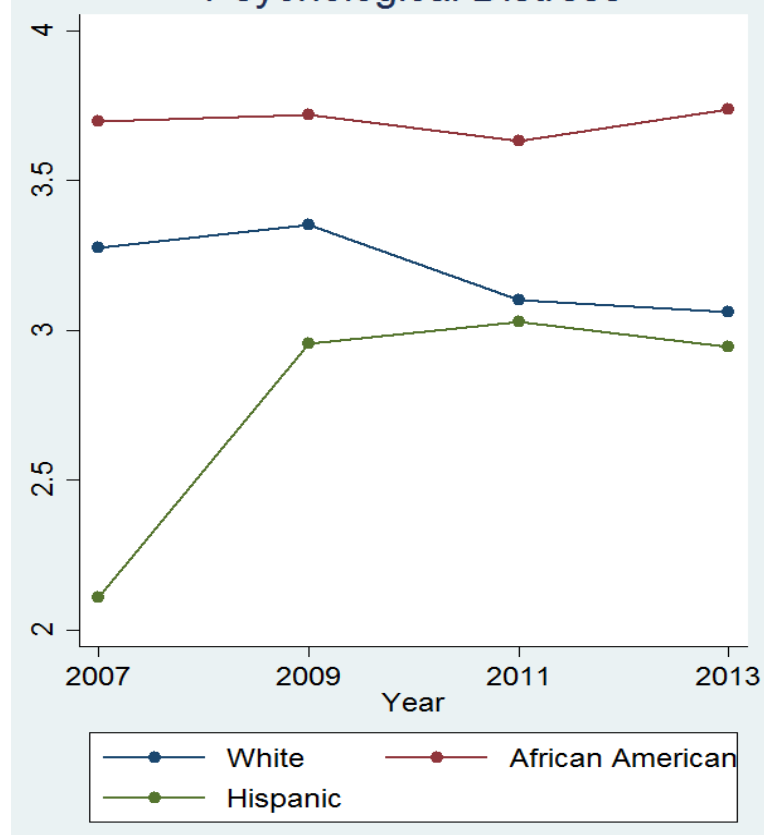

Note: SRH is based on 2,693 head of household participants of the Panel Study of Income Dynamics and for whom data were available for all years between 1999 and 2013.

White: 1,576; African Americans: 848; Hispanics: 155.

Psychological distress is based on 4,867 head of household participants of the Panel Study of Income Dynamics and for whom data were available for all years between 2007 and 2013 .

White: 2,568; African Americans: 1,782; Hispanics: 375 . 
Table 4.3

Parameter Estimates and Standard Errors of Labor Income on SRH

Arellano-Bond (System-GMM)

Working-age US Adults (18-64 Years)

The Panel Study of Income Dynamics, 1999-2013, (N=2,693)

\begin{tabular}{|c|c|c|c|}
\hline & White & African American & Hispanic \\
\hline Quartile 1 & & Reference & \\
\hline Quartile 2 & $4.869 * * *$ & $3.687 * * *$ & $6.306 * * *$ \\
\hline Quartile 3 & $\begin{array}{c}3.541 * * * \\
(1.053)\end{array}$ & $\begin{array}{c}4.499 * * * \\
(1.332)\end{array}$ & $\begin{array}{l}4.145^{*} \\
(2.033)\end{array}$ \\
\hline Quartile 4 & $\begin{array}{c}4.120 * * * \\
(1.142)\end{array}$ & $\begin{array}{c}4.089 * * \\
(1.418)\end{array}$ & $\begin{array}{c}8.283 * * * \\
(1.622)\end{array}$ \\
\hline $\begin{array}{l}\text { \#IV } \\
\text { Hansen J }\end{array}$ & $\operatorname{chi}^{2}(85): 79.37 ; \mathrm{P}=0.652$ & $\begin{array}{c}118 \\
\operatorname{chi}^{2}(85): 109.24 ; \mathrm{P}=0.039\end{array}$ & $\operatorname{chi}^{2}(85): 99.72 ; \mathrm{P}=0.131$ \\
\hline \multicolumn{4}{|c|}{$\begin{array}{c}\text { Parameter Estimates and Standard Errors of Labor Income on Psychological Distress } \\
\text { Heteroscedasticity-Based Instruments (Lewbel 2012) } \\
\text { Working-Age Adults (18-64 Years) } \\
\text { Panel Study of Income Dynamics, 2007-2013, (N=4,867) }\end{array}$} \\
\hline & White & African American & Hispanic \\
\hline Quartile 1 & & Reference & \\
\hline Quartile 2 & $\begin{array}{c}-1.494 * * * \\
(0.412)\end{array}$ & $\begin{array}{c}-1.708 * * \\
(0.492)\end{array}$ & $\begin{array}{r}-0.1543 \\
(0.831)\end{array}$ \\
\hline Quartile 3 & $\begin{array}{l}-1.457 * * \\
(0.457)\end{array}$ & $\begin{array}{l}-2.538 * * * \\
(0.485)\end{array}$ & $\begin{array}{l}-0.553 \\
(0.696)\end{array}$ \\
\hline Quartile 4 & $\begin{array}{c}-1.646 * * * \\
(0.368)\end{array}$ & $\begin{array}{c}-2.604 * * * \\
(0.430)\end{array}$ & $\begin{array}{l}-0.853 \\
(0.651)\end{array}$ \\
\hline
\end{tabular}

Note: SRH is based on 2,693 head of household participants of the Panel Study of Income Dynamics and for whom data were available for all years between 1999 and 2013.

Whites: 1,576; African Americans: 848; Hispanics: 155.

System-GMM adjusted for includes age, number of chronic conditions, body mass index, alcohol use, smoking status, light physical activity, marital status, number of children under 18 years of age, health insurance, external financial support, and financial liabilities to others.

Psychological distress is based on 4,867 head of household participants of the Panel Study of Income Dynamics and for whom data were available for all years between 2007 and 2013.

Whites: 2,568; African Americans: 1,782; Hispanics: 375.

Heteroscedasticity-based instruments regressions adjusted for age, body mass index, alcohol use, smoking status, light physical activity, marital status, number of children under 18 years of age, health insurance, external financial support, and financial liabilities to others.

$* * * \mathrm{p}<.001 ; * * .001 \leq \mathrm{p}<.01 ; * .01 \leq \mathrm{p}<.05$. 


\section{Table 4.4}

The Relation of Changes in Labor Income to Changes in Physical and Mental Health

Working-Age Adults (18-64 Years)

The Panel Study of Income Dynamics

Gain in Labor Income and SRH

FD

(Adjusted)

\begin{tabular}{|c|c|c|c|c|c|c|}
\hline & White & $\begin{array}{c}\text { African } \\
\text { American }\end{array}$ & Hispanic & White & $\begin{array}{c}\text { African } \\
\text { American }\end{array}$ & Hispanic \\
\hline $\begin{array}{l}\text { Change in Income Labor } \\
\text { Income Quartile }\end{array}$ & $\begin{array}{c}0.017 \\
(0.012)\end{array}$ & $\begin{array}{c}0.002 \\
(0.030)\end{array}$ & $\begin{array}{c}0.035 \\
(0.036)\end{array}$ & $\begin{array}{c}0.980 \\
(0.628)\end{array}$ & $\begin{array}{c}2.689 \\
(1.374)\end{array}$ & $\begin{array}{c}4.171 \\
(2.771)\end{array}$ \\
\hline \multicolumn{7}{|c|}{ Loss in Labor Income and SRH } \\
\hline & \multicolumn{3}{|c|}{$\begin{array}{c}\text { FD } \\
\text { (Adjusted) }\end{array}$} & \multicolumn{3}{|c|}{ Lagged Fixed Effect } \\
\hline & White & $\begin{array}{l}\text { African } \\
\text { American }\end{array}$ & Hispanic & White & $\begin{array}{c}\text { African } \\
\text { American }\end{array}$ & Hispanic \\
\hline $\begin{array}{l}\text { Change in Income Labor } \\
\text { Income Quartile }\end{array}$ & $\begin{array}{l}0.034 * \\
(0.014)\end{array}$ & $\begin{array}{c}0.040 \\
(0.028)\end{array}$ & $\begin{array}{c}0.004 \\
(0.044)\end{array}$ & $\begin{array}{l}-1.394 * \\
(0.637)\end{array}$ & $\begin{array}{c}-4.542 * \\
(1.777)\end{array}$ & $\begin{array}{l}-1.403 \\
(1.982)\end{array}$ \\
\hline \multicolumn{7}{|c|}{ Gain in Labor Income and Mental Health } \\
\hline & \multicolumn{3}{|c|}{$\begin{array}{c}\text { FD } \\
\text { (Adjusted) }\end{array}$} & \multicolumn{3}{|c|}{ Lagged Fixed Effects } \\
\hline & White & $\begin{array}{l}\text { African } \\
\text { Americans }\end{array}$ & Hispanics & White & $\begin{array}{c}\text { African } \\
\text { American }\end{array}$ & Hispanic \\
\hline $\begin{array}{l}\text { Change in Income Labor } \\
\text { Income Quartile }\end{array}$ & $\begin{array}{l}0.045^{*} \\
(0.018)\end{array}$ & $\begin{array}{l}-0.008 \\
(0.033)\end{array}$ & $\begin{array}{c}0.079 \\
(0.049)\end{array}$ & $\begin{array}{l}-0.166 \\
(0.159)\end{array}$ & $\begin{array}{l}-0.169 \\
(0.397)\end{array}$ & $\begin{array}{c}0.280 \\
(0.554)\end{array}$ \\
\hline \multicolumn{7}{|c|}{ Loss in Labor Income and Mental Health } \\
\hline & White & $\begin{array}{l}\text { African } \\
\text { American }\end{array}$ & Hispanic & White & $\begin{array}{c}\text { African } \\
\text { American }\end{array}$ & Hispanic \\
\hline $\begin{array}{l}\text { Change in Income Labor } \\
\text { Income Quartile }\end{array}$ & $\begin{array}{l}0.043^{*} \\
(0.018)\end{array}$ & $\begin{array}{c}0.024 \\
(0.034)\end{array}$ & $\begin{array}{c}0.070 \\
(0.050)\end{array}$ & $\begin{array}{l}0.455^{* *} \\
(0.161)\end{array}$ & $\begin{array}{l}-0.535 \\
(0.363)\end{array}$ & $\begin{array}{c}0.579 \\
(0.566)\end{array}$ \\
\hline
\end{tabular}

Note: SRH is based on 2,693 households' head participants of the Panel Study of Income Dynamics and for whom data were available for all years between 1999 and 2013

Whites: 1,576; African Americans: 848; Hispanics: 155.

Psychological distress is based on 4,867 head of household participants of the Panel Study of Income Dynamics and for whom data were available for all years between 2007 and 2013.

Whites: 2,568; African Americans: 1,782; Hispanics: 375.

$* * * \mathrm{p}<.001 ; * * .001 \leq \mathrm{p}<.01 ; * .01 \leq \mathrm{p}<.05$.

Health Improvement (SRH): A binary indicator variable measuring one-period change in SRH with the value of 1 representing improvements in SRH and zero representing no change or worsening health.

Health Decline (SRH): A binary indicator variable measuring one-period change in SRH with the value of 1 representing decline in SRH and zero representing no change or health improvement.

Decline in mental health: A binary indicator variable with the value of 1 representing an increase in psychological distress scores from one wave to the next and zero representing no change or decreases in psychological distress scores from one wave to the next. 
Improvements in mental health: A binary indicator variable with the value of 1 representing decline in psychological distress scores from one wave to the next and zero representing no change or increase in psychological distress scores from one wave to the next.

In FD model, the outcome is health improvement (or decline) and the key endogenous variable is economic gain (or loss). FD adjusted for one-period changes in age, number of chronic conditions (only SRH), body mass index, alcohol use, smoking status, light physical activity, marital status, number of children under 18 years of age, health insurance, external financial support, and financial liabilities to others.

In lagged fixed effects model, the outcome is the SRH or psychological distress at time t. The key independent variable is either economic gain or loss. Lagged fixed effect model included the following variables measured at $\mathrm{t}-1$ : health measures, economic indicator, age, number of chronic conditions (SRH only), body mass index, alcohol use, smoking status, light physical activity, marital status, number of children under 18 years of age, health insurance, external financial support, and financial liabilities to others.

Economic Gain: The transition from a lower quartile to an upper quartile.

Economic Loss: The transition from an upper quartile to a lower quartile.

SRH: Self-rated health. 


\section{Chapter 5 \\ Summary and Conclusions}

\section{Study Summary and Discussion}

The relationship between economic status and health has been a subject of research for the last two decades in the United States (US) (1-12). Economic, sociological and epidemiological studies have indicated that higher economic status is associated with better physical $(1-4,7,8)$ and mental health $(9,11,12)$. Nonetheless, a comprehensive evaluation of the relationship between economic status and health is still lacking. Most studies have used a single measure of health (1-12); the concept of health is abstract, and no single measure can capture all health dimensions (13). Further, most studies have focused on one-direction - economic status affecting health; little is known as to whether subsequent recovery from declining health improves economic status. In addition, given the long-history of racial discrimination, differential effect of poverty on health between whites and African Americans, racial inequities in education and healthcare resources (14-16), it is important to examine racial disparities in the relationship between economic status and health. Only a few studies have conducted comparative analysis of whites and racial minorities (11,17-19). Furthermore, previous studies have not adequately controlled for endogeneity between economic status and health due to reverse causality, omitted variables and unobserved heterogeneity $(2,4-6,9,11,12,20)$.

Therefore, this dissertation has three objectives: 1) to examine the dynamic relationships between various measures of economic status (family income, labor income and net wealth) and physical health (Self-rated health and functional limitations) using a sample of working-age adults (18-64 years) in the US; 2) to evaluate the bidirectional relationships between economic indicators (family income, labor income and net wealth) and mental health measures (mental illness and psychological distress) with adjustments for endogeneity between economic status 
and mental health; 3) to evaluate the heterogeneous relationships between labor income and two measures of physical and mental health stratified by racial groups.

In the present study, family income, labor income and net wealth were positively associated with self-rated health (SRH) after adjustment for endogeneity and other external factors. However, only labor income and net wealth were negatively associated with functional limitations. Our study results suggest that the relationship between economic indicators and health is dependent on the health measures that used to examine the relationship. Health is a multidimensional concept and economic indicators seem to have different dynamic relationships with different components of health.

Furthermore, this study found strong relationships between losses in family or labor income and health decline. It was also observed that improvement in SRH increased likelihood of increases in family income, labor income and net wealth after adjusting for other factors; conversely, decreases in SRH increased likelihood of decreases in family income, labor income, and net wealth. These results highlight the need for policies to provide safety nets for adults who experience a decline in income to prevent further deterioration in health. Our results also revealed that economic stability plays an important role in individuals' physical health.

With regard to mental health, the current study indicated that family income, labor income and net wealth were negatively associated with mental illnesses and psychological distress. Specifically, this study found that adults in higher family income, labor income and net wealth quintiles were less likely to have a mental illness than their counterparts in the lowest quintile of these economic indicators. The results also revealed that working-age adults who experienced an economic loss were more likely to have a mental illness and higher psychological distress. These findings suggest that mental health and economic status have a bidirectional 
relationship. Therefore, programs and policies to improve either mental health or economic status of individuals need to be comprehensive and target both mental health and economic sectors in the US.

The current study observed that whites and African Americans in higher labor income quartiles had better SRH and lower psychological distress than their counterparts in the lowest quartile. In these two racial groups, those who experienced a decline in labor income also experienced a decline in SRH. However, decreases in labor income were associated with increases in psychological distress among whites only. Among Hispanics, there was a significant positive relationship between labor income and SRH. However, Hispanics who experienced a decline in income did not experience a decline in SRH. With regard to mental health, the study observed that Hispanics had lower psychological distress scores than whites or African Americans. Also, there was no relationship between labor income and psychological distress and no relationship between change in labor income and change in mental health among Hispanics. These findings suggest heterogeneous race-stratified relationships between labor income and physical and mental health. These findings again highlight the need for policies to provide safety nets for adults who experience a decline in income to prevent further deterioration in health.

\section{Implications of the Findings}

The findings from the current dissertation highlight the need for initiatives that improve health of the individuals by incorporating health considerations into decision-making across policy areas. Although the US has disparate policies $(21,22)$, these policies need to be strengthened and include integrated and cohesive health components. Two initiatives in the US and Europe have been proposed to improve individuals' health: "Health in All Policies (23)" and "Mental Health in All Policies (24)". Both initiatives comprehensively target health 
improvement in all sectors. Under these approaches re-shaping individuals' economic, physical, social, and service environments can help improving physical and mental health (23). Therefore, it is important to strengthening the protective factors throughout an individual's life such as affordable day-care centers for children, affordable housing, and return-to-work policies and programs (24).

The current study found that negative economic shocks adversely affect physical and mental health. There are several mechanisms through which low financial resources can impact health negatively. Adults with lower financial resources have lower access to housing, nutritious food and health care which can affect their health. Therefore, it is crucial to provide safety nets for adults who experience a decline in economic status to prevent deterioration in health.

The present study also indicated that SRH improvement had a positive impact on family income, labor income and net wealth. In the US, adults with chronic health conditions are more likely to report that their health is fair or poor (25), suggesting that policies and interventions that decrease the burden of chronic diseases among working-age adults could have significant positive effects on economic status in this population. In addition, given that SRH is widely considered to be an excellent measure of healthcare quality in the US (26), improving the healthcare quality in the US may likewise promote/lead to improvement in economic well-being.

Our findings also have implications for improving access to mental healthcare as well as mental health treatment. Nearly 1 in 5 working-age adults with severe mental illnesses was uninsured in a nationally representative sample of US adults (27). In addition, 30.4\% of workingage adults with serious psychological distress were uninsured in the period from 2009-2013 (28). Even with insurance coverage, individuals with mental illnesses can face a high economic burden in terms of out-of-pocket spending (27). Evidence also exists on cost as a barrier to 
receiving mental health services (29), which may lead to foregoing mental health care due to high-cost sharing and out-of-pocket spending burden. Lack of mental health treatment may further worsen the mental illness of adults, which can lead to further reductions in income. These findings again highlight the need for "Mental Health in All Policies," recommended by the experts in the European countries (24).

Our study findings have also implications for healthcare professionals such as social workers and others who often coordinate care for those with low income and/or mental health conditions (30). For example, healthcare professionals need to take into account the economic status of the adults to treat a mental illness episode successfully and to increase the quality of the mental healthcare (30). Healthcare professionals need also to assess the adult's educational accomplishments and occupational progression when tailoring intervention programs that address mental illnesses.

\section{Suggestions for future research}

This study conducted a comprehensive evaluation of the relationship between economic status and health using various measures of the two. The current study found that increases in economic resources had a positive impact on health. However, there is a need to explore the effect of income supplementation and state funded welfare programs on health outcomes. Further, this study revealed that losses in labor income had a negative impact on physical and mental health. Therefore, future studies need to examine the reasons for decline in labor income because policy prescriptions for protection against job loss and reduced work hours differ. It is plausible that many adults in the US experienced income losses due to job losses because our study period overlapped with the great 2007-2009 recession (31). Additionally, the study findings suggest heterogeneous race-stratified relationships between labor income and physical and mental health. 
Future research may need to investigate the role of the social capital factors in the heterogeneous relationships between labor income and two measures of physical and mental health stratified by racial groups.

\section{Strengths}

This dissertation has several strengths. This dissertation examined the potential reciprocal relationships between economic status and health using a variety of economic and physical and mental health measures. Further, this study assessed the relationship of health to both continuous and categorical measures of economic status. The present study also controlled for a comprehensive list of other exogenous explanatory variables. In addition, by tracking individuals over a 14-year period, the current study was able to analyze causal relationships between economic status and health, including bidirectional relationships. This dissertation also used dynamic panel data estimators and other novel techniques to overcome the limitations of lack of readily available valid instrumental variables.

\section{Limitations}

The current study has some limitations. First, the study cohort was restricted to heads of households. Thus, the estimates may be not generalizable especially to married women. Second, although we controlled for fixed effects due to time-invariant factors such as sex, race/ethnicity and other contextual factors, the study did not provide the estimates of the effects of these factors. Third, information on all variables was based on self-reported data, raising the possibility of recall bias. Fourth, the included physical and mental health measures may not capture the whole aspects of health. 


\section{REFERENCES}

(1) Fiscella K, Franks P. Individual income, income inequality, health, and mortality: what are the relationships? Health services research 2000;35(1 pt2):307-318.

(2) McDonough P, Berglund P. Histories of poverty and self-rated health trajectories. Journal of Health and Social Behavior 2003;44(2):198-214.

(3) Meer J, Miller DL, Rosen HS. Exploring the health-wealth nexus. . Journal of health economics 2003;22(5):713-730.

(4) Berry B. Does money buy better health? Unpacking the income to health association after midlife. Health(London) 2007;11(2):199-226.

(5) Hajat A, Kaufman JS, Rose KM, Siddiqi A, Thomas JC. Do the wealthy have a health advantage? Cardiovascular disease risk factors and wealth. Social Science and Medicine 2010;71(11):1935-1942.

(6) Hajat A, Kaufman JS, Rose KM, Siddiqi A, Thomas JC. Long-term effects of wealth on mortality and self-rated health status. American Journal of Epidemiology 2011;173(2):192-200.

(7) Michaud PC, van Soest A. Health and wealth of elderly couples: causality tests using dynamic panel data models. Journal of Health Economics 2008;27(5):1312-1325.

(8) Halliday TJ. Earnings Growth and Movements in Self-Reported Health. Review of Income and Wealth 2016.

(9) Sareen J, Afifi TO, McMillan KA, Asmundson GJ. Relationship between household income and mental disorders: findings from a population-based longitudinal study. Archives of General Psychiatry 2011;68(4):419-427.

(10) Lorant V, Deliège D, Eaton W, Robert A, Philippot P, Ansseau M. Socioeconomic inequalities in depression: a meta-analysis. American Journal of Epidemiology 2003;157(2):98112.

(11) McMillan KA, Enns MW, Asmundson GJ, Sareen J. The association between income and distress, mental disorders, and suicidal ideation and attempts: findings from the collaborative psychiatric epidemiology surveys. . The Journal of clinical psychiatry 2010;71(9):1168-1175.

(12) Yilmazer T, Babiarz P, Liu F. The impact of diminished housing wealth on health in the United States: Evidence from the Great Recession. Social science \& medicine 2015;130:234241.

(13) Turnock B J. Chapter 2: Understanding and Measuring Health. Public Health: what it is and how it works turnock. 6th ed. Burlington, MA, USA: Jones \& Bartlett Publishers; 2011. p. 21-47.

(14) Shapiro TM, Meschede T, Sullivan L. The racial wealth gap increases fourfold. Waltham, MA: Institute on Assets and Social Policy, Brandeis University 2010.

(15) Orsi JM, Margellos-Anast H, Whitman S. Black-White health disparities in the United States and Chicago: a 15-year progress analysis. . American Journal of Public Health 2010;100(2):349-356. 
(16) Musu-Gillette L, Robinson J, McFarland J, KewalRamani, A, Zhang A, Wilkinson-Flicker S. Status and Trends in the Education of Racial and Ethnic Groups 2016 (NCES 2016-007). U S Department of Education, National Center for Education Statistics Washington, DC 2016.

(17) Shea DG, Miles T, Hayward M. The health-wealth connection: Racial differences. The Gerontologist 1996;36(3):342-349.

(18) Braveman PA, Cubbin C, Egerter S, Williams DR, Pamuk E. Socioeconomic disparities in health in the United States: what the patterns tell us. American journal of public health 2010;100(S1):S186-S196.

(19) Pollack CE, Cubbin C, Sania A, Hayward M, Vallone D, Flaherty B, Braveman PA. Do wealth disparities contribute to health disparities within racial/ethnic groups? Journal of epidemiology and community health 2013;67(5):439-445.

(20) Franks P, Gold MR, Fiscella K. Sociodemographics, self-rated health, and mortality in the US. Social science \& medicine 2003;56(12):2505-2514.

(21) O'Hara A CE. 2 SECTION 8 MADE SIMPLE: Using The Housing Choice Voucher Program To Assist People With Disabilities. 2003.

(22) Section 811 Supportive Housing for Persons with Disabilities. Available at: https://portal.hud.gov/hudportal/HUD?src=/program_offices/housing/mfh/progdesc/disab811. Accessed 1/1, 2017.

(23) Rudolph L, Caplan J, Ben-Moshe K, Dillon L. Health in All Policies: A Guide for State and Local Governments. American Public Health Association and Public Health Institute 2013.

(24) EU Regional Conference Mental Health in All Policies - Supporting sustainability and growth in Europe. Mental Health in All Policies - A fundamental platform for sustainability and growth for people, communities and economies; May/11-12/2015; ; 2016.

(25) Blackwell DL LJ. Tables of Summary Health Statistics for U.S. Adults: 2014 National Health Interview Survey. 2015.

(26) Frosch DL. Patient-Reported Outcomes as a Measure of Healthcare Quality. . Journal of general internal medicine 2015;30(10):1383-1384.

(27) Soni A. The five most costly conditions, 1996 and 2006: Estimates for the US civilian noninstitutionalized population. American Journal of Psychiatry 2009;168(5):486-494.

(28) Weissman J, Pratt LA, Miller EA, Parker JD. Serious psychological distress among adults: United States, 2009-2013. National Center for Health Statistics 2015;NCHS data brief(203).

(29) Rowan K, McAlpine DD, Blewett LA. Access and cost barriers to mental health care, by insurance status, 1999-2010. Health Affairs 2013;32(10):1723-1730.

(30) Hudson CG. Social Class and Mental Illness Correlation: Implications of the Research for Policy and Practice. The Journal of Sociology \& Social Welfare 1988;15(1):27-54.

(31) Goodman CJ MS. Employment loss and the 2007-09 recession: an overview. Monthly Labor Review 2011;134(4):3-12. 